NBER WORKING PAPER SERIES

THE SAFETY TRAP

Ricardo J. Caballero

Emmanuel Farhi

Working Paper 19927

http://www.nber.org/papers/w19927

\author{
NATIONAL BUREAU OF ECONOMIC RESEARCH \\ 1050 Massachusetts Avenue \\ Cambridge, MA 02138 \\ February 2014
}

For useful comments, we thank Daron Acemoglu, Guillermo Calvo, Gauti Eggertsson, Oliver Hart, Gary Gorton, Valentin Haddad, Bengt Holmström, Narayana Kocherlakota, Anton Korinek, Arvind Krishnamurthy, Matteo Maggiori, Neil Mehrota, Guillermo Ordonez, Ricardo Reis, Yuliy Sannikov, Andrei Shleifer, Alp Simsek, Jeremy Stein, Kevin Stiroh, Jesus Fernandez-Villaverde, Iv'an Werning, and Mike Woodford. An earlier version of this paper circulated under the title: "A Model of the Safe Asset Mechanism (SAM): Safety Traps and Economic Policy." The views expressed herein are those of the authors and do not necessarily reflect the views of the National Bureau of Economic Research.

NBER working papers are circulated for discussion and comment purposes. They have not been peer-reviewed or been subject to the review by the NBER Board of Directors that accompanies official NBER publications.

(C) 2014 by Ricardo J. Caballero and Emmanuel Farhi. All rights reserved. Short sections of text, not to exceed two paragraphs, may be quoted without explicit permission provided that full credit, including $\odot$ notice, is given to the source. 
The Safety Trap

Ricardo J. Caballero and Emmanuel Farhi

NBER Working Paper No. 19927

February 2014, Revised January 2017

JEL No. E0,E1,E5,E52

\begin{abstract}
$\underline{\text { ABSTRACT }}$
In this paper we provide a model of the macroeconomic implications of safe asset shortages. In particular, we discuss the emergence of a deflationary safety trap equilibrium with endogenous risk premia. It is an acute form of a liquidity trap, in which the shortage of a specific form of assets, safe assets, as opposed to a general shortage of assets, is the fundamental driving force. At the ZLB, our model has a Keynesian cross representation, in which net safe asset supply plays the role of an aggregate demand shifter. Essentially, safety traps correspond to liquidity traps in which the emergence of an endogenous risk premium significantly alters the connection between macroeconomic policy and economic activity. "Helicopter drops" of money, safe public debt issuances, swaps of private risky assets for safe public debt, or increases in the inflation target, stimulate aggregate demand and output, while forward guidance is less effective. The safety trap can be arbitrarily persistent, as in the secular stagnation hypothesis, despite the existence of infinitely lived assets.
\end{abstract}

Ricardo J. Caballero

Department of Economics, E52-528

MIT

77 Massachusetts Avenue

Cambridge, MA 02139

and NBER

caball@mit.edu

Emmanuel Farhi

Harvard University

Department of Economics

Littauer Center

Cambridge, MA 02138

and NBER

emmanuel.farhi@gmail.com 


\title{
The Safety Trap
}

\section{Ricardo J. Caballero Emmanuel Farhi*}

\section{This version: January 18, 2017}

\begin{abstract}
In this paper we provide a model of the macroeconomic implications of safe asset shortages. In particular, we discuss the emergence of a deflationary safety trap equilibrium with endogenous risk premia. It is an acute form of a liquidity trap, in which the shortage of a specific form of assets, safe assets, as opposed to a general shortage of assets, is the fundamental driving force. At the ZLB, our model has a Keynesian cross representation, in which net safe asset supply plays the role of an aggregate demand shifter. Essentially, safety traps correspond to liquidity traps in which the emergence of an endogenous risk premium significantly alters the connection between macroeconomic policy and economic activity. "Helicopter drops" of money, safe public debt issuances, swaps of private risky assets for safe public debt, or increases in the inflation target, stimulate aggregate demand and output, while forward guidance is less effective. The safety trap can be arbitrarily persistent, as in the secular stagnation hypothesis, despite the existence of infinitely lived assets.
\end{abstract}

\section{Introduction}

One of the main structural features of the global economy in recent years is the apparent shortage of safe assets. The two black lines in Figure 1 illustrate the paths of the short-term interest rate (dark blue area) and an estimate of the expected return on equity. The difference between the two lines is the equity risk premium (light blue area). ${ }^{1}$ Short-term rates feature a widely noted downward secular trend and a sharp drop during the Great Recession. The evolution of the expected return on equity is markedly different: It features the same downward trend as the short-term interest rate until the early 2000s but then remains more or less stable. The disconnect between a stable expected return on equity and a declining short-term interest rate is particularly salient after 2002, and even more so since the beginning of the Great Recession. A similar disconnect is observed

*Respectively: MIT and NBER; Harvard and NBER. E-mails: caball@mit.edu, efarhi@harvard.edu. Ricardo Caballero thanks the NSF for financial support. First draft: October 9, 2012. For useful comments, we thank Daron Acemoglu, Guillermo Calvo, Gauti Eggertsson, Oliver Hart, Gary Gorton, Valentin Haddad, Bengt Holmström, Narayana Kocherlakota, Anton Korinek, Arvind Krishnamurthy, Matteo Maggiori, Neil Mehrota, Guillermo Ordonez, Ricardo Reis, Yuliy Sannikov, Andrei Shleifer, Alp Simsek, Jeremy Stein, Kevin Stiroh, Jesus Fernandez-Villaverde, Ivàn Werning, and Mike Woodford. An earlier version of this paper circulated under the title: "A Model of the Safe Asset Mechanism (SAM): Safety Traps and Economic Policy."

${ }^{1}$ The expected return on equity and the equity risk premium are notoriously hard to estimate, and hence our description of the evolution of these variables should be interpreted as a central scenario but with caution. Other studies report broadly similar results. See for example Daly (2016). Campbell (2008) document similar evolutions but of a smaller magnitude. 


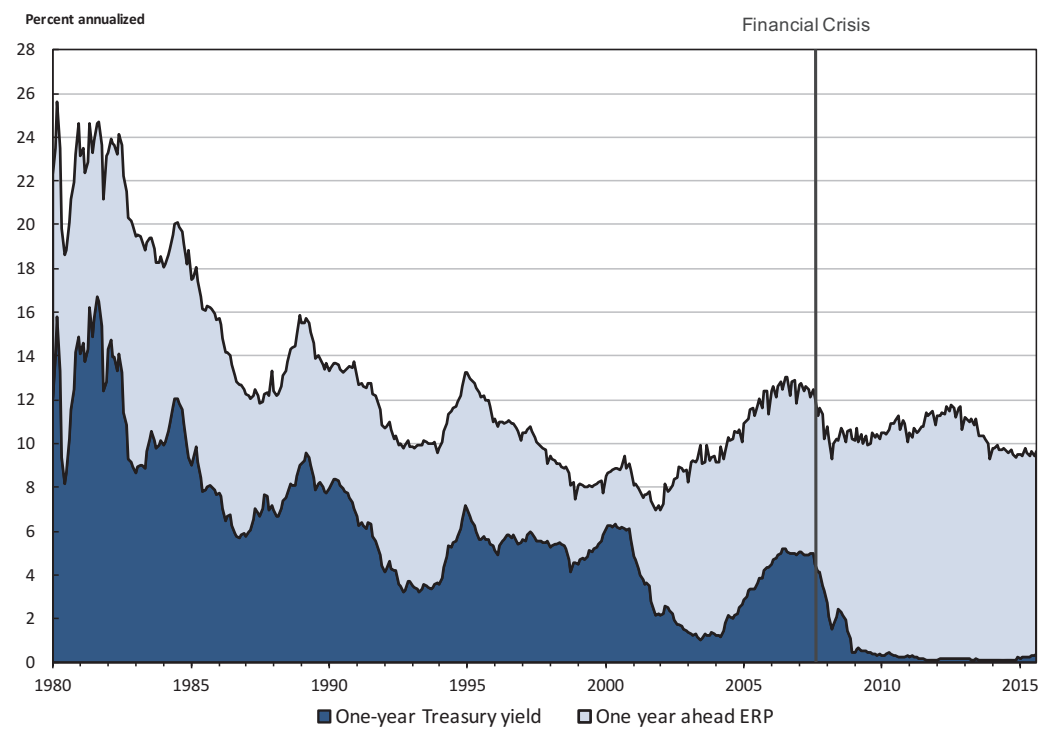

Figure 1: Short-term interest rates (one-year Treasury yield), equity risk premium (one-year ahead equity risk premium or ERP), and expected return on equity (sum of one-year ahead Treasury yield and of one-year ahead ERP). Sources: one-year Treasury yield: Federal Reserve H.15; one year ahead ERP: Duarte and Rosa (2015). The ERP is calculated as the first principal component of twenty models of the one-year-ahead equity risk premium.

between estimates of real returns on (risky) productive capital by Gomme et al. (2011) as well as Hall (2014) and short-term interest rates (see e.g. Caballero et al. 2017).

The stark divergence between safe and risky expected rates of return is suggestive of an increased shortage of safe assets, the intensification of which at the onset of the Great Recession pushed the U.S. economy against the Zero Lower Bound (ZLB) where it remained for a long time, and still remains in many developed economies. Decomposing these developments into shifts in safe asset demand and safe asset supply is plagued with difficulties, and some studies attribute the shortage to a decrease in the supply of safe assets (see e.g. Barclays 2012 who estimates that about $50 \%$ of the supply of safe assets was destroyed during the U.S. and European crises) while others emphasize the increase in the demand for safe assets (see e.g. Goldman Sachs 2012).

In this paper we provide a simple model of the macroeconomic implications of safe asset shortages. Safe assets are in zero net supply, issued by some agents to other agents through a process of securitization of risky assets in positive net supply hampered by a financial friction. We discuss the emergence of a deflationary safety trap equilibrium with endogenous risk premia once the economy hits the ZLB. It is an acute form of a liquidity trap, in which the shortage of a specific form of assets (safe assets), as opposed to a general shortage of assets, is the fundamental driving force.

The model is a perpetual youth OLG model with nominal rigidities and heterogeneous agents: Neutrals (risk neutral) and Knightians (infinitely risk averse). Neutrals act as financial intermediaries by owning risky Lucas' trees (aggregate risk) and issuing safe assets to Knightians. This securitization process is hampered by a financial friction. At a given safe interest rate, as the supply 
of safe assets shrinks relative to demand, a shortage of safe assets develops. The safe interest rate drops and the risk premium rises. This mechanism transfers resources from Knightians to Neutrals, reduces the demand for safe assets, and restores equilibrium in the safe asset market.

However, once the safe rate hits the ZLB, the transfer mechanism breaks down, and instead equilibrium in the safe asset market is endogenously restored through a drop in output (income), which reduces the demand for safe assets. This leads to a dual view of safe asset shortages. As long as safe interest rates are positive, safe asset shortages are essentially benign. But when safe interest rates reach the ZLB, they become malign. This is because at the ZLB tipping point, the virtuous equilibrating mechanism through a reduction in safe interest rates is replaced by a perverse equilibrating mechanism through a reduction in output.

There is an alternative, goods-markets, representation of the equilibrating mechanism. Figure 2 illustrates how equilibrium output $(\xi X)$ endogenously drops below exogenous potential output $(X)$ at the ZLB (when the safe interest rate is $r^{K}=0$ ). When prices are rigid, the determination of equilibrium capacity utilization $(\xi)$ can be represented by a standard Keynesian cross where $A S(\xi X)$ is aggregate supply and $A D(\xi X)$ is aggregate demand. Reflecting the fact that output is demand determined, aggregate supply is simply the 45 degree line $A S(\xi X)=\xi X$. Aggregate demand is the sum of the aggregate consumptions of Knightians and Neutrals. The aggregate consumption of Knightians $\theta V^{S}$ is a constant fraction $\theta$ of their aggregate wealth which is equal to the gross supply of safe assets $V^{S}$. The aggregate consumption of Neutrals is equal to their aggregate steadystate income which is equal to the sum of their aggregate labor income $(1-\alpha)(1-\delta) \xi X$ and their aggregate dividend income $\delta \xi X$ net of the aggregate interest payments to Knightians $r^{K} V^{S}$, where $\delta$ is the fraction of output that accrues as dividends and $\alpha$ is the fraction of Knightians in the population (an index of the gross demand for safe assets). The key observation is that aggregate demand increases with output $\xi X$, decreases with the safe interest rate $r^{K}$, increases with the supply of safe assets $V^{S}$, decreases with the demand index for safe assets $\alpha$.

A drop in safe asset supply or an increase in safe asset demand shift aggregate demand down. At the ZLB, this contractionary demand shock cannot be counteracted by a reduction in safe interest rates $r^{K}$. The endogenous result is a recession $(\xi X<X)$ accompanied by an increase in risk premia $\left(r-r^{K}\right)$ (determined by the other equilibrium equations of the model). Intuitively, the reduction in aggregate demand resulting from a reduction in the supply of safe assets lowers output, which further reduces aggregate demand, etc. ad infinitum until the economy reaches a new fixed point with lower output. More precisely, the reduction in the value of safe assets reduces the wealth of Knightians and hence their consumption. This impulse depresses output. This initial reduction in output then reduces the income of Neutrals, and hence their consumption, which further reduces output. This feedback loop between output and the consumption of Neutrals keeps going until the economy settles at a new fixed point with lower values of output, assets, wealth, consumption and income.

When prices have some degree of flexibility captured by a Phillips curve, safety traps trigger deflationary forces, which raise the Keynesian multiplier and exacerbate the output drop by increasing 


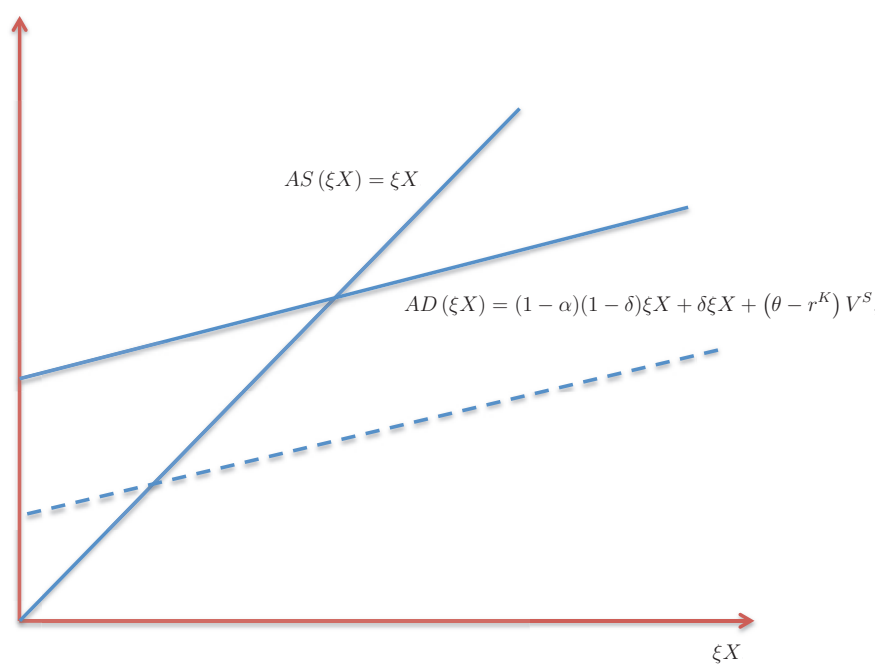

Figure 2: AS-AD representation and the Keynesian cross. Recession caused by a decrease in the supply of safe assets $\left(V^{S}\right)$ or an increase in the demand for safe assets $(\alpha)$. Aggregate demand shifts down.

real safe interest rates.

The safety trap can be arbitrarily persistent, or even permanent, consistent with the secular stagnation hypothesis (Hansen 1939, Summers 2013, Eggertsson and Mehrota 2014) and despite the existence of a positive supply of infinitely lived risky assets (safe assets are in zero net supply): The value of risky assets remains finite even when the safe interest rate $\left(r^{K}\right)$ is zero because our model features risk premia so that the discount rate $(r)$ that applies to the risky cash flows of risky infinitely lived assets remains positive.

Figure 2 also hints at the kind of policies that are likely to be effective in a safety trap. Policies that increase the gross supply of safe assets $\left(V^{S}\right)$, such as "helicopter drops" of money, safe public debt issuances, and versions of QE (such as QE1 in the U.S. and LTRO in the Eurozone) involving swaps of "positive-beta" private risky assets for "zero-beta" public safe assets, stimulate aggregate demand and output, and lower risk premia. ${ }^{2}$ In contrast, Operation Twist (OT) type policies involving swaps of "negative-beta" long-term government debt for "zero-beta" short-term public debt (such as QE2 and QE3 in the U.S.) are ineffective or even counterproductive. Similarly, policies that seek to stimulate aggregate demand by boosting the value of risky assets, such as Forward Guidance (FG), are largely ineffective in safety traps because they end up being dissipated in higher risk premia: The positive effect of higher future asset values on the current value of risky assets is endogenously offset by an increase in risky discount rates $(r)$, limiting the resulting increase in wealth and aggregate demand. Finally, policies that succeed in directly reducing the

\footnotetext{
${ }^{2}$ We refer the reader to Remark 3 in Section 3 and Appendix A.2.3 for an analysis of "helicopter drops" of money. Their effects depends on whether the extra money is retired using tax revenues once the economy exits the safety trap. If it is, then they are equivalent to safe public debt issuances: they generate the same stimulus in the safety trap, and they require the same increase in tax revenues after the economy exits the safety trap. If it is not, then they are more stimulative than safe public debt issuances, but this extra stimulation is no free lunch and instead comes at the cost of an over-stimulation of the economy after the economy exits the safety trap. In both cases, money issuances are no "silver bullet".
} 
safe real interest rate, such as a large enough and credible increase in the inflation target, lead to the emergence of a good equilibrium with no recession, positive inflation, and negative safe real interest rates.

The sharp distinction between the risk tolerance of the two groups of agents allows us to isolate the safety trap from more conventional liquidity traps. In our context, a safety trap corresponds to a situation where the economy is at the ZLB and the securitization constraint is binding. In contrast, a liquidity trap is a situation where the economy is at the ZLB but the securitization constraint is not binding. In liquidity traps, in contrast to safety traps, QE does not stimulate output while FG does. Of course reality is not as stark and both type of elements, safety and liquidity, are likely to play a role. Our framework is designed to highlight the importance of safe asset markets in determining the relative effectiveness of macroeconomic and financial policies in ZLB contexts. ${ }^{3}$

We close the paper with a summary of two extensions developed in the appendix: First, the low rates of a safety trap environment create a fertile ground for the emergence of bubbles. However, we show that risky bubbles do not alleviate the safety trap situation, as they do not expand the stock of safe assets. This formalizes some observations in Summers (2013) that in secular stagnation environments, even large financial bubbles only seem to create moderate economic expansions. Conversely, safe bubbles do alleviate the problem. We associate the latter concept to that of public debt, and show that the existence of a bubbly region expands the fiscal capacity of the government and reduces the crowding out effect, as bubble-debt does not require future taxation if real rates remain secularly low. Second, we show that when the securitization capacity of the economy is endogenous, private securitization decisions are efficient outside of a safety trap, but inefficient inside of it. This is because in a safety trap, private agents do not internalize the stimulative effects of safe asset creation, and hence private incentives to securitize are too low.

Related literature. Our paper is related to several strands of literature. First and most closely related is the literature that identifies the shortage of safe assets as a key macroeconomic fact (see e.g. Caballero 2006, Caballero et al. 2008a and 2008b, Caballero and Krishnamurthy 2009, Caballero 2010, Bernanke et al. 2011, and Barclay's 2012). ${ }^{4}$ Our paper provides a model that captures many of the key insights in that literature and that allows us to study the main

\footnotetext{
${ }^{3}$ For example, the complete ineffectiveness of FG in safety traps as opposed to standard liquidity traps is an extreme result, which relies on the stark assumptions of the model. It should not be interpreted as an indictment of FG, but rather as a demonstration that the features of safety traps, even if they appear only in some milder forms, are likely to mitigate the effect of FG. In this sense, the safety trap offers a possible resolution of the "forward guidance puzzle", a term that refers to the discrepancy between the implausibly large effects of forward guidance in standard New Keynesian DSGE models of liquidity traps and its more limited effects observed in the data. See e.g. Carlstrom et al. (2012) and Del Negro et al. (2015) for an exposition of this puzzle. See also Del Negro et al. (2015) and McKay et al. (2015) for other possible rationalizations in models with incomplete markets and borrowing constraints.

${ }^{4}$ Caballero et al. (2008a,b) developed the idea that global imbalances originated in the superior development of financial markets in developed economies, and in particular the U.S. Global imbalances resulted from an asset imbalance. Although we do not develop the open economy version of our model here (see Caballero et al. 2015), our model could capture a specific channel that lies behind global imbalances: The latter were caused by the funding countries' demand for financial assets in excess of their ability to produce them, but this gap is particularly acute for safe assets since emerging markets have very limited institutional capability to produce them.
} 
macroeconomic policy implications of this environment more precisely. Like us, Barro and Mollerus (2014) considers an environment with heterogenous risk aversion. They show that such a model can quantitatively match the value of safe assets to GDP as well as a number of asset pricing facts. He et al. (2015) emphasize that the public supply of safe assets is determined not only by fiscal capacity (as in our paper), but also by self-fulfilling expectations supported by strategic complementarities among investors arising in the presence of default decisions.

Second, there is the literature on liquidity traps (see e.g. Keynes 1936, Krugman 1998, Eggertsson and Woodford 2003, Christiano, Eichenbaum and Rebelo 2011, Correia et al. 2012, and Werning 2012). This literature emphasizes that the binding ZLB on nominal interest rates presents a challenge for macroeconomic stabilization. Recent models (see e.g. Guerrieri and Lorenzoni 2011, and Eggertsson and Krugman 2012) emphasize the role of tightened borrowing constraints in economies with heterogeneous agents (borrowers and savers) in generating the aggregate demand contraction that brings the economy into the ZLB. In our model it is the shortage of safe assets that causes a similar phenomenon, with distinctive policy implications.

Third, there is an emerging literature on secular stagnation: the possibility of a permanent ZLB situation (see e.g. Kocherlakota 2013 and especially Eggertsson and Mehrota 2014). Like us, they use an OLG structure with a ZLB. Unlike us, they do not consider risk and risk premia. As we show, this difference has important consequences for the relative effectiveness of different policy options. An additional difference has to do with the theoretical possibility of permanent ZLB equilibrium in the presence of infinitely-lived assets, such as land. Indeed, infinitely-lived assets would rule out a permanent ZLB in Kocherlakota (2013) and Eggertsson and Mehrota (2014). In our model, trees are infinitely lived but their value remains finite even when the safe interest rate is permanently at zero. This is only possible because our model features risk and risk premia, which are ignored in most liquidity trap analyzes. Finally, our modelling of inflation in Section 5 borrows heavily from Eggertsson and Mehrota (2014).

Fourth, there is a literature that documents significant deviations from the predictions of standard asset-pricing models - patterns which can be thought of as reflecting money-like convenience services - in the pricing of Treasury securities generally, and in the pricing of short-term T-bills more specifically (Krishnamurthy and Vissing-Jorgensen 2011, 2012, Greenwood and Vayanos 2010, Duffee 1996, Gurkaynak et al. 2006). Our model offers an interpretation of these stylized facts, where the "specialness" of public debt is its safety during bad aggregate states.

Fifth, there is a literature which emphasizes how the aforementioned premium creates incentives for private agents to rely heavily on short-term debt, even when this creates systemic instabilities (Gorton 2010, Stein 2012, Woodford 2012, Gennaioli et al. 2012). Greenwood et al. (2012) consider the role of the government in increasing the supply of short-term debt and affecting the premium. Gorton and Ordonez (2013) also consider this question but in the context of a model with (asymmetric) information acquisition about collateral where the key characteristic of public debt that drives its premium is its information insensitivity. The inefficiency takes the form of too much securitization. It occurs ex ante (before the crisis), because of a pecuniary externality (fire sales). 
Instead, in our model, the inefficiency takes the form of too little securitization. The inefficiency occurs ex post (during the crisis) if there is a safety trap, and it does not originate in a pecuniary externality, but rather in a Keynesian externality operating through the level of aggregate demand.

The paper is organized as follows. Section 2 describes our basic model and introduces the key mechanism of a safety trap. Section 3 introduces public debt and considers the effects of QE policies. Section 4 analyzes the role of forward guidance. Section 5 introduces inflation. Section 6 discusses the robustness of the results to a relaxation of some of the extreme assumptions of the model. It also summarizes two extensions discussed in the Appendix: the emergence and role of bubbles, and the presence of a securitization externality. Section 7 concludes and is followed by an extensive appendix.

\section{The Model}

In this section we introduce our basic model, which is a stylized stochastic overlapping generations model. We start by developing a benchmark flexible price model. We then introduce nominal rigidities, whose only purpose is to bring relevance to the nominal ZLB. In this model, as long as safe nominal interest rates are positive, safe assets shortages can be accommodated with reductions in safe nominal interest rates. The associated reduction in the return of safe assets reduces their demand and restores equilibrium in the market for safe assets. But if safe nominal interest rates are at the ZLB, then a safety trap emerges and asset markets are cleared through a recession.

\subsection{Flexible Prices Benchmark}

Demographics. The horizon is infinite and time is continuous. Population is constant and normalized to one. Agents are born and die at hazard rate $\theta$, independent across agents. Each dying agent is instantaneously replaced by a newborn. Therefore, in an interval $d t, \theta d t$ agents die and $\theta d t$ agents are born.

Aggregate risk. We model aggregate risk as follows. There are two aggregate Poisson processes: a good Poisson process with intensity $\lambda^{+}$and a bad Poisson process with intensity $\lambda^{-}$. We denote by $\sigma^{+}$and $\sigma^{-}$the stopping times for the realizations of the good and bad Poisson processes. We define a Poisson event to be the first realization of either the good or the bad Poisson process, with corresponding stopping time $\sigma=\min \left\{\sigma^{+}, \sigma^{-}\right\}$. We say that the Poisson event is good if $\sigma=\sigma^{+}$ and bad if $\sigma=\sigma^{-}$. Before the Poisson event, for $t<\sigma$, output $X_{t}$ per unit of time is equal to $X$. After the Poisson event, for $t \geq \sigma$, output $X_{t}$ is equal to $\mu^{+} X>X$ if the Poisson event is good, and to $\mu^{-} X<X$ if the Poisson event is bad. The focus of our analysis is on the period before the realization of the aggregate Poisson event, when agents make portfolio decisions in anticipation of such an event. While most of our results only rely on the bad Poisson event, the good Poisson event will be important when we consider the effects of forward guidance, and so we introduce it 
from the start.

Preferences. We assume that agents only have an opportunity to consume when they die, $c_{t}$. We denote by $\sigma_{\theta}$ the stopping time for the idiosyncratic Poisson process controlling an agent's death. This risk is uninsurable and plays no role in our model, aside from its aggregate saving implication.

There are two types of agents in the population: a fraction $\alpha$ of Knightians and $1-\alpha$ of Neutrals, with identical demographics. These agents have different preferences over aggregate risk: Knightians are infinitely risk averse over short time intervals, while Neutrals are risk neutrals over short time intervals. More precisely, for a given stochastic consumption process $\left\{c_{t}\right\}$ which is measurable with respect to the information available at date $t$, we define the utility $U_{t}^{N}$ of a Neutral alive at date $t$, and $U_{t}^{K}$ of a Knightian alive at date $t$, with the following stochastic differential equations

$$
U_{t}^{N}=1_{\left\{t-d t \leq \sigma_{\theta}<t\right\}} c_{t}+1_{\left\{t \leq \sigma_{\theta}\right\}} \mathbb{E}_{t}\left[U_{t+d t}^{N}\right],
$$

and

$$
U_{t}^{K}=1_{\left\{t-d t \leq \sigma_{\theta}<t\right\}} c_{t}+1_{\left\{t \leq \sigma_{\theta}\right\}} \min _{t}\left\{U_{t+d t}^{K}\right\},
$$

where we use the notation $\mathbb{E}_{t}\left[U_{t+d t}^{N}\right]$ to denote the expectation of $U_{t+d t}^{N}$ conditional on the information available at date $t$ and $\min _{t}\left\{U_{t+d t}^{K}\right\}$ to denote the minimum possible realization of $U_{t+d t}^{K}$ given the information available at date $t$.

Note that the information at date $t$ contains the information about the realization of the idiosyncratic and aggregate Poisson events up to $t$, implying that $1_{\left\{t-d t \leq \sigma_{\theta}<t\right\}}$ and $c_{t}$ are known at date $t$. Similarly, the conditional expectation $\mathbb{E}_{t}$ is an expectation over both aggregate shocks and idiosyncratic Poisson death shocks.

Basically, Neutrals are risk neutral with no discounting, and Knightians have Epstein-Zin preferences with infinite relative risk aversion and infinite intertemporal elasticity of substitution, with no discounting. When there is no aggregate risk (as happens after an aggregate Poisson event), the preferences of Knightians and Neutrals coincide.

Non-traded inputs, monopolistic competition, and output. Even though we assume that prices are flexible in this section, we will later introduce nominal rigidities in Section 2.2. To be able to do so, we introduce monopolistic competition: We assume that monopolistic firms produce imperfectly substitutable varieties of final goods and compete in prices. Later, when we introduce nominal rigidities, we will assume that the firms' posted prices are rigid and that they accommodate demand at the posted price. These are standard modelling assumptions in the New Keynesian literature following Blanchard and Kiyotaki (1987).

Between $t$ and $t+d t$, there is an endowment $X_{t} d t$ of each differentiated variety $i \in[0,1]$ of non-traded input. Each variety $i$ of non-traded input can be transformed into one unit of variety $i$ of final good using a one-to-one linear technology by a monopolistic firm indexed by $i$ which is owned and operated by the agent supplying variety $i$ of the non-traded input. 
The differentiated varieties of final goods are valued by consumers according to a standard DixitStiglitz aggregator $c_{t} d t=\left(\int_{0}^{1} x_{i, t}^{\frac{\sigma-1}{\sigma}} d i\right)^{\frac{\sigma}{\sigma-1}} d t$, where $x_{i, t} d t$ is the quantity consumed of variety $i$ of the final good, with associated consumption expenditure $P_{t} c_{t} d t=\int_{0}^{1} p_{i, t} x_{i, t} d t d i$ and price index, $P_{t}=\left(\int_{0}^{1} p_{i, t}^{1-\sigma} d i\right)^{\frac{1}{1-\sigma}}$, where $p_{i, t}$ is the price posted by monopolistic firm $i$ for variety $i$ of the final good. The resulting demand for each variety is given by $x_{i, t} d t=\left(\frac{p_{i, t}}{P_{t}}\right)^{-\sigma} c_{t} d t$.

We denote by $C_{t} d t$ the aggregate consumption by all Knightians and Neutrals between $t$ and $t+d t$. Similarly we denote by and $X_{i, t}$ the aggregate consumption of variety $i$ by all Knightians and Neutrals between $t$ and $t+d t$. We have $X_{i, t} d t=\left(\frac{p_{i, t}}{P_{t}}\right)^{-\sigma} C_{t} d t$.

For now, we assume that the prices set by monopolistic firms are perfectly flexible. Monopolistic firm $i$ takes $P_{t}$ and $C_{t}$ as given and sets $p_{i, t}$ so as to maximize profits $p_{i, t} X_{i, t} d t$, where the demand function $X_{i, t}$ is given above, and subject to its capacity constraint $X_{i, t} d t \leq X_{t} d t$. The optimal price $p_{i, t}$ exhausts the capacity constraint $X_{i, t} d t=X_{t} d t$. Because all firms are symmetric, they set identical prices in equilibrium $p_{i, t}=P_{t}$. Output is then given by $C_{t} d t=X_{t} d t$.

Endowments and assets in positive net supply. Between $t$ and $t+d t$, the varieties of non-traded inputs indexed by $i \in[\delta, 1]$, are distributed equally to the different agents who are born during that interval of time. The varieties of non-traded inputs indexed by $i \in[0, \delta]$ accrue equally as dividends on the different infinitely lived Lucas trees from a continuum of measure one. No variety is endowed to two different newborns, or accrues to two different Lucas trees.

Given that the prices of all varieties are identical and equal to the price index $p_{i, t}=P_{t}$, real income (equal to real output) $X_{t} d t$ is divided into an endowment $(1-\delta) X_{t} d t$ distributed equally to agents who are born during that interval of time, and the dividend $\delta X_{t} d t$ of a unit measure of identical infinitely lived Lucas trees.

Limited pledgeability and state-contingent assets in zero net supply. Only Neutrals can own and operate Lucas trees (a Lucas tree owned and operated by a Knightian yields no dividends). A Neutral can then securitize (borrow against) a tree that he owns by issuing arbitrary state-contingent securities to outside investors (other Neutrals or Knightians) against the cash flows of that tree. We assume that these state-contingent securities cannot be made contingent on idiosyncratic death Poisson processes. Neutrals therefore act like banks in many models of financial intermediation (see e.g. Holmström and Tirole 1997).

The securitization process is hampered by an agency problem: only a fraction $\rho$ of the cash flows of each tree can be pledged to outside investors. This assumption could be motivated in various ways. One popular microfoundation in the financial constraints literature (see e.g. Holmström and Tirole 1997, 1998, Kiyotaki and Moore 1997, and a vast literature since then) is the existence of a moral hazard problem whereby the owner of a tree can abscond with a fraction $1-\rho$ of the cash flows. We refer to $\rho$ as the securitization capacity of the economy.

We also make two technical financial friction assumptions which we maintain throughout the paper. The first assumption, $\rho>\alpha$, ensures that the financial friction would have no bite in the 
absence of aggregate risk (i.e., if we had $\mu^{+}=\mu^{-}=1$ ). This allows us to isolate the limits to the securitization of safe assets, from the more standard financial friction that limits the securitization of assets in general. In particular, this implies that the financial friction has no bite after the realization of the Poisson event (good or bad). This matters when we derive the value of safe assets $V^{S}=\rho \mu^{-} \frac{X}{\theta}$ below. The second assumption, $\mu^{-}\left[1+\frac{\lambda^{+}\left(\mu^{+}-1\right)+\lambda^{-}\left(\mu^{-}-1\right)}{\delta \theta}\right]<1$ and $\mu^{-}\left[1-\frac{\alpha-\rho \mu^{-}}{\rho \mu^{-}} \frac{1-\delta}{\delta}\right]<1$, ensures that at $t$, where either a bad Poisson event, or a good Poisson event, or no Poisson event, could take place between $t$ and $t+d t$, the only relevant pledgeability constraint (binding in equilibrium) pertains to cash flows following a potential bad Poisson event.

Money, the cashless limit, and the ZLB. A monetary authority sets the nominal interest rate $i_{t}$. We focus on equilibria where the price level $P_{t}$ has continuous paths and where the monetary authority is constrained by the ZLB $i_{t} \geq 0$.

For a justification of this ZLB constraint, we refer the reader to Appendix A.2 where we explicitly introduce money into the model through a cash-in-advance constraint. In the monetary model, because the price level has continuous paths, money is a safe asset with real rate of return $-\pi_{t}$ where $\pi_{t}=\frac{\dot{P}_{t}}{P_{t}}$ is the inflation rate. Non-monetary safe assets have a real rate of return $r_{t}^{K}=i_{t}-\pi_{t}$. When $i_{t}>0$, money is dominated by non-monetary safe assets as a safe store of value, and it is then only held for the transaction services that it provides (the cash-in-advance constraint is binding). When $i_{t}=0$, money is not dominated by non-monetary safe assets as a safe store of value, and it is then also held as a safe store of value (the cash-in-advance constraint is slack). The monetary model has no equilibrium with $i_{t}<0$ because money would then dominate non-monetary safe assets as a safe store of value. The cashless limit of the monetary model (see e.g. Woodford 2003) coincides with the model that we focus on here with a ZLB constraint.

Because prices are assumed to be flexible (for now), the assumption that the price level is continuous and the imposition of the ZLB constraint on nominal interest rates $i_{t} \geq 0$ have no bearing on the real allocations that arise in equilibrium. This is because for any nominal interest rate $i_{t}$, the inflation rate $\pi_{t}$ is an equilibrium variable which freely adjusts to deliver the required equilibrium real rate of return on safe assets $r_{t}^{K}=i_{t}-\pi_{t}$ (the real interest rate). As we shall see shortly in Section 2.2, this is no longer true when prices are not perfectly flexible. But for now we focus exclusively on real variables.

Equilibrium. As we mentioned, we focus on the period before the (aggregate) Poisson event. That is, we analyze the consequences of the possibility and fear of a shock rather than of the realization of that shock.

Newborns trade their endowments for assets. They keep reinvesting and rebalancing their portfolio until they die, at which point they sell their assets for goods and consume them. Agents choose their portfolios of assets to maximize their utility. Crucially, Knightians and Neutrals choose different portfolios.

The main features of the portfolios can be understood intuitively. In order to maximize his utility at date $t$, a Knightian agent chooses to invest his wealth between $t$ and $t+d t$ in safe assets; 
that is assets whose value at $t+d t$ is independent of the realization of aggregate shocks (a good Poisson event, a bad Poisson event, or no Poisson event) between $t$ and $t+d t$. Similarly, in order to maximize his utility at date $t$, a Neutral agent chooses to hold some Lucas trees and to issue some safe assets to Knightians against their pledgeable dividends. This is all we need to know about optimal portfolios in order to derive the equilibrium.

Because of the linearity of preferences and the i.i.d. (across agents and time) nature of death, the model aggregates cleanly. We denote by $W_{t}^{K}$ the total wealth of Knightians and $W_{t}^{N}$ the total wealth of Neutrals. We denote by $V_{t}^{S}$ the total value of safe assets that can be issued against the Lucas trees, and by $V_{t}^{R}$ the total value of risky assets, by which we mean the value of the Lucas trees net of the value of the safe assets that can be issued against them. Note that we have defined $V_{t}^{S}$ as the total value of safe assets that can be issued, not the value of safe assets that are actually issued by Neutrals to Knightians. It is therefore possible that some safe assets are held by Neutrals. We denote total wealth by $W_{t}$ with $W_{t}=W_{t}^{K}+W_{t}^{N}$, and the total value of assets by $V_{t}=V_{t}^{R}+V_{t}^{S}$. Note that $V_{t}$ is the total value of Lucas trees, the only assets in positive net supply.

Between $t$ and $t+d t$ a fraction $\theta$ of agents die and consume. Because dying agents are a representative sample of the population, consumption between $t$ and $t+d t$ is $\theta W_{t} d t$. Given that output between $t$ and $t+d t$ is $X d t$, market clearing in the goods market pins down the equilibrium level of wealth:

$$
W_{t}=W=\frac{X}{\theta} .
$$

Asset market clearing then determines the value of existing assets:

$$
V_{t}=V=W=\frac{X}{\theta}
$$

We can find $V_{t}^{S}$ by solving backwards. After the Poisson event, the total value of Lucas trees $V^{+}$(after a good Poisson event) and $V^{-}$(after a bad Poisson event) can be found by applying a similar logic to that prior to the shock, so that:

$$
V_{t}^{+}=V^{+}=W_{t}^{+}=W^{+}=\mu^{+} \frac{X}{\theta} \quad \text { and } \quad V_{t}^{-}=V^{-}=W_{t}^{-}=W^{-}=\mu^{-} \frac{X}{\theta} .
$$

Given that only a fraction $\rho$ of the cash flows after the Poisson event can be pledged, and that the financial constraint has no bite after the Poisson event (because $\rho>\alpha$ ), the maximal value of safe assets is $\rho V^{-}$. We will verify later that the equilibrium value of safe assets before and after the Poisson event is indeed

$$
V_{t}^{S}=V^{S}=V_{t}^{S+}=V^{S+}=V_{t}^{S-}=V^{S-}=\rho \mu^{-} \frac{X}{\theta}
$$

For now, we proceed as if it were the case. Risky assets are worth the residual

$$
V_{t}^{R}=V^{R}=\left(1-\rho \mu^{-}\right) \frac{X}{\theta}, \quad V_{t}^{R+}=V^{R+}=\left(\mu^{+}-\rho \mu^{-}\right) \frac{X}{\theta}, \quad \text { and } \quad V_{t}^{R-}=V^{R-}=\left(\mu^{-}-\rho \mu^{-}\right) \frac{X}{\theta} .
$$


Let $r_{t}, r_{t}^{K}$, and $\delta_{t}^{S}$ denote the expected rate of return on risky assets, the rate of return on safe assets, and an index of the dividend pledged to safe assets, respectively. Then equilibrium before the Poisson event is characterized by the following equations:

$$
\begin{gathered}
r_{t}^{K} V^{S}=\delta_{t}^{S} X \\
r_{t} V^{R}=\left(\delta-\delta_{t}^{S}\right) X+\lambda^{+}\left(V^{R+}-V^{R}\right)+\lambda^{-}\left(V^{R-}-V^{R}\right), \\
\dot{W}_{t}^{K}=-\theta W_{t}^{K}+\alpha(1-\delta) X+r_{t}^{K} W_{t}^{K}, \\
\dot{W}_{t}^{N}=-\theta W_{t}^{N}+(1-\alpha)(1-\delta) X+r_{t}^{K}\left(V^{S}-W_{t}^{K}\right)+r_{t} V^{R}-\lambda^{+}\left(V^{R+}-V^{R}\right)-\lambda^{-}\left(V^{R-}-V^{R}\right) \\
W_{t}^{K}+W_{t}^{N}=V^{S}+V^{R}, \\
r_{t} \geq r_{t}^{K}, \quad W_{t}^{K} \leq V^{S} \text { and }\left(r_{t}-r_{t}^{K}\right)\left(V^{S}-W_{t}^{K}\right)=0 .
\end{gathered}
$$

The first two equations are the standard asset pricing equation for safe and risky assets. The third and fourth equations are the wealth evolution equations for Knightians and Neutrals. The fifth equation is just the asset market clearing equation. The sixth equation must hold because Neutrals rank assets according to expected returns, so that either $r_{t}=r_{t}^{K}$ and Neutrals are indifferent between safe and risky assets or $r_{t}>r_{t}^{K}$ and Neutrals hold only risky assets.

The first asset pricing equation is for safe assets and captures the immunity of such asset with respect to aggregate shocks as the return is entirely given by the flow dividend $\delta_{t}^{S} X$. The second asset pricing equation is for risky assets, and the dividend flow $\left(\delta-\delta_{t}^{S}\right) X$ is complemented by expected capital gains and losses $\lambda^{+}\left(V^{R+}-V^{R}\right)+\lambda^{-}\left(V^{R-}-V^{R}\right)$ in the event of an aggregate Poisson event.

One can think of safe asset in two equivalent ways: as safe short-term debt which is rolled over every period, with interest rate $r_{t}^{K}$, and exactly collateralized by a fraction of the dividends of Lucas tree; or as a long-lived assets capitalizing this fractional stream of dividends. Correspondingly, one can think of risky assets either as levered Lucas trees or as simply capitalizing the fraction of dividends that has not been pledged to safe assets. In both cases, it is worth stressing that just like the safe real interest rate $r_{t}^{K}$, the variable indexing the dividend pledged to safe assets $\delta_{t}^{S}$ is an equilibrium variable. It is endogenously determined to ensure that safe assets are indeed safe, i.e. that their value $V^{S}$ does not change when a Poisson event occurs.

As we shall see, safe real interest rate jump (to $\delta \theta$ ) when a Poisson event occurs and so does the endowment (to $\mu^{+} X$ after a good Poisson event and to $\mu^{-} X$ after a bad Poisson event). This means that the variable indexing the dividend pledged to safe assets must also jump after a Poisson event (to $\delta^{S+}=\delta \rho \frac{\mu^{-}}{\mu^{+}}$after a good Poisson event and to $\delta^{S-}=\delta \rho$ after a bad Poisson event). That $\delta^{S-}=\delta \rho$ and $\delta^{S+}>\delta \rho$ indicates that while the pledgeability constraint is binding after the bad Poisson event, it is slack after the good Poisson event. Given our technical assumptions above, we always have $\delta_{t}^{S}<\delta \rho$ in equilibrium so that the pledgeability constraint is also slack before the 
Poisson event. ${ }^{5}$ The binding pledgeability constraint after the bad Poisson event is the limit on safe asset creation. The extra pledgeable dividend after the good Poisson event and before the Poisson event can only be pledged to risky assets. ${ }^{6}$

The evolution equation for Knightian wealth can be understood as follows: First, between $t$ and $t+d t$, a fraction $\theta d t$ of Knightians die, sell their assets, and consume. Because the dying Knightians are a representative sample of Knightians, this depletes the stock of Knightian wealth by $\theta W_{t}^{K} d t$. Second, between $t$ and $t+d t, \theta \alpha d t$ new Knightians are born with a total endowment $\alpha(1-\delta) X d t$, which they sell to acquire assets. This increases Knightian wealth by $\alpha(1-\delta) X d t$. Third, between $t$ and $t+d t$, Knightians collect interest rates $r_{t}^{K} W_{t}^{K} d t$. Overall, the increase in Knightian wealth is therefore $W_{t+d t}^{K}-W_{t}^{K}=-\theta W_{t}^{K} d t+\alpha(1-\delta) X d t+r_{t}^{K} W_{t}^{K} d t$. Taking the limit $d t \rightarrow 0$ yields the stated equation.

The intuition for the evolution equation of Neutral wealth is similar. The only twist is that conditional on no Poisson event, the total return earned on Neutral wealth between $t$ and $t+d t$ is the sum of the return on the safe assets held by Neutrals $r_{t}^{K}\left(V^{S}-W_{t}^{K}\right) d t$ and of the expected return on the risky assets held by Neutrals $r_{t} V^{R} d t$ net of the expected capital gains $\lambda^{+}\left(V^{R+}-V^{R}\right) d t$ and $\lambda^{-}\left(V^{R-}-V^{R}\right) d t$ in case of a Poisson event.

Two regimes. The dynamic system describing the equilibrium converges to a unique stochastic steady state before the Poisson event, conditional on the Poisson event not occurring, and to a unique deterministic steady state after the Poisson event. We focus on the former stochastic steady state, and drop $t$ subscripts. There are two regimes, depending on whether the constraint $W_{t}^{K} \leq V^{S}$ is slack (unconstrained regime) or binding (constrained regime).

In the unconstrained regime, Neutrals are the marginal holders of safe assets so that safe and risky rates are equalized $r=r^{K}$. A couple of steps of algebra show that in this case:

$$
\begin{gathered}
\delta^{S}=\delta \rho \mu^{-}\left[1+\frac{\lambda^{+}\left(\mu^{+}-1\right)+\lambda^{-}\left(\mu^{-}-1\right)}{\delta \theta}\right]<\delta \rho, \\
r=r^{K}=\delta \theta+\lambda^{+}\left(\mu^{+}-1\right)+\lambda^{-}\left(\mu^{-}-1\right) .
\end{gathered}
$$

It is easy to verify that this regime holds as long as the following safe asset shortage condition

$$
\frac{\alpha-\rho \mu^{-}}{\rho \mu^{-}}(1-\delta) \theta+\lambda^{+}\left(\mu^{+}-1\right)+\lambda^{-}\left(\mu^{-}-1\right)>0
$$

does not hold. The interesting case for us is the constrained regime, where Knightians are the

\footnotetext{
${ }^{5}$ This validates our earlier claim that the value of safe assets is given by $V^{S}=\rho V^{-}$.

${ }^{6} \mathrm{As}$ we shall see, it is entirely possible for $\delta_{t}^{S}$ and $r_{t}^{K}$ to be negative before the Poisson event. If one chooses to view safe assets as short-term debt which is rolled over every period, then this simply means that interest rate on this debt is negative for a while. If instead one chooses to view safe assets as long-lived assets capitalizing a stream of dividends, then this means that the dividends are negative for a while. In both cases, it represents a flow payment from safe asset holders to their issuers. But note that after the Poisson event, safe real interest rates, $\delta^{S+}$, and $\delta^{S-}$ are all positive and so payments necessarily flow from safe asset issuers to holders. This explains why even in this case, the value of safe assets (viewed as long-lived assets capitalizing a stream of dividends) remains positive and finite before the Poisson event.
} 
marginal holders of safe assets, and which captures the safe asset shortage environment. In it, Knightians demand all the safe assets:

$$
W^{K}=V^{S}=\rho \mu^{-} \frac{X}{\theta},
$$

and there is a risk premium $r>r^{K}$. We then have:

$$
\begin{gathered}
\delta^{S}=\delta \rho \mu^{-}-\left(\alpha-\rho \mu^{-}\right)(1-\delta)<\delta \rho \\
r^{K}=\delta \theta-\frac{\alpha-\rho \mu^{-}}{\rho \mu^{-}}(1-\delta) \theta \\
r=\delta \theta+\frac{\alpha-\rho \mu^{-}}{1-\rho \mu^{-}}(1-\delta) \theta+\frac{\lambda^{+}\left(\mu^{+}-1\right)+\lambda^{-}\left(\mu^{-}-1\right)}{1-\rho \mu^{-}} .
\end{gathered}
$$

It follows that in this constrained region there is a risk premium

$$
r-r^{K}=\frac{\frac{\alpha-\rho \mu^{-}}{\rho \mu^{-}}(1-\delta) \theta+\lambda^{+}\left(\mu^{+}-1\right)+\lambda^{-}\left(\mu^{-}-1\right)}{1-\rho \mu^{-}}>0 .
$$

It is easy to verify that this regime holds as long as the safe asset shortage condition (1) holds. ${ }^{7}$

The limit $\lambda^{+} \rightarrow 0$ and $\lambda^{-} \rightarrow 0$. These expressions simplify in the limit $\lambda^{+} \rightarrow 0$ and $\lambda^{-} \rightarrow 0$. Because the marginal investor for risky assets is a Neutral, the expected capital gains for risky assets in the case of a Poisson event vanish in this limit. In the unconstrained regime, neither $\mu^{+}$nor $\mu^{-}$ appears in the equilibrium equations before the Poisson event. But in the constrained regime, $\mu^{-}$ features prominently, because it determines the supply of safe assets for which the marginal investor is a Knightian.

The demand for safe assets is summarized by the fraction of Knightians $(\alpha)$. The supply of safe assets is determined by the severity of the potential bad shock $\left(\mu^{-}\right)$and the ability of the economy to create safe assets $(\rho)$ through the sufficient statistic $\rho \mu^{-}$. In the limit $\lambda^{+} \rightarrow 0$ and $\lambda^{-} \rightarrow 0$, these sufficient statistics together determine whether we are in the unconstrained regime $\left(\alpha \leq \rho \mu^{-}\right)$or in the constrained regime $\left(\alpha>\rho \mu^{-}\right)$, the rate of return on safe assets, the rate of return on risky assets, and the risk premium. ${ }^{8}$

Remark 1 Our demographics and preferences allow us to capture a stylized version of a life-cycle

\footnotetext{
${ }^{7}$ Note that all these equations only apply in the stochastic steady state before the Poissont event, conditional on the Poisson event not occurring. In particular, after the Poisson event, safe assets are claims to a stream of dividends $\delta \rho \mu^{-} X$, and the safe and risky expected rates of return jump to $\delta \theta$, and the value of safe assets is the same as in the stochastic steady state before the Poisson event $V^{S}=\frac{\rho \mu^{-} X}{\theta}$. In other words, safe assets are claims to dividends $\delta^{S} X$ before the Poisson event and $\delta \rho \mu^{-} X$ after the Poisson event, and the relevant discount rate is $r^{K}=\frac{\delta^{S}}{V^{S}}$ before the Poisson event and $\delta \theta$ after the Poisson event.

${ }^{8}$ Away from the limit $\lambda^{+} \rightarrow 0$ and $\lambda^{-} \rightarrow 0$, for a given $r$ and $r^{K}$, the wealth of Neutrals in the stochastic steady state before the Poisson event increases with the intensity of the bad Poisson event $\lambda^{-}$and decreases with the intensity $\lambda^{+}$of the good Poisson event. Therefore in equilibrium, $r$ decreases with $\lambda^{-}$and increases with $\lambda^{+}$, while $r^{K}$ is independent of $\lambda^{+}$and $\lambda^{-}$. This explains why the condition for the constrained regime is tightened by an increase in $\lambda^{-}$and relaxed by an increase in $\lambda^{+}$.
} 
model with a portfolio choice, abstracting from intertemporal substitution in consumption which is not central to the questions we want to analyze. The only decision that agents are making is how to invest their wealth at every point in time, and because Knightians and Neutrals have different attitudes towards risk, they choose different portfolios.

Remark 2 Our model features two forms of market incompleteness. The first one is tied to our overlapping generations structure, which makes future endowment ("wages") non-pledgeable. The second market incompleteness is the pledegeability of dividends constraint $(\rho)$ which limits the ability to securitize (tranche) Lucas' trees. Tranching is desirable because it decomposes an asset into a safe tranche which can be sold to Knightian agents and a risky tranche. In the policy discussion we will not exploit the first form of incompleteness (we use the OLG structure mostly because it yields a stationary distribution of wealth between Neutrals and Knightians) and focus instead on the second form. The latter implies that in equilibrium risky assets held by Neutrals contain an unpledgable safe claim of size $(1-\rho) \mu^{-\frac{X}{\theta}}$ which is the starting point of our macroeconomic policy analysis later on. See Section 3 for a more detailed discussion.

\subsection{Nominal Rigidities, the Safety Trap, and the Liquidity Trap}

In this section, we introduce nominal rigidities. We refer to the allocation of the above flexible price model as the natural allocation. We write $r_{t}^{K, n}$ for the natural safe interest rate (the Wicksellian interest rate) before the Poisson event, and we write $r_{t}^{n}$ for the natural risky expected rate of return before the Poisson event. Both are equal to $\delta \theta$ after the Poisson event (good or bad). For natural output, we also sometimes use the term potential output. It is equal to $X$ before the Poisson event, to $\mu^{+} X$ after a good Poisson event, and to $\mu^{-} X$ after a bad Poisson event.

With nominal rigidities, there is potentially a gap between actual output and potential output. Appropriate monetary policy can ensure that actual output is at potential as long as the safe natural interest rate is positive. But when the safe natural interest rate is negative, the economy reaches the ZLB and actual output drops below potential.

Depending on whether we are in the unconstrained regime where the financial friction is slack and the heterogeneity in risk aversion plays no role, or in the constrained regime where it is binding and where the heterogeneity in risk aversion matters, the situation that emerges is either a liquidity trap or a safety trap. In our rendition, liquidity traps feature no risk premia while safety traps feature positive and endogenous risk premia. It will become apparent that the key distinction between the two situations has to do with the difference in the sensitivity of risk premia and its specific drivers. ${ }^{9}$

Our focus is on the safety trap, which is novel, but we also characterize the more standard liquidity trap as it will help us to highlight (by contrast) the unique policy implications of safety

\footnotetext{
${ }^{9}$ In the broader literature on liquidity traps, risk premia are either assumed away by analysis relying on loglinearizations or play at best a peripheral role in analyses with non-linearized models.
} 
traps later in the paper.

\subsubsection{Rigid Prices, Monetary Policy, and the ZLB}

We use the traditional ingredients of New Keynesian economics: imperfect competition, sticky prices, and a monetary authority.

Rigid prices. We assume that the prices of the different varieties are entirely fixed (an extreme form of sticky prices, which we shall relax later in Section 5) and equal to each other, $p_{i t}=P$, where without loss of generality we take $P=1$. Monopolistic firms accommodate demand for their variety of final good at the posted price.

Because the prices of all varieties are identical, the demand for all varieties is the same. Output is demand-determined, and as a result, $x_{i, t}=C_{t}=\xi_{t} X_{t}$ for all $i$ where the capacity utilization rate $\xi_{t} \leq 1$ is the same for all firms. Capacity utilization $\xi_{t}$ represents the wedge between actual output $\xi_{t} X_{t}$ and potential output $X_{t}$.

Monetary policy and the ZLB. In contrast with the case of flexible prices, with rigid prices, the ZLB constraint impacts the real allocations that arise in equilibrium. This is because with rigid prices, the nominal interest rate determines the safe real interest rate $r_{t}^{K}=i_{t}$ and hence we have a constraint $r_{t}^{K} \geq 0$.

The safe natural interest rate is always positive at $\delta \theta$ after a Poisson event (good or bad). By setting the nominal interest rate equal to this safe natural interest rate, the monetary authority can replicate the natural allocation after a Poisson event. Before the Poisson event however, the safe natural interest rate $r_{t}^{K, n}$ need not be positive. If the safe natural interest rate is positive, then by setting the nominal interest rate equal to the natural safe interest rate $i=r_{t}^{K, n}>0$, the monetary authority can replicate the natural allocation, ensuring that output is at potential $\xi=1$. But if the safe natural interest rate is negative $r_{t}^{K, n}<0$, then there is a recession $\left(\xi_{t}<1\right)$ with $i_{t}=r_{t}^{K}=0$. As we shall see, it makes a great difference whether this happens in the unconstrained regime (liquidity trap) or in the constrained regime (safety trap). The regime that is of most interest to us is the safety trap. We therefore start with this case and then contrast it with the liquidity trap case. As in the case where prices are flexible, we focus on stochastic steady states before the Poisson event and drop $t$-subscripts.

\subsubsection{The Safety Trap}

With rigid prices, when $r^{K, n}<0$ and hence $i=r^{K}=0$, capacity utilization $\xi$ becomes an equilibrium variable, in the same way that prices are equilibrium variables in standard Walrasian theory with flexible prices. We now explain how $\xi$ is determined in two different but equivalent ways. First we explain how $\xi$ enters the system of equilibrium equations. Second, we provide a simple AS-AD 


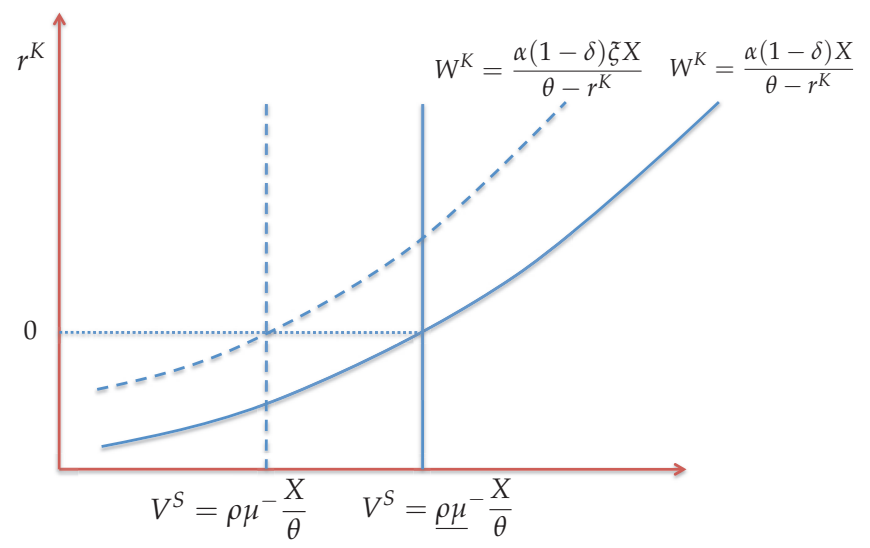

Figure 3: Safety trap. Recession caused by a decrease in the supply of safe assets. The safe asset supply curve shifts left $\left(\rho \mu^{-}<\rho \mu^{-}\right)$, the endogenous recession shifts the safe asset demand curve left $(\xi<1)$, and the safe interest rate remains unchanged at 0 .

Keynesian cross representation of the equilibrium where $\xi$ is determined as a fixed point. ${ }^{10}$

Recall that we have assumed that actual and potential output coincide after the bad Poisson event and therefore the value of safe assets (before the event) is still given by

$$
V^{S}=\rho \mu^{-} \frac{X}{\theta}
$$

Mechanically, the equilibrium values of all the variables are identical to those in the flexible price model but with $\mu^{+}, \mu^{-}$and $X$, replaced by $\frac{\mu^{+}}{\xi}, \frac{\mu^{-}}{\xi}$, and $\xi X$. The requirement that $r^{K}=0$ determines the severity of the equilibrium recession $\xi$ :

$$
0=\delta \theta-(1-\delta) \theta \frac{\alpha-\frac{\rho \mu^{-}}{\xi}}{\frac{\rho \mu^{-}}{\xi}},
$$

yielding

$$
\xi=1+\frac{r^{K, n}}{\alpha(1-\delta) \theta}=\frac{\rho \mu^{-}}{\underline{\rho \mu^{-}}}<1,
$$

where $\rho \mu^{-}=\alpha(1-\delta)$ corresponds to the value of these combined parameters for which zero is the natural safe interest rate. ${ }^{11}$

We call this equilibrium a safety trap, since at full employment there is an excess demand for safe assets. A recession lowers the absolute demand for safe assets while keeping the absolute supply

\footnotetext{
${ }^{10} \mathrm{We}$ assume throughout the paper in all our analyses of safety traps (and later in the corresponding analysis of liquidity traps) that our technical financial friction assumptions as well as condition (1) continue to hold when $\mu^{-}$is replaced by $\frac{\mu^{-}}{\xi}$ and $\mu^{+}$is replaced by $\frac{\mu^{+}}{\xi}$. This is guaranteed to hold if $r^{K, n}$ is not too negative, so that the recession is not too severe.

${ }^{11}$ Note that output in the safety trap can be higher or lower than output after the bad Poisson event. Indeed we have $\xi X>\mu^{-} X$ if and only if the securitization capacity is large enough $\rho>(1-\delta) \alpha$. This makes clear that in our model the safety trap recession arises endogenously as the result of the fear of a bad shock, of the kind that have been routinely emphasized in the recent macroeconomic uncertainty and rare disasters literatures, rather than by the realization of a bad shock itself (a second moment shock vs. a first moment shock).
} 
of safe assets fixed and restores equilibrium. Figure 3 illustrates this mechanism, which we describe next. $^{12}$

The supply and demand of safe assets are $V^{S}=\rho \mu^{-\frac{X}{\theta}}$ and $W^{K}=\frac{\alpha(1-\delta) \xi X}{\theta-r^{K}}$ respectively. Equilibrium in the safe asset market requires that $W^{K}=V^{S}$, i.e.

$$
\frac{\alpha(1-\delta) \xi X}{\theta-r^{K}}=\rho \mu^{-} \frac{X}{\theta} .
$$

Consider a one time unexpected (zero ex-ante probability) shock that lowers the supply of safe assets (a reduction in $\rho \mu^{-}$). ${ }^{13}$ In response to this shock, the economy immediately jumps to a new steady state without any transitional dynamics. The mechanism by which equilibrium in the safe asset market is restored has two parts. The first part immediately reduces Knightian wealth $W^{K}$ to a lower level, consistent with the lower supply of safe assets $\rho \mu^{-} \frac{X}{\theta}$. The second part maintains Knightian wealth $W^{K}$ at this lower level.

The first part of the mechanism is as follows. The economy undergoes an immediate wealth adjustment (the wealth of Knightians drops) through a round of trading between Knightians and Neutrals born in previous periods. At impact, Knightians hold assets that now carry some risk. They react by selling the risky part of their portfolio to Neutrals. This shedding of risky assets catalyzes an instantaneous fire sale whereby the price of risky assets collapses before immediately recovering once risky assets have changed hands. Needless to say, in reality this phase takes time, which we have removed to focus on the phase following the initial turmoil.

The second part of the equilibrating mechanism differs depending on whether the safe interest rate $r^{K}=i$ is above or at the ZLB. If $r^{K}=i>0$, then a reduction in the safe interest rate $r^{K}=i$ takes place. This reduction in the safe interest rate effectively implements a transfer (in every period) from Knightians to Neutrals, which limits the growth of Knightian wealth. As a result, the safe asset market remains in equilibrium, and so does the goods market. But if the safe interest rate is against the ZLB $r^{K}=i=0$, then this reduction in the safe interest rate cannot take place and the associated transfer cannot occur. The only adjustment mechanism is with a decline in output (income), which also drags down Neutral's wealth.

AS-AD representation and the Keynesian cross. We now provide an alternative way of understanding the equilibrium determination of capacity utilization $\xi$ in a safety trap as a fixed point in an $\mathrm{AS}-\mathrm{AD}$ Keynesian cross representation where $\xi$ equalizes aggregate demand and aggregate supply $A D(\xi X)=A S(\xi X)$. This representation puts the goods market instead of the safe asset

\footnotetext{
${ }^{12} \mathrm{We}$ rule out rationing in the safe asset market. The reason is that the safe asset market is postulated to be competitive and the price of safe safe assets to be flexible, which is an assumption shared by all the New Keynesian literature. This is unlike the goods market where monopolistic suppliers of the different varieties of final goods post rigid prices and accommodate demand at these posted prices.

${ }^{13}$ The one time unexpected shock could be a reduction in the securitization capacity $\rho$ of the economy. It could also be a reduction in $\mu^{-}$, akin to an increase in macroeconomic uncertainty in the macroeconomic uncertainty literature, or to an increase in the severity of disasters in the rare disasters literature. The safety trap recession then arises transitorily but potentialy very persistently (in fact essentially permanently in the limit $\lambda^{+} \rightarrow 0$ and $\lambda^{-} \rightarrow 0$ ) in response to a shock.
} 
market at the center stage.

Aggregate supply is simply the 45 degree line

$$
A S(\xi X)=\xi X
$$

This captures the fact that with rigid prices, output is demand determined. Aggregate demand for goods $A D(\xi X)=\theta W^{K}+\theta W^{N}$ is given by the sum of the consumption of Knightians $\theta W^{K}$ and Neutrals $\theta W^{N}$, where $\theta$ acts as the effective aggregate average propensity to consume out of wealth. Since Knightians only hold safe assets and safe assets are only held by Knightians in the constrained regime, Knightian wealth coincides with the value of safe assets $W^{K}=V^{S}$, and Knightian consumption is $\theta W^{K}=\theta V^{S}$. Similarly, since Neutrals only hold risky assets and risky assets are only held by Neutrals, Neutral wealth coincides with the value of risky assets $W^{N}=V^{R}$ and Neutral consumption is $\theta W^{N}=\theta V^{R}$, which can be computed to be $\theta W^{N}=\theta V^{R}=$ $(1-\alpha)(1-\delta) \xi X+\delta \xi X-r^{K} V^{S}$. The intuition is simply that in a stochastic steady state before the Poisson event, Neutral consumption equals Neutral income, which is the sum of the income of Neutral newborns $(1-\alpha)(1-\delta) \xi$ and of dividend income $\delta \xi X$ net of interest payments on safe assets held by Knightians $r^{K} V^{S}$. Aggregate demand for goods is therefore given by

$$
A D(\xi X)=(1-\alpha)(1-\delta) \xi X+\delta \xi X+\left(\theta-r^{K}\right) V^{S}
$$

Aggregate demand increases with output $\xi X$ because the consumption of Neutrals increases with output (their income increases with output). Aggregate demand increases with the value of safe assets $V^{S}$ because the consumption of Knightians increases more with the value of safe assets (their wealth is equal to the value of safe assets) than the consumption of Neutrals decreases with the value of safe assets (the interest payments on safe assets held by Knightians is proportional to the value of safe assets). Aggregate demand decreases with the safe real interest rate $r^{K}=i$ because the consumption of Neutrals decreases with the safe real interest rate (the interest payments on safe assets held by Knightians is proportional to the safe real interest rate).

When $r^{K, n} \geq 0$, we have $A D(X)=A S(X)$ when $i=r^{K}=r^{K, n}$. But when $r^{K, n}<0$, we have $i=r^{K}=0$ and $\xi$ is the solution of the fixed point equation $A D(\xi X)=A S(\xi X)$. Aggregate demand and aggregate supply are then two increasing functions of income $\xi X$. Aggregate demand is flatter than aggregate supply. Equilibrium is determined by a Keynesian cross at the intersection of the aggregate demand and aggregate supply curves.

Crucially, a reduction $d V^{S}<0$ in the value of safe assets $V^{S}$ represents an adverse (downward) shift to aggregate demand. Away from the ZLB, this reduction in aggregate demand can be accommodated by an easing of monetary policy (a reduction in $i=r^{K}$ ), thereby maintaining output at potential $(\xi=1)$. But at the ZLB, monetary policy cannot be eased, and instead the reduction in aggregate demand lowers output, which further reduces aggregate demand, etc. ad infinitum until the economy reaches a new fixed point with lower output. Intuitively, the reduction in the value of safe assets reduces Knightian wealth and hence Knightian consumption. This impulse depresses 
output. This initial reduction in output then reduces the income of Neutrals, and hence their consumption, which further reduces output. This feedback loop between output and the consumption of Neutrals keeps going until the economy settles at a new fixed point with lower values of output, assets, wealth, consumption and income. The reduction in income of Neutrals and Knightians are constant at these new lower levels.

This adjustment is captured by a familiar Keynesian multiplier

$$
\frac{\xi X}{\theta V^{S}}>1
$$

which amplifies the effect of the initial reduction $\theta d V^{S}$ in aggregate demand to a final effect of $d(\xi X)=\frac{\xi X}{\theta V^{S}} \theta d V^{S}$ - a proportional increase in output. ${ }^{14}$ Figure 2 in the introduction provides a graphical illustration of this adjustment.

Risk premium. The equilibrium is block recursive in $(\xi, r)$ so that $r$ can be computed given $\xi$ :

$$
r=\delta \theta+(1-\delta) \theta \frac{\alpha-\frac{\rho \mu^{-}}{\xi}}{1-\frac{\rho \mu^{-}}{\xi}}+\frac{\lambda^{+}\left(\frac{\mu^{+}}{\xi}-1\right)+\lambda^{-}\left(\frac{\mu^{-}}{\xi}-1\right)}{1-\frac{\rho \mu^{-}}{\xi}}
$$

In the limit $\lambda^{+} \rightarrow 0$ and $\lambda^{-} \rightarrow 0$, if the economy is already in a safety trap with $r^{K}=0$, decreases in the supply of safe assets $\rho \mu^{-}$leave $r$ (and hence $r-r^{K}$ ) unchanged while increases in the demand for safe assets $\alpha$ increase $r$ (and hence $r-r^{K}$ ). ${ }^{15}$ But if the economy is initially outside a safety trap, large enough decreases in the supply of safe assets or increases in the demand for safe assets will push the economy into a safety trap and lead to a drop in output and an increase in risk premia.

\subsubsection{Contrasting Safety and Liquidity Traps}

We now contrast safety traps $\left(r^{K, n}<0\right.$ in the constrained regime) with liquidity traps $\left(r^{K, n}<0\right.$ in the unconstrained regime). We therefore assume that $r^{n}=r^{K, n}<0$ and $i=r=r^{K}=0$. We follow similar steps to those of Section 2.2.2 and keep the analysis short in the interest of space.

The liquidity trap. Mechanically, the equilibrium equations are identical to those in the flexible price model but with $\mu^{+}, \mu^{-}$and $X$, replaced by $\frac{\mu^{+}}{\xi}, \frac{\mu^{-}}{\xi}$, and $\xi X$. Capacity utilization $\xi$ is

\footnotetext{
${ }^{14}$ The analysis above goes through as well if we raise the share of Knightian agents $\alpha$ instead of reducing $\rho \mu^{-}$, in which case the recession factor is $\xi=\frac{\theta}{\theta-r K, n}=\frac{\alpha}{\alpha}<1$, where $\underline{\alpha}=\frac{\rho \mu^{-}}{1-\delta}$ corresponds to the value of this parameter for which zero is the natural safe interest rate. The increase in $\alpha$ acts as an adverse shift in aggregate demand.This interpretation resembles the Keynesian paradox of thrift. Combining both, asset supply and demand factors, we have that the severity of the recession is determined by the sufficient statistic $\frac{\rho \mu^{-}}{\alpha}$ according to the simple equation: $\xi=\frac{\underline{\alpha}}{\underline{\rho \mu^{-}}} \frac{\rho \mu^{-}}{\alpha}$, where $\frac{\rho \mu^{-}}{\underline{\alpha}}=1-\delta$ corresponds to the value of these combined parameters for which zero is the natural safe interest rate.

${ }^{15}$ When $\lambda^{+}>0$ or $\lambda^{-}>0$, additional expected capital gains effects come into play. For example, decreases in $\rho$ now increase $r$ (and hence $r-r^{K}$ ).
} 
determined by the requirement that $r=r^{K}=0$ :

$$
\delta \theta+\lambda^{+}\left(\frac{\mu^{+}}{\xi}-1\right)+\lambda^{-}\left(\frac{\mu^{-}}{\xi}-1\right)=0
$$

i.e.

$$
\xi=\frac{1}{1-\frac{r^{n}}{\lambda^{-} \mu^{-}+\lambda^{+} \mu^{+}}} .
$$

The recession originates from a scarcity of assets (stores of value). It is more severe, the worse the Poisson shocks (the lower are $\mu^{+}$and $\mu^{-}$), the more likely the good Poisson event (the higher $\lambda^{+}$), the more likely the bad Poisson event (the higher $\lambda^{-}$), the higher the propensity to save (the lower $\theta$ ), and the lower the ability of the economy to create assets that capitalize future income (the lower is $\delta$ ).

To understand this result, it is useful to derive the equilibrium condition in the asset market $W=V$ by expressing total asset demand $W$ (left-hand side) and total asset supply $V$ (right-hand side) as a function of $\xi$ and $r$ :

$$
\frac{(1-\delta) \xi X-\lambda^{+} \frac{\mu^{+} X}{\theta}-\lambda^{-\frac{\mu^{-} X}{\theta}}}{\theta-r-\lambda^{+}-\lambda^{-}}=\frac{\delta \xi X+\lambda^{+\frac{\mu^{+} X}{\theta}}+\lambda^{-\frac{\mu^{-} X}{\theta}}}{r+\lambda^{+}+\lambda^{-}} .
$$

Asset demand is increasing in $r$ and in $\xi$. Asset supply is decreasing in $r$ and increasing in $\xi$. When $r^{n}=r^{K, n}>0$, the asset market is in equilibrium at full capacity utilization when $i=r^{n}=r^{K, n}$. But when $r^{n}=r^{K, n}<0$, and $r=r^{K}=i=0$, at full employment, there is an excess demand for assets. It is easy to see that a recession reduces asset demand more than asset supply, and lowers the excess demand for assets, and helps restore equilibrium (otherwise, there is simply no equilibrium).

AS-AD representation and the Keynesian cross. We can also provide an AS-AD Keynesian cross representation of the determination of capacity utilization $\xi$ in a liquidity trap. Aggregate supply is given by the 45 degree line

$$
A S(\xi X)=\xi X
$$

and aggregate demand for goods is given by $\theta W=\theta V=A D(\xi X)$

$$
A D(\xi X)=\theta \frac{\delta \xi X+\lambda^{+\frac{\mu^{+} X}{\theta}}+\lambda^{-\frac{\mu^{-} X}{\theta}}}{r+\lambda^{+}+\lambda^{-}} .
$$

When $r^{n}=r^{K, n} \geq 0$, we have $A D(X)=A S(X)$ when $r=r^{K}=r^{n}=r^{K, n}$. But when $r^{n}=$ $r^{K, n}<0$, we have $r=r^{K}=0$ and $\xi$ is the solution of the fixed point equation $A D(\xi X)=A S(\xi X)$. Aggregate demand and aggregate supply are then two increasing functions of income $\xi X$. Aggregate demand is flatter than aggregate supply because $\delta \theta<\lambda^{+}+\lambda^{-}$which automatically holds when $r^{n}=r^{K, n}<0$. Equilibrium is determined by a Keynesian cross at the intersection of the aggregate demand and aggregate supply curves.

Safety traps vs. liquidity traps. We conclude this section by highlighting three broad 
- Risk premium. Both safety traps and liquidity traps occur when the natural safe interest rate is negative $r^{K, n}<0$ and the ZLB binds $i=r^{K}=0$. In both cases a recession ensues $\xi<1$. The key difference between safety traps and liquidity traps is the reason behind the ZLB: Safety traps arise because of a shortage of safe assets and positive while liquidity traps originate in a shortage of assets in general. Positive and endogenous risk premia are at the core of the mechanics of safety traps, while they only play a peripheral role in liquidity traps (in fact, in our rendition, they are zero). The securitization capacity $\rho$, and more generally the supply of safe assets $V^{S}$ play no role in liquidity traps, whereas they are the key bottlenecks in safety traps. Aside from the direct relevance of endogenous risk premia during severe recessions, this distinction has important implications for the persistence and policy implications of the different kinds of traps.

- Persistence and secular stagnation. The possibility of a permanent ZLB equilibrium is sometimes disputed on the grounds that this would imply an infinite value for infinitely-lived assets, such as land. In our model, Lucas trees are indeed infinitely lived, and for that reason, a permanent liquidity trap cannot occur. Indeed, in the limit $\lambda^{+} \rightarrow 0$ and $\lambda^{-} \rightarrow 0$, we have $r^{K, n}=\delta \theta>0$ so that a liquidity trap is simply impossible. In contrast, in the constrained regime, in the limit $\lambda^{+} \rightarrow 0$ and $\lambda^{-} \rightarrow 0$, we have $r^{K, n}=\delta \theta-\frac{\alpha-\rho \mu^{-}}{\rho \mu^{-}}(1-\delta) \theta$ which can be negative. In that case, an essentially permanent safety trap emerges. The value of trees remains finite even when the safe interest rate is $r^{K}=i=0$ because our model features risk premia so that the discount rate that applies to the risky cash flows of Lucas trees remains positive $r>0$.

- Policy options: a roadmap. In the next sections, we analyze policy options in safety traps, and contrast them briefly with liquidity traps. In safety traps, effective stimulative policies work by influencing the value of safe assets $V^{S}$ (public debt issuances and QE in Section 3) and $r^{K}$ (increasing the inflation target in Section 5).

The risky rate $r$ does not appear either in aggregate demand or in aggregate supply. The equilibrium is block-recursive in $\xi$ and $\left(r, V^{R}\right)$. Even when $\lambda^{+}>0$, the future value of risky assets after the good Poisson event does not affect the determination of $\xi$ (it only matters for the risky rate of return $r$ and the risk premium $\left.r-r^{K}\right)$. This point will prove crucial later on when we discuss the ineffectiveness of forward guidance in a safety trap (Section 4). In sharp contrast, the relative effectiveness of safe public debt issuances and QE and the relative ineffectiveness of Forward Guidance (FG) in safety traps are exactly inverted in liquidity traps. Public debt issuances and QE become ineffective because they increase the value of safe assets $V^{S}$ but crowd out the value of risky assets $V^{R}$ and hence do not increase the value of assets $V$ in general. FG becomes effective in liquidity traps because when $\lambda^{+}>0$, the future value of risky assets after the good Poisson event affects the determination of $\xi$. 
In the rest of the paper, we focus on the constrained regime and safety traps in the main text, and treat the unconstrained regime and liquidity traps in remarks at the end of each section.

\section{$3 \quad$ Public Debt and Quantitative Easing}

In this section we introduce safe public debt to our analysis. We focus on the safety creation and transformation roles of the government by assuming that the taxes that support public debt are levied on dividends (and are hence fully capitalized). As a result, the economy is de facto Ricardian in the unconstrained regime, but not in the constrained one.

The government's capacity to increase the total supply of safe assets by issuing safe public debt depends on two factors: fiscal capacity and crowding out of private safe assets by public safe assets. In a safe asset shortage situation, the relevant form of fiscal capacity is the government's ability to raise taxes in the bad events feared by Knightians. Crowding out, on the other hand, depends on how much these taxes reduce the private sector's capacity to issue safe claims backed by the risky dividends of Lucas trees. In our model, there is less crowding out when the securitization capacity of the economy is impaired (when the financial friction is severe). In a safety trap, issuing public debt, and possibly undertaking QE by purchasing private risky assets, increases the supply of safe assets, stimulates the economy, and reduces risk premia. By contrast, these policies are much less relevant (irrelevant in our stylized model) in conventional liquidity traps.

\subsection{Public Debt and Fiscal Capacity}

Public debt. Let us first introduce safe public debt outside of a safety trap with $r^{K}>0$.

The government taxes dividends, $\delta X$. The tax rate is $\tau^{+}$after the good Poisson event occurs, $\tau^{-}$after the bad Poisson event occurs, while the tax rate before the Poisson event is set to a value $\tau_{t}$ that satisfies the government flow budget constraint. The government issues a fixed amount of risk-free bonds that capitalize future tax revenues and pays a variable rate $r_{t}^{K}$. The proceeds of the sales of these bonds are rebated lump-sum to agents at date 0 .

Let the value of (safe) public debt be given by $D$. We have

$$
D=\tau^{-} \mu^{-} \frac{X}{\theta}
$$

Assumption 1 (Regalian taxation power): Taxes backing government safe debt can be levied on the claim $(1-\rho) \mu^{-\frac{X}{\theta}}$ to the privately unpledgable part of future dividends.

That is, the government is essentially better than private investors at collecting dividend revenues from Neutrals once borrowers' incentives are weak, and can hence essentially get around the pledgeability constraint of the economy through dividend taxation and debt issuance. This confers 
the government a comparative advantage in the production of safe assets. ${ }^{16}$ In Section A.6, we develop a different rationale for government intervention in the securitization market. There, we endogenize the securitization capacity $\rho$ and show that in a safety trap there is a securitization externality that justifies government intervention; we postpone a full discussion of this justification for intervention until then.

Note, however, that the scope for policy depends crucially on the securitization capacity of the economy (indexed by $\rho$ ). In a very developed market, $\rho$ is high, and soon public debt starts to crowd out privately produced safe assets. To see this, note that because the consumption of a Neutral cannot be negative (a form of limited liability), the fraction of dividends that it can pledge is now $\rho\left(\tau^{-}\right)=\min \left\{\rho, 1-\tau^{-}\right\}$. Thus, as long as $\tau^{-} \leq 1-\rho$ there is no crowding out, but above this threshold public safe assets crowd out private safe assets one for one (we return to this issue below).

The total (private and public) value of safe assets is then given by

$$
V^{S}=\rho\left(\tau^{-}\right) \mu^{-} \frac{X}{\theta}+D=\left[\rho\left(\tau^{-}\right)+\tau^{-}\right] \mu^{-} \frac{X}{\theta} .
$$

The model is isomorphic to the one described in Section 2, with $\rho$ replaced by $\rho\left(\tau^{-}\right)+\tau^{-} .17,18$

Crowding out. In this model safe government debt acts exactly like tranching, with $\tau^{-}$playing the same role as $\rho$, as long as public debt is low enough $\left(\tau^{-}<1-\rho\right)$. In this non-Ricardian region, issuing safe public debt does not crowd out private safe assets, resulting in a one for one expansion of the supply of safe assets $V^{S}$, an increase in the safe interest rate $r^{K}$, a reduction in the risky expected rate of return $r$, and a reduction in the risk premium $r-r^{K}$. There is also a Ricardian region where public debt is high enough $\left(\tau^{-} \geq 1-\rho\right)$ so that issuing safe public debt crowds out private safe assets one for one, leaving unchanged the supply of safe assets $V^{S}$, the safe interest rate $r^{K}$ and the risky expected rate of return $r$ as well as the risk premium $r-r^{K}$. The economy is more likely to be in the Ricardian region than in the non-Ricardian region, the higher is the securitization capacity $\rho$.

It will sometimes prove convenient to write

$$
V^{S}=\frac{\mu^{-} X}{\theta} v^{S}\left(\frac{D}{X}\right)
$$

\footnotetext{
${ }^{16}$ This mechanism has some commonality with the idea in Holmström and Tirole (1998) that the government has a comparative advantage in providing liquidity. In their model like in ours, this result arises from the assumption that some agents (consumers in their model) lack commitment and hence cannot borrow because they cannot issue securities that pledge their future endowments. This can result in a scarcity of stores of value. The government can alleviate this scarcity by issuing public debt and repaying this debt by taxing consumers. The proceeds of the debt issuance can actually be rebated to consumers. At the aggregate level, this essentially relaxes the borrowing constraint of consumers, as they borrow indirectly through the government. In their model like in ours, the comparative advantage of the government in providing liquidity arises because it is better than private lenders at collecting revenues from consumers.

${ }^{17}$ We assume throughout that the technical financial friction assumptions as well as condition (1) hold when $\rho$ is replaced by $\rho\left(\tau^{-}\right)+\tau^{-}$. We also assume that this continues to be the case in a safety trap when in addition $\mu^{+}$and $\mu^{-}$are replaced by $\frac{\mu^{+}}{\xi}$ and $\frac{\mu^{-}}{\xi}$, which is guaranteed as long as $r^{K, n}$ is not too negative so that the recession is not too severe.

${ }^{18}$ And we can also use $r^{K} D=\tau \delta X$ to compute $\tau=\tau^{-} \mu^{-} \frac{r^{K}}{\delta \theta}$.
} 
where the function $v^{S}\left(\frac{D}{X}\right)$ is defined together with the function $\tau^{-}\left(\frac{D}{X}\right)$ by the following equations

$$
v^{S}\left(\frac{D}{X}\right)=\left(\rho \tau^{-}\left(\frac{D}{X}\right)\right)+\frac{\theta}{\mu^{-}} \frac{D}{X}=\rho\left(\tau^{-}\left(\frac{D}{X}\right)\right)+\tau^{-}\left(\frac{D}{X}\right),
$$

and

$$
\tau^{-}\left(\frac{D}{X}\right)=\frac{\theta}{\mu^{-}} \frac{D}{X}
$$

Crowding out of private safe assets $\frac{\mu^{-} X}{\theta} v^{S}\left(\frac{D}{X}\right)-D$ by public debt $D$ is

$$
1-\frac{\mu^{-}}{\theta} \frac{d v^{S}}{d\left(\frac{D}{X}\right)}=-\frac{d \rho}{d \tau^{-}}
$$

is either 0 (in the non-Ricardian region) or 1 (in the Ricardian region). With this notation, the model is isomorphic to the one described in Section 2, with $\rho$ replaced by $v^{S}\left(\frac{D}{X}\right) .{ }^{19}$

The tight link between imperfect crowding out and the failure of Ricardian equivalence in our model relies on the assumption that taxes are capitalized. It would not hold if, for example, taxes were levied on the endowment of newborns. ${ }^{20}$ We view this feature as desirable since it allows us to focus on the market failure that is central to our analysis - the financial friction that hampers the securitization process - rather than on more conventional features of OLG models.

Public debt and the safety trap. Now imagine that the economy is in a safety trap with $r^{K, n}<0, r^{K}=0$, and $\xi<1$. Just like in the basic model of Section 2, the safety trap equilibrium simply amounts to replacing $\mu^{+}, \mu^{-}$, and $X$ by $\frac{\mu^{+}}{\xi}, \frac{\mu^{-}}{\xi}$. The requirement that $r^{K}=0$ determines the severity of the equilibrium recession $\xi$ :

$$
0=\delta \theta-(1-\delta) \theta \frac{\alpha-\frac{\mu^{-} v^{S}\left(\frac{D}{X}\right)}{\xi}}{\frac{\rho \mu^{-} v^{S}\left(\frac{D}{X}\right)}{\xi}} .
$$

As already noted in Section 2, we confirm that $\xi$ is proportional to the supply of safe assets $V^{S}=$ $\frac{\mu^{-} X}{\theta} v^{S}\left(\frac{D}{X}\right)$.

Increasing safe public debt from $D$ to $\hat{D}>D$ increases the supply of safe assets $\hat{V}^{S}>V^{S}$ where $\hat{V}^{S}=\frac{\mu^{-} X}{\theta} v^{S}\left(\frac{\hat{D}}{X}\right)$ and $V^{S}=\frac{\mu^{-} X}{\theta} v^{S}\left(\frac{D}{X}\right)$, as long as there is less than full crowding out. This stimulates output, increasing $\xi$ to $\hat{\xi}$ where

$$
\hat{\xi}=\frac{\hat{V}^{S}}{V^{S}} \xi>\xi .
$$

\footnotetext{
${ }^{19}$ We can easily extend the model to feature intermediate crowding out by assuming that the trees differ in their pledgeability $\tilde{\rho}$ with a distribution $F(\tilde{\rho})$. This extension can be exactly mapped into the model above. The only difference is that we now have $\rho\left(\tau^{-}\right)=\int \min \left\{\tilde{\rho}, 1-\tau^{-}\right\} d F(\tilde{\rho})$, so that crowding out is now given by $-\frac{d \rho}{d \tau^{-}}=$ $\left[1-F\left(1-\tau^{-}\right)\right] \in[0,1]$.

${ }^{20}$ More generally, the distribution of taxes matters for this result. We refer the reader to an earlier version of this paper, Caballero and Farhi (2013), for an exploration of this idea. In a recent paper, Barro and Mollerus (2014) consider a model with heterogeneous risk aversion and assume that taxes are distributed independently of risk aversion. They generate a crowding out of 0.5 despite the fact that Ricardian equivalence holds in their model. See Abel (2015) for a detailed exploration of the determinants of crowding out in Ricardian economies.
} 
The stimulative effects of safe public debt can be understood most clearly by going back to our AS-AD equilibrium representation. Because issuing safe public debt increases the supply of safe assets $V^{S}$, it produces and upward shift in aggregate demand, which in turn results in a proportional increase in output through the Keynesian multiplier. ${ }^{21,22}$

In the model, we necessarily have $\tau^{+} \mu^{+}=\tau^{-} \mu^{-}$, which implies that $\tau^{+}<\tau^{-}$. For this reason, it is natural to expect fiscal constraints to be more binding after the bad Poisson event than after the good Poisson event. This is why we adopt $\tau^{-}$, a measure of the ability of the government to raise tax revenues after the bad Poisson event, as our measure of future fiscal capacity. In particular, in a safety trap, increasing the supply of safe public debt to $\hat{D}$ requires the government to have spare future fiscal capacity; that is to have the ability to raise more taxes after the bad Poisson event

$$
\hat{\tau}^{-}=\frac{\hat{D}}{D} \tau^{-}>\tau^{-} .
$$

Note however that taxes do not have to be raised while the economy is in the safety trap before the Poisson event. Indeed $\hat{\tau}=\tau$ (and both are equal to 0 ) since the safe interest rates on debt is $r^{K}=0$.

If the government issues more public debt than can be supported by its future fiscal capacity, then public debt becomes risky. For example, suppose that $\tau^{-}$has an upped bound at $\bar{\tau}^{-}$reached for a level of public debt $\bar{D}$ such that $\bar{\tau}^{-}=\tau^{-}\left(\frac{\bar{D}}{X}\right)$. Then public debt issuances beyond that level $\hat{D}>\bar{D}$ is not safe and instead results in a partial default after the bad Poisson event with a haircut of at least $h=\frac{\hat{D}-\bar{D}}{\hat{D}} \in(0,1]$. Only the safe tranche of public debt $\hat{D}(1-h)$, and only to the extent that it can be isolated through securitization, increases the supply of safe assets and stimulates the economy.

Remark 3 Money is a safe assets. At the ZLB, money has the same return as non-monetary safe assets. Money and non-monetary safe assets then become perfect substitutes. One may wonder what happens when the government issues extra money through a "helicopter drop" before the Poisson event when the economy is in a safety trap and rebates the proceeds lump sum. There are two options which differ in what the government does once the economy is no longer at the ZLB after the Poisson event: (a) retire the extra money; (b) not retire the extra money. Option (a) is literally identical to what would happen if instead of extra money, the government had issued extra safe short-term debt before the Poisson event and paid it back after the Poisson event. In both cases, the government must raise the same amount of extra taxes after the Poisson event to either retire the extra money or pay back the extra debt. This stimulates the economy before the Poisson event in a safety trap. To analyze option (b) we must use the modification of the model introduced later in Section 4 which allows for capacity over-utilization as well as capacity under-utilization. Compared

\footnotetext{
${ }^{21}$ If the proceeds $\hat{D}-D$ of the additional safe debt issuance are rebated to Knightians, then there are no transitional dynamics and the economy jumps immediately to the new stochastic steady state before the Poisson event. Otherwise the new stochastic steady state before the Poisson event is only reached gradually over time.

${ }^{22}$ In Appendix A.4, we show that safe public debt issuances can sometimes lead to Pareto improvements, or if not, at least to welfare improvements for certain classes of Utilitarian welfare functions.
} 
to option (a), option (b) further stimulates the economy before the Poisson event in a safety trap but at the cost of over-stimulating the economy after the Poisson event. In other words, there is a policy tradeoff. This tradeoff is unavoidable: It it precisely because it over-stimulates the economy after the bad Poisson event that it further increases the value of safe assets and further stimulates the economy before the Poisson event in a safety trap. See Appendix A.2.3 for a detailed exposition of these arguments.

\subsection{Quantitative Easing}

Here we use the term QE loosely to encompass policies that swap risky assets for safe assets such as QE1, LTRO, and many other lender of last resort central bank interventions. We model QE as follows: The government issues additional safe short term debt and purchases private risky assets (the value of which drops to zero after the bad Poisson event). Let $\hat{\beta}^{g}$ be the fraction of the value of risky assets purchased by the government where ${ }^{23}$

$$
\hat{\beta}^{g}\left[1-\left[\rho\left(\hat{\tau}^{-}\right)+\hat{\tau}^{-}\right] \mu^{-}\right] \frac{X}{\theta}=\hat{D}-D .
$$

The key difference between QE and simply issuing more safe public debt is what the government does with the proceeds from the debt issuance, but the equilibrium rates of return $r$ and $r^{K}$ and capacity utilization $\xi$ are identical. In QE, the government uses the proceeds to purchase private risky assets instead of simply rebating them lump sum to private agents. The revenues from the taxes $\hat{\tau}$ before the bad Poisson event can be lowered because the government can now avail itself of additional investment revenues from its holdings of private risky assets. If $\tau=0$, as would be the case in a safety trap, then we can get $\hat{\tau}<0$. This should then be interpreted as a possibility to reduce taxes if there were some other reasons for which taxes had to be raised.

As long as there is less than full crowding out, the safe asset shortage is alleviated by this policy: $r^{K}$ increases, $r$ decreases, and the risk premium shrinks. Here QE works not so much by removing risky private assets from private balance sheets, but rather by injecting public assets into private balance sheets. In other words, QE works by increasing the supply of safe assets. The proceeds of the extra debt issuance can either be rebated lump sum as in Section 3.1 or reinvested in a portfolio of private assets as long as these assets are risky.

If the economy is in a safety trap, QE acts by stimulating output, increasing the value of $\xi$ to $\hat{\xi}$ in proportion to the increase in the value of safe assets, exactly as in the case analyzed in Section 3.1 where the revenues from safe public debt issuance are rebated lump sum instead of being reinvested in a portfolio of private assets as long as these assets are risky and not safe as in this section

$$
\hat{\xi}=\frac{\hat{V}^{S}}{V^{S}} \xi>\xi
$$

\footnotetext{
${ }^{23}$ As long as $\hat{\beta}^{g}$ is low enough, this can be done without violating the pledgeability condition.
} 
with as before $\hat{V}^{S}>V^{S}$ where $\hat{V}^{S}=\frac{\mu^{-} X}{\theta} v^{S}\left(\frac{\hat{D}}{X}\right)$ and $V^{S}=\frac{\mu^{-} X}{\theta} v^{S}\left(\frac{D}{X}\right)$ as long as there is less than full crowding out. ${ }^{24,25}$

Remark 4 These results in safety traps (constrained regime) are in sharp contrast with liquidity traps (unconstrained regime). In our stylized setup, safe public debt issuances and QE have no effect at all on the recession $\xi$ in liquidity traps (the unconstrained regime). This follows immediately from the fact that the securitization capacity $\rho$ does not show up anywhere in the equilibrium equations in liquidity traps. In our model, the effects of safe public debt issuances and QE in safety traps rely entirely on the (assumed) superior ability of the government to address a form of market incompleteness - the difficulty to isolate (macro) safe from risky assets. ${ }^{26}$

This irrelevance result relies on our assumption (made throughout the paper) that dividends are taxed while the endowment of newborns (wages) is not. As a result, safe public debt issuances and QE simply reshuffle the fraction of dividends that accrues to private asset holders and the fraction of dividends that is absorbed by taxes to pay interest on debt of various maturities. This assumption renders our framework de facto Ricardian in the unconstrained regime, despite the fact that we have overlapping generations of agents.

\section{Forward Guidance}

Another major policy tool advocated in the context of the ZLB is Forward Guidance (FG): the commitment to low future interest rates once the economy recovers. We show in this section that this policy, which is very effective in liquidity traps, is not in safety traps. In a nutshell, the reason is that in safety traps the effects of FG are largely dissipated in higher risk premia: The positive effect of higher future asset values on the current value of risky assets is endogenously offset by an increase in risky premia, leaving the current value of risky assets, wealth, and aggregate demand unchanged.

We introduce one modification to our model in Section 2 (and also drop public debt since it is not central to our message): Agents now can stretch capacity utilization and produce $\xi_{t}>1$ units of output per unit of non traded input. This comes at a cost as there is a (proportional separable) per period utility loss from capacity utilization overextension, equal to $\max \left\{\xi_{t}-1,0\right\}$. We introduce this modification to capture the standard effects of FG which is to commit to over-stimulating the

\footnotetext{
${ }^{24}$ Because the proceeds $\hat{D}-D$ of the additional safe debt issuance are not rebated to Knightians, there are transitional dynamics and the new stochastic steady state before the Poisson event is only reached gradually over time.

${ }^{25}$ Going back to equation (2), we see that in the limit $\lambda^{+} \rightarrow 0$ and $\lambda^{-} \rightarrow 0$, in a safety trap when $r^{K}=0$, public debt issuances and QE leave $r$ (and hence also $r-r^{K}$ ) unchanged. When $\lambda^{+}>0$ or $\lambda^{-}>0$, additional expected capital gains effects come into play and safe public debt issuances and QE now decreases $r$ (and hence $r-r^{K}$ ).

${ }^{26}$ If we allowed the endowments of newborns to be taxed, then safe public debt issuances and QE could have some non-Ricardian effects, depending on exactly how these taxes are levied, and hence affect economic activity in a liquidity trap. For example, Kocherlakota (2013) and Caballero et al. (2015) study non-Ricardian environments where issuing safe public debt can stimulate the economy in a liquidity trap.
} 
economy in the future after the good Poisson even when it has exited the ZLB by lowering interest rates, while at the same time preserving all the results that we have derived so far.

We assume that the cost is large enough so that under flexible prices, we still have $\xi_{t}=1$ before and after the Poisson event, with the same natural allocation as that characterized in Section 2.27 Importantly, with nominal rigidities where output is demand determined, this need not be true, depending on the stance of monetary policy. The equilibrium conditions are then identical to those in Section 2, but with the possibility that capacity utilization exceeds one before or after the Poisson event. All the results derived so far are unchanged in this modified model.

In this context, consider the following FG policy: Suppose that the good Poisson event occurs at $\sigma^{+}$. After the good Poisson event, the central bank stimulates the economy by setting the interest rate $i_{t}^{+}$below the natural interest rate $\delta \theta$ until $\sigma^{+}+T$, at which point it reverts to setting the nominal interest rate equal to the natural interest rate $i^{+}=\delta \theta$. Agents know throughout that the central bank is committed to such policy.

We can now solve the model backwards. We start by characterizing the endogenous path of equilibrium capacity utilization $\xi_{t}^{+}$after the good Poisson event. It is easy to see that for $t>\sigma^{+}+T$, output is equal to potential so that equilibrium capacity utilization is $\xi_{t}^{+}=1$. For $\sigma^{+} \leq t \leq \sigma^{+}+T$, output is above potential, and equilibrium capacity utilization satisfies a simple differential equation

$$
\frac{\dot{\xi}_{t}^{+}}{\xi_{t}^{+}}=i_{t}^{+}-\delta \theta \leq 0,
$$

with terminal condition $\xi_{\sigma^{+}+T}^{+}=1$. The solution for $\sigma^{+} \leq t \leq \sigma^{+}+T$ is

$$
\xi_{t}^{+}=e^{\int_{t}^{\sigma^{+}+T}\left(\delta \theta-i_{s}^{+}\right) d s} \geq 1
$$

The model before the Poisson event is then isomorphic to the model without forward guidance analyzed in Section 2.2 but with $\mu^{+}$replaced by $\mu^{+} \xi_{\sigma^{+}}^{+} \cdot{ }^{28}$

By lowering interest rates, the central bank creates a temporary boom after the good Poisson event. This boom boosts the total value of assets immediately after the good Poisson event from $\mu^{+} \frac{X}{\theta}$ to $\mu^{+} \xi_{\sigma^{+}}^{+} \frac{X}{\theta}>\mu^{+} \frac{X}{\theta}$.

Now suppose that the economy is in a safety trap before the Poisson event. Taking the above boundary condition and working backward into the equilibrium equations pre-Poisson shows that

\footnotetext{
${ }^{27} \mathrm{We}$ imagine that there is separable, additive, and risk neutral, per period utility loss $-\max \left\{\xi_{t}-1,0\right\} \Delta u d t$ incurred by each agent transforming a unit of a variety of nontraded inputs into $\xi_{t}$ units of the corresponding variety of nontraded final good between $t$ and $t+d t$. We denote the corresponding per period utility loss for a given Neutral agent by $\Delta u_{t}^{N} d t$ and for a Knightian agent by $\Delta u_{t}^{K} d t$. The total utility of a Neutral agent is then $U_{t}^{N}+\Delta U_{t}^{N}$ and that of a Knightian agent $U_{t}^{K}+\Delta U_{t}^{K}$ where $U_{t}^{N}=\Delta u_{t}^{N} d t+\mathbb{E}_{t}\left[U_{t+d t}^{N}\right]$ and $U_{t}^{K}=\Delta u_{t}^{K} d t+\mathbb{E}_{t}\left[U_{t+d t}^{K}\right]$, where $U_{t}^{N}$ and $U_{t}^{K}$ are given by the same formulas as in Section 2. We choose $\Delta u>0$ large enough so that when prices are flexible, we still have $\xi_{t}=1$ before and after the Poisson event.

${ }^{28}$ We assume throughout that the techncial financial friction assumptions as well as condition (1) hold when $\mu^{+}$ and $\mu^{-}$are replaced by $\frac{\mu^{+} \xi_{\sigma}^{+}}{\xi}$ and $\frac{\mu^{-}}{\xi}$, which is guaranteed as long as $r^{K, n}$ is not too negative so that the recession is not too severe and for the forward guidance is not too extreme.
} 
the only effect of this policy is to increase the interest rate $r$ during the safety trap to

$$
r=\delta \theta+(1-\delta) \theta \frac{\alpha-\frac{\rho \mu^{-}}{\xi}}{1-\frac{\rho \mu^{-}}{\xi}}+\frac{\lambda^{+}\left(\frac{\xi_{\sigma^{+}}^{+} \mu^{+}}{\xi}-1\right)+\lambda^{-}\left(\frac{\mu^{-}}{\xi}-1\right)}{1-\frac{\rho \mu^{-}}{\xi}} .
$$

This increase in the risky expected return $r$ is such that the contemporaneous value of risky assets $V^{R}$ (and hence the wealth of Neutrals $W^{N}$ ) is unchanged, despite the fact that its future value after a good Poisson event has increased to $\frac{\xi_{\sigma}+\mu^{+} X}{\theta}-V^{S}$. But there is no effect on current output $\xi X$. This can be seen most clearly by going back to the AS-AD equilibrium representation. Neither $\xi_{\sigma^{+}}$ nor $r$ affect the value of safe assets $V^{S}$ or aggregate demand. The future increase in risky asset values and the contemporaneous increase in risky expected rate of return are orthogonal to the safe-asset shortage problem. Since the policy leaves the supply of safe assets unchanged, it does not expand aggregate demand or output. ${ }^{29,30}$

A safety trap is addressed more directly by committing to provide support during bad rather than good times, as would be the case of a commitment to lower interest $i_{t}^{-}$rates after the bad Poisson event. However, it is natural to question whether monetary authorities would have the ability to lower interest rates in that state. If indeed the bad state happens to coincide with yet another safety or liquidity trap, monetary authorities could find themselves unable to deliver a lower interest rate (see Appendix A.3).

Remark 5 These results in safety traps (constrained regime) are, again, in sharp contrast with those in liquidity traps (unconstrained regime). In a liquidity trap, forward guidance alleviates the recession by pushing $\xi$ to $\hat{\xi}$ where

$$
\hat{\xi}=\xi \frac{\frac{\lambda^{-}}{\lambda^{-}+\lambda^{+}} \mu^{-}+\frac{\lambda^{+}}{\lambda^{-}+\lambda^{+}} \xi_{\sigma^{+}}^{+} \mu^{+}}{\frac{\lambda^{-}}{\lambda^{-}+\lambda^{+}} \mu^{-}+\frac{\lambda^{+}}{\lambda^{-}+\lambda^{+}} \mu^{+}}>\xi
$$

Committing to low interest rates after the good Poisson event increases future value of assets after the good Poisson event. In contrast to the safety trap case, this also increases the value of assets before the Poisson event while the economy is in the liquidity trap. This wealth effect increases demand and mitigates the recession. Forward guidance works by alleviating the asset shortage that is at the root of the recession. It trades off a future boom (output above potential) after the good Poisson event against a mitigation of the recession (output below potential) before it. ${ }^{31}$

\footnotetext{
${ }^{29}$ There is one caveat to this conclusion. We have assumed that prices are entirely rigid. If prices could adjust gradually over time in a forward looking manner, then forward guidance could regain some kick: A commitment to lower interest rates after the good Poisson event could increase inflation while the economy is in a safety trap. This would lower the safe interest rate $r^{K}$ and mitigate the recession. Note than when we model inflation in Section 5 , we assume, motivated by a desire to capture downward wage rigidity, that inflation is determined by a myopic Philipps curve rather than an expectations-augmented Philipps curve, so that this effect does not arise.

A similar comment applies to the unconventional tax policies considered by Correia et al. (2012), which here could simply take the form of an increasing path of sales taxes - say through a sales tax holiday — which would create inflation in consumer prices and hence reduce $r^{K}$.

${ }^{30}$ In Appendix A.4, we show that FG is Pareto dominated by no FG.

${ }^{31}$ There are no transitional dynamics before the Poisson event for the aggregate variables $\xi$, $V$, and $W$, when
} 


\section{Inflation}

In this section we relax the extreme sticky price rigidity assumption and show how safety traps trigger deflationary forces, which exacerbate the output drop. We also show that the policy multiplier (of increasing safe assets) is enhanced by its positive effect on inflation. Finally, as always, inflation also opens the door for expectations and targets to alleviate the trap by lowering real rates.

\subsection{Safety Trap, Deflation, and Inflation Targets}

We assume that prices cannot fall faster than at a certain pace: $\pi_{t} \geq-\left(\kappa_{0}+\kappa_{1}\left(1-\xi_{t}\right)\right)$, with $\kappa_{1}>0$. The more slack there is in the economy, the more prices can fall. We impose that if there is slack in the economy, prices fall as fast as they can: I.e., $\xi_{t}<1$ implies $\pi_{t}=-\left(\kappa_{0}+\kappa_{1}\left(1-\xi_{t}\right)\right)$. We capture this requirement with the complementary slackness condition

$$
\left[\pi_{t}+\left(\kappa_{0}+\kappa_{1}\left(1-\xi_{t}\right)\right)\right]\left(1-\xi_{t}\right)=0
$$

This is a traditional upward sloping Phillips curve relating inflation $\pi_{t}$ and capacity utilization $\xi_{t}$. The Phillips curve becomes vertical at $\xi_{t}=1$. Our motivation is to capture downward nominal rigidities. This specification of the Phillips curve can be justified by appealing to a "nominal social norm", which can only be slowly revised downward over time, so that agents would never accept setting prices falling faster than $-\left(\kappa_{0}+\kappa_{1}\left(1-\xi_{t}\right)\right)$ per unit of time. If $\kappa_{1}=0$ and $\kappa_{0}=0$, this corresponds to complete downward nominal rigidities. If $\kappa_{0}=0$ and $\kappa_{1}=\infty$, this corresponds to the case of perfectly flexible prices. This modeling strategy and the results that follow borrows heavily from Eggertsson and Mehrota (2014).

Together with the Phillips curve, we introduce a (truncated) Taylor rule for monetary policy

$$
i_{t}=\max \left\{0, r_{t}^{K, n}+\pi^{*}+\phi\left(\pi_{t}-\pi^{*}\right)\right\}
$$

with $\phi>1, \pi^{*} \geq 0$ where $r_{t}^{K, n}$ is the safe natural interest rate at $t$.

Equilibrium inflation $\pi$ and capacity utilization $\xi$ are jointly determined by the following equations:

$$
\begin{gathered}
\max \left\{0, r^{K, n}+\pi^{*}+\phi\left(\pi-\pi^{*}\right)\right\}-\pi=\delta \theta-(1-\delta) \theta \frac{\alpha-\frac{\rho \mu^{-}}{\xi}}{\frac{\rho \mu^{-}}{\xi}}, \\
{\left[\pi+\left(\kappa_{0}+\kappa_{1}(1-\xi)\right)\right](1-\xi)=0}
\end{gathered}
$$

where recall that $r^{K, n}=\delta \theta-(1-\delta) \theta \frac{\alpha-\rho \mu^{-}}{\rho \mu^{-}}$. The first equation is simply the requirement that $i-\pi=r^{K}$, where we have used the Taylor rule to replace $i$ and the equilibrium equations to replace $r^{K}$. The second equation is the Phillips curve. These two correspondences link inflation $\pi$ and output $\xi X$ and can be interpreted as aggregate demand and aggregate supply respectively. forward guidance is announced. All these variables jump immediately to their new stochastic steady state values. 


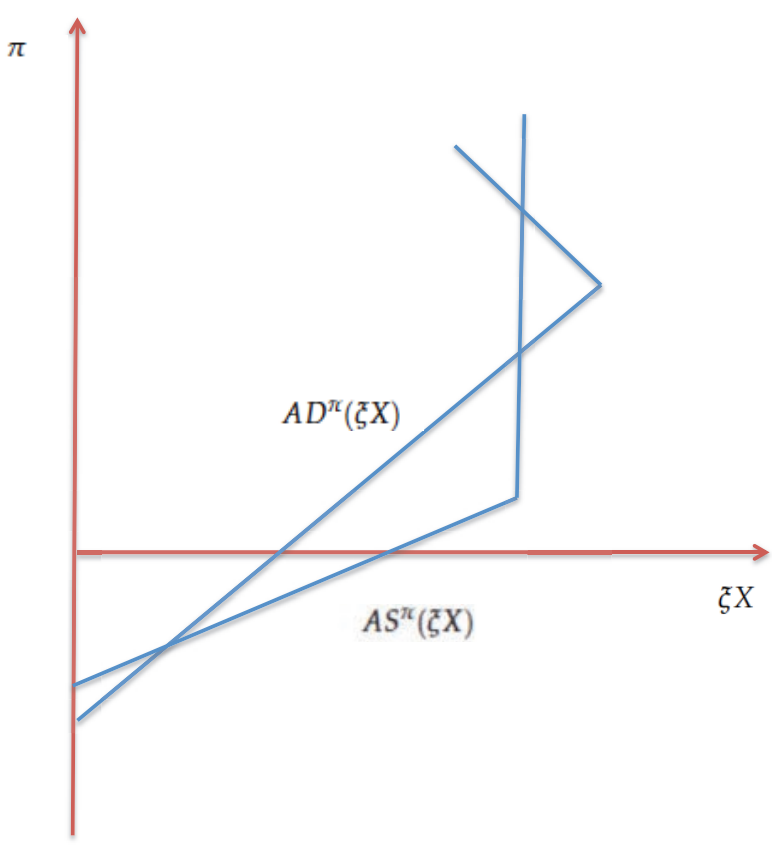

Figure 4: Aggregate supply and aggregate demand with inflation.

We denote them by $\pi=A D^{\pi}(\xi X)$ and $\pi=A S^{\pi}(\xi X)$ to distinguish them from the aggregate supply and demand functions $A S(\xi X)$ and $A D(\xi X)$ that we introduced in the Keynesian cross equilibrium representation in Section 2. We discuss the link between these two representations in detail below.

We make additional assumptions that guarantee that there is a safety trap equilibrium $-\kappa_{0}<$ $\min \left\{-r^{K, n}, \pi^{*}\right\}$ and $\kappa_{0}+\kappa_{1}<\theta$. The first assumption ensures that $A D^{\pi}(1)>A S^{\pi}(1)$ and the second one guarantees that $A D^{\pi}(0)<A S^{\pi}(0)$ so that the feedback loop between inflation and output remains bounded. We summarize all our assumptions regarding nominal rigidities.

Assumption 2 (Nominal rigidities) $-\kappa_{0}<\min \left\{-r^{K, n}, \pi^{*}\right\}, \kappa_{1}>0$, and $\kappa_{0}+\kappa_{1}<\theta$.

In this context, there is always a deflationary safety trap equilibrium (with $\pi \leq-\kappa_{0} \leq \pi^{*}$ and $\xi<1)$. Inflation $\pi$ and capacity utilization $\xi$ are determined by the following equations

$$
\begin{gathered}
\pi=(1-\delta) \theta \frac{\alpha-\frac{\rho \mu^{-}}{\xi}}{\frac{\rho \mu^{-}}{\xi}}-\delta \theta, \\
\pi=-\left(\kappa_{0}+\kappa_{1}(1-\xi)\right) .
\end{gathered}
$$

Both equations expresses $\pi$ as increasing linear functions of $\xi$. The first one is aggregate demand $\pi=A D^{\pi}(\xi X)$, while the second one is aggregate supply $\pi=A S^{\pi}(\xi X)$. With our assumptions above, aggregate demand is steeper than aggregate supply and both curves intersect exactly once on $[0,1]$ at some value $\xi$. This is the "bad" safety trap equilibrium, analog to the one discussed in the previous sections. 
But this model may also feature inflationary full employment equilibria (with $\pi>-\kappa_{0}$ and $\xi=1$ ). To see this, note that the supply curve becomes vertical at $\xi=1$ and the demand curve has a kink at the value of $\pi=\tilde{\pi}$ that solves $r^{K, n}+\pi^{*}+\phi\left(\pi-\pi^{*}\right)=0$ : the demand curve is an upward sloping function $\xi(\pi)$ for $\pi \leq \tilde{\pi}$ and downward sloping for $\pi>\tilde{\pi}$. As a result, there are either one or three intersections between the supply and demand curves. We have already seen the bad equilibrium. The other equilibria, which exist if the inflation target is high enough $\pi^{*} \geq-r^{K, n}$, feature $\pi>-\kappa_{0}$ and $\xi=1 .^{32}$

To summarize, when $-\kappa_{0}+r^{K, n}<0$, there is always a safety trap equilibrium with $\xi<1$ and $\pi<-\kappa_{0} \leq \pi^{*}$ and it is locally determinate. If the inflation target is high enough $\left(0 \leq r^{K, n}+\pi^{*}\right)$, then there are also two other equilibria with $\xi=1$ with two different nominal interest rates $(i=0$ and $\left.i=r^{K, n}+\pi^{*}>0\right)$ and two different inflation rates $\left(\pi=-r^{K, n}\right.$ and $\left.\pi=\pi^{*}\right)$, but only the latter is locally determinate. In other words, the increase in the inflation target needs to be large enough to even have a chance to work. Note however that even when there is a "good" equilibrium with $\xi=1$ and $i=r^{K, n}+\pi^{*}>0$, the "bad" equilibrium with $\xi<1$ and $i=0$ still exists because expectations of low inflation are self-fulfilling: Starting from the "good" equilibrium, low enough expected inflation increases the real interest rate despite the reduction of the nominal interest rate to zero, depresses the economy, which in turn generates low inflation. Policy cannot select among these equilibria: The best a high inflation target can achieve is the possibility of a good equilibrium, not the elimination of the possibility of the bad equilibrium. ${ }^{33,34}$ Figure 4 provides a graphical illustration. In the figure, equilibrium inflation in the safety trap equilibrium is negative but this need not be the case.

We can connect this discussion with the Keynesian cross equilibrium representation developed in Section 2, which can still be used with $r^{K}=i-\pi$ once inflation $\pi$ has been solved out. Given nominal interest rates $i$, higher inflation helps to reduce safe interest rates, causing an upward shift in aggregate demand and resulting in a increase in output. When $r^{K, n}<0$ and $\pi^{*}>-r^{K, n}$ in the good equilibrium, this logic is strong enough to generate a low enough safe real interest rate $r^{K}=r^{K, n}$. But in the bad safety trap equilibrium with $i=0$ and $\pi<-\kappa_{0} \leq \pi^{*}$, it is not. In fact, when $-\kappa_{0}<0$, this logic can work in reverse, with the recession causing deflation, increasing safe real interest rates $r^{K}=-\pi>0$, reducing aggregate demand, further reducing output etc.

Also note that adding an inflation channel to the model increases the value of the Keynesian multiplier to

$$
\frac{1}{1-\frac{\kappa_{1} \xi}{\theta-r^{K}}} \frac{\xi X}{\theta V^{S}}
$$

\footnotetext{
${ }^{32}$ In an equilibrium with $\pi>0$ and $\xi=1$, inflation is determined by $\pi=\frac{1}{\phi-1}\left[\phi \pi^{*}+r^{K, n}\right]$ if $r^{K, n}+\pi^{*}+\phi\left(\pi-\pi^{*}\right)>0$ (in which case $i=r^{K, n}+\pi^{*}+\phi\left(\pi-\pi^{*}\right)$ ) or by $\pi=-r^{K, n}$ if $r^{K, n}+\pi^{*}+\phi\left(\pi-\pi^{*}\right) \leq 0$ (in which case $i=0$ ). The condition for existence of both equilibria is the same and is given by $0 \leq r^{K, n}+\pi^{*}$.

${ }^{33}$ This multiplicity is also present, and for similar reasons, in the analysis of liquidity traps in Eggertsson and Mehrota (2014).

${ }^{34}$ In Appendix A.4, we show that increases in the inflation target can sometimes lead to Pareto improvements, or if not, at least to welfare improvements for certain classes of Utilitarian welfare functions. We also show that they always lead to Pareto improvements if lump sum taxes are available to redistribute among Neutrals and among Knightians in any given period.
} 
so that $d(\xi X)=\frac{1}{1-\frac{\kappa_{1} \xi}{\theta-r^{K}}} \frac{\xi X}{\theta V^{S}} \theta d V^{S}$. This is because an increase in the value of safe assets, increases aggregate demand, which increases output, increasing inflation, reducing the safe real interest rate, further increasing aggregate demand and output etc. ad infinitum. The more responsive is inflation to capacity utilization $\xi$ (the larger is $\kappa_{1}$ ), the larger is the Keynesian multiplier. In other words, increased price flexibility is destabilizing as in DeLong and Summers (1986).

\subsection{Public Debt, QE and Forward Guidance with Inflation}

We now turn to the effects of the policies considered in Sections 3 and 4 in this extended model with inflation. We focus on the safety trap equilibrium and show that the main conclusions remain qualitatively unchanged but the power of QE is enhanced.

We start with safe public debt and QE. In a safety trap, $\xi<1$ and $\pi<0$ are determined by the intersection of the demand and supply curves:

$$
\begin{gathered}
\pi=(1-\delta) \theta \frac{\alpha-\frac{v^{S}\left(\frac{D}{X}\right) \mu^{-}}{\xi}}{\frac{v^{S}\left(\frac{D}{X}\right) \mu^{-}}{\xi}}-\delta \theta \\
\pi=-\left(\kappa_{0}+\kappa_{1}(1-\xi)\right) .
\end{gathered}
$$

Clearly, increasing $D$ to $\hat{D}>D$ (and either rebating the proceeds to consumers or purchasing private risky assets) shifts the demand curve down which, given that it is steeper than the supply curve, results in an increase in $\xi$ to $\hat{\xi}>\xi$. Note that the stimulus is stronger in this extended setup with endogenous inflation

$$
\hat{\xi}>\frac{\hat{V}^{S}}{V^{S}} \xi,
$$

with $V^{S}=\frac{\mu^{-} X}{\theta} v^{S}\left(\frac{D}{X}\right)$ and $\hat{V}^{S}=\frac{\mu^{-} X}{\theta} v^{S}\left(\frac{\hat{D}}{X}\right)$. This is because of a virtuous cycle whereby additional safe assets increase output, which increases inflation (reduces deflation), which lowers the real interest, further stimulating output etc. ad infinitum, resulting in a larger value of the Keynesian multiplier as explained above.

We turn next to forward guidance. In order for monetary policy to be able to generate a boom after the good Poisson event, we introduce the following modification of our setup. We assume that the Phillips curve only becomes vertical at a value $\bar{\xi}>1$ so that we now have

$$
\left[\pi_{t}+\left(\kappa_{0}+\kappa_{1}\left(1-\xi_{t}\right)\right)\right]\left(\bar{\xi}-\xi_{t}\right)=0
$$

Furthermore, we assume that $\kappa_{0}=-\pi^{*}$ so that inflation is $\pi^{*}$ if the economy is at capacity.

To capture forward guidance, we continue to assume that monetary policy follows the truncated Taylor rule

$$
i_{t}=\max \left\{0, r_{t}^{K, n}+\pi^{*}+\phi\left(\pi_{t}-\pi^{*}\right)\right\}
$$


before and after the bad Poisson event, but we allow monetary policy to depart from this rule after the good Poisson event and follow instead (recall that $r_{t}^{K, n}=\delta \theta$ after the good Poisson event)

$$
i_{t}^{+}=\max \left\{0, \hat{\imath}_{t}^{+}+\pi^{*}+\phi\left(\pi_{t}-\pi^{*}\right)\right\}
$$

where $\hat{\imath}_{t}^{+}<\delta \theta$ for $\sigma^{+} \leq t \leq \sigma^{+}+T$ and $\hat{\imath}_{t}^{+}=\delta \theta$ for $t>\sigma^{+}+T$. Then output is above potential after the good Poisson event. Capacity utilization satisfies the differential equation

$$
\begin{gathered}
\frac{\dot{\xi}_{t}^{+}}{\xi_{t}^{+}}=\left(\hat{\imath}_{t}^{+}-\delta \theta\right)+(\phi-1)\left(\pi_{t}-\pi^{*}\right) \leq 0 \\
\pi_{t}-\pi^{*}+\kappa_{1}\left(1-\xi_{t}^{+}\right)=0
\end{gathered}
$$

with terminal condition $\xi_{\sigma^{+}+T}^{+}=1$.

Just as in Section 4, the solution features $\xi_{t}^{+}>1$ and $\pi_{t} \geq \pi^{*}$ for $\sigma^{+} \leq t<\sigma^{+}+T$. The rest of the analysis is identical and the conclusion is identical. Forward guidance stimulates the economy after the good Poisson event, resulting in a boom and inflation above target. But this fails to stimulate the economy before the Poisson when the economy is in a safety trap.

Remark 6 We could also introduce inflation in the unconstrained regime and liquidity traps. Just like in the constrained regime, when the natural safe interest rate is negative $r^{K, n}<0$, there is always a bad liquidity trap equilibrium with a recession $\xi<1$ and deflation $\pi<0$. If the inflation target $\bar{\pi}$ is high enough, there is also a good equilibrium with no recession $\xi=1$ and inflation at target $\pi=\bar{\pi}$. Introducing inflation does not change the results that safe public debt and QE are ineffective in liquidity traps. Forward guidance gains an extra kick by increasing inflation, reducing real interest rates, further stimulating output and inflation, and so on.

\section{Extensions and Robustness}

In the appendix we present two extensions, which we briefly summarize here: an analysis of the role of bubbles (Appendix A.5) and an endogenization of the securitization process to demonstrate the presence of a securitization externality (Appendix A.6). We also comment on the robustness of our results.

Bubbles and fiscal capacity. The very low interest rates that characterize a safety trap raises the issue of whether speculative bubbles may emerge, and whether these can play a useful role through their wealth effect. We show in Appendix A.5 that bubbles can indeed arise in safety traps, but that only the emergence of safe bubbles (as opposed to risky bubbles) can stimulate economic activity. This is because only safe bubbles alleviate the shortage of safe assets while risky bubbles end up simply crowding out other risky assets. The fact that risky bubbles have no effect on output in a safety trap formalizes some observations in Summers (2013) that in secular stagnation environments, even large financial bubbles only seem to create moderate economic expansions. It 
stands in contrast to standard liquidity trap environments, where both safe and risky bubbles stimulate output. This is because in standard liquidity trap environments, both increase total asset supply and alleviate the underlying shortage of assets.

We associate safe bubbles to (some) safe public debt: The existence of a bubbly-region where the safe real interest rate is permanently below the growth rate of the economy is equivalent to an expansion of the fiscal capacity of the government who can issue some amount of safe debt without ever having to raise taxes.

Securitization externality. In Appendix A.6 we endogenize the securitization capacity of the economy. We assume that by investing resources $j_{t} X d t$, a Neutral agent can increase $\rho\left(j_{t}\right)$ and, with it, increase the supply of safe assets (i.e., the share of the tree's revenue in the bad state of the world that is pledgable today).

We show in this extension that outside of a safety trap, the competitive equilibrium is constrained Pareto efficient, but that in a safety trap, it is constrained inefficient (there is underprovision of safe assets). We trace back this inefficiency to a securitization externality. In a safety trap, private agents do not internalize the full social benefit of creating safe assets. More specifically, they do not take into account the stimulative effects of these assets. This market failure builds a case for government intervention in securitization markets. The government could use taxes or quantity restrictions to encourage securitization, force financial institutions to raise more fresh capital than they would do otherwise or directly recapitalize them to boost their securitization capacity, or simply directly engage in securitization through QE. This argument is distinct from the comparative advantage of the government in safe asset creation that we analyzed in Section 3.

Robustness. Our model is stylized, which allows us to isolate and illustrate the key mechanisms, and to bring out most clearly the differences between safety traps and liquidity traps. Of course, its stark assumptions are likely to hold in a milder form in practice, and it is important to understand how our results would be altered in such contexts.

The fundamental features of our model, which drive our results, are the following: (i) nominal rigidities and a ZLB; (ii) macroeconomic uncertainty and risk aversion; (iii) heterogeneity in risk aversion with risk tolerant and risk averse agents; (iv) financial frictions hampering securitization. Features (i) and (ii) are standard, although they are rarely combined in standard liquidity trap analyses which rely on perfect foresight or log-linearizations. Feature (iii) gives rise to risk sharing through asset markets, and in particular through the issuance of zero-net-supply safe assets from risk tolerant agents to risk averse agents (one could imagine either the issuance of entirely safe assets as in our model and also as in Barro and Mollerus 2014, or simply of safer assets than the positive-net-supply Lucas trees). Feature (iv) hampers this securitization process by limiting the collateral that can be used to back these safe assets.

We model macroeconomic uncertainty in feature (ii) as a macroeconomic Poisson event, and we assume that all uncertainty is resolved at once after this Poisson event. The safety trap then only arises before the Poisson event, precisely because a bad Poisson event might occur in the future. 
At the cost of analytical tractability, one could allow for more general stochastic processes, and relax the assumption that uncertainty is resolved all at once with the realization of the event. For example, if another Poisson event could occur after the first Poisson event, then the economy could end up in a safety trap not only before the first realization of the Poisson event, but also after the realization of the first bad Poisson event, because another future bad Poisson event might occur. The resulting compounding of macroeconomic uncertainty would further reduce safe asset supply, and trigger an even bigger recession before the first Poisson event. Output after the first bad Poisson event would also be lower, not only because of the exogenous impact of the first bad Poisson event, but also because of an endogenous recession.

In our model, features (iii) and (iv) take an extreme form: agents are either risk neutral or infinitely risk averse; and there is a hard securitization constraint. In addition, we have assumed that agents do not substitute consumption intertemporally. These extreme assumptions make the model tractable and transparent, and allow us to derive our results in closed form. Milder versions of these features would lead to milder forms of our main results: recessions at the ZLB associated with increases in risk premia generated by shortages of safe assets; stimulative effects of safe debt issuances and QE; reduced effectiveness of FG. For example, and focusing on FG, with finite differences in risk aversion, FG would increase the attractiveness of risky assets and hence reduce the demand of safe assets by risk averse agents, thereby stimulating the economy, the more so, the lower the risk aversion of risk averse agents, and the higher the intertemporal elasticity of substitution. Likewise, with an active investment margin to relax financial frictions as in Appendix A.6, FG would increase the incentives of risk tolerant agents to invest in securitization and issue safe assets to capture risk premia, increase the supply of safe assets, and hence stimulate the economy, the more so, the higher the elasticity of securitization capacity to investment or, equivalently, the responsiveness of the supply of safe assets to risk premia. Similar observations apply to safe debt issuances and QE. In particular, it is no longer key that public debt be absolutely safe in order to stimulate output: It is enough that it be safer (lower beta) than the private risky assets that are being purchased with the proceeds of the debt issuance.

\section{Final Remarks}

In this paper we provide a model that captures some of the most salient macroeconomic consequences and policy implications of a safety trap. The model is deliberately highly stylized, which allows us to isolate the specific role of safe asset shortages at the ZLB. Safety traps correspond to liquidity traps in which the emergence of an endogenous risk premium significantly alters the connection between macroeconomic policy, wealth, and economic activity.

In a nutshell, in a situation of safety trap, private agents (and some sovereigns) want to substitute some of their risky holdings for safer ones. In the absence of mechanisms to lower safe interest rates to restore equilibrium, the most powerful policies are those that help the private sector implement this swap. As we mentioned in the main text, the early QE policies implemented by the FED during 
the subprime crises did just that, and there is extensive evidence of their effectiveness. Another successful example is the OMT (outright monetary transactions) program established by the ECB in late 2012, which had an immediate impact on the Eurozone risk perception, or the more recent (April 2016) move of the ECB to purchase corporate bonds.

However, over time and partly as a result of lack of political support, asset purchase policies have turned mostly into swaps of one form of safe asset for another, which is not nearly as effective in a safety trap context. In fact, in a previous version of this paper (Caballero and Farhi 2013), we argued that Operation Twist (OT) type polices, where the FED purchases long maturity Treasuries and sells short maturity ones, could be counterproductive. The reason is that long-term public debt, while risky, is a negative-beta asset. OT type policies boil down to swapping negative-beta assets for zero-beta assets, which reduces the effective supply of safe assets. By contrast, the right form of QE policies entails swapping positive-beta assets for zero-beta assets, which increases the effective supply of safe assets.

Similarly, forward guidance policies are largely ineffective and can be seen as a mostly failed attempts at stimulating the economy by attempting to increase the value of risky assets, which are essentially dissipated in offsetting increases in risk premia.

Sufficient increases in the inflation target, by reducing safe real interest rates, are effective at stimulating output. The same goes for imposing negative interest rates $r^{K}<0$, to the extent that it is possible. Recently, some countries have experimented with modest levels of negative interest rates. At this stage, it is unclear exactly how far below zero interest rates can go. Of course safety traps can emerge even if the lower bound is not exactly at zero, as long as there is some finite lower bound.

Given the faster growth of safe-asset-consumer economies than that of safe-asset-producer economies as well as the aging of wealth-rich economies, absent major financial innovations, the shortage of safe assets is only likely to worsen over time, perhaps as a latent factor during booms but reemerging in full force during contractions. It is our conjecture that the shortage of safe assets will remain as a structural drag, lowering safe rates, increasing safety spreads, straining the financial system, and weakening the effectiveness of conventional monetary policy during contractions. 


\section{References}

[1] Abel, Andrew, 2015, "Crowd Out in Ricardian Economies," mimeo Wharton.

[2] Acharya, Viral V. and Philipp Schnabl, 2009, "Do Global Banks Spread Global Imbalances? The Case of Asset-Backed Commercial Paper During the Financial Crisis of 2007-09," Paper presented at the 10th Jacques Polak Annual Research Conference, International Monetary Fund. November.

[3] Adrian, Tobias, Richard K. Crump, and Emanuel Moench, 2014, "Efficient, regression-based estimation of dynamic asset pricing models," Staff Reports 493, Federal Reserve Bank of New York.

[4] Barclays 2012. Equity Gilt Study.

[5] Barro, Robert J. and Andrew Mollerus, 2014, "Safe Assets," mimeo Harvard University.

[6] Barro, Robert .J and Herschel I. Grossman, 1971, "A General Disequilibrium Model of Income and Employment," American Economic Review, 61(1), pp. 82-93, March.

[7] Bénassy, Jean-Pascal, 1986, "Macroeconomics: An Introduction to the Non-Walrasian Approach," Academic Press, Orlando.

[8] Bernanke, Ben, Carol Bertaut, Laurie Ponder DeMarco, and Steven Kamin, 2011. "International Capital Flows and the Returns to Safe Assets in the United States, 2003-2007," International Finance Discussion Paper 1014, Federal Reserve Board of Governors.

[9] Blanchard, Olivier J, and Nobuhiro Kiyotaki, 1987. "Monopolistic Competition and the Effects of Aggregate Demand." American Economic Review, 77(4), pp. 647-66.

[10] Caballero, Ricardo J., 2006. "On the Macroeconomics of Asset Shortages." In The Role of Money: Money and Monetary Policy in the Twenty-First Century The Fourth European Central Banking Conference 9-10 November, Andreas Beyer and Lucrezia Reichlin, editors, pp. $272-283$.

[11] Caballero, Ricardo J., 2009. "The 'Other' Imbalance and the Financial Crisis," Paolo Baffi Lecture, Bank of Italy.

[12] Caballero, Ricardo J. and Emmanuel Farhi, 2013, "A Model of the Safe Asset Mechanism (SAM): Safety Traps and Economic Policy." MIT and Harvard mimeo.

[13] Caballero, Ricardo J., Emmanuel Farhi and Pierre-Olivier Gourinchas, 2008a, "Financial Crash, Commodity Prices, and Global Imbalances." Brookings Papers on Economic Activity, Fall, pp. 1-55. 
[14] Caballero, Ricardo J., Emmanuel Farhi and Pierre-Olivier Gourinchas, 2008b, "An Equilibrium Model of "Global Imbalances" and Low Interest Rates." American Economic Review, 98(1), pp. 358-393.

[15] Caballero, Ricardo J., Emmanuel Farhi and Pierre-Olivier Gourinchas, 2015, "Global Imbalances and Currency Wars at the ZLB." Harvard mimeo.

[16] Caballero, Ricardo J., Emmanuel Farhi and Pierre-Olivier Gourinchas, 2017, "Rents, Technical Change, and Risk Premia: Accounting for Secular Trends in Interest Rates, Returns on Capial, Earnigs Yield, and Factor Shares." forthcoming in the American Economic Review Papers and Proceedings.

[17] Caballero, Ricardo J. and Arvind Krishnamurthy, 2009, "Global Imbalances and Financial Fragility," American Economic Review Papers and Proceedings, May.

[18] Carlstrom, Charles T., Timothy S. Fuerst and Matthias Paustian, 2012, "Inflation and output in New Keynesian models with a transient interest rate peg," mimeo Federal Reserve Bank of Cleveland.

[19] Campbell, John, 2008, "Estimating the Equity Premium," Canadian Journal of Economics,41(1), pp. 1-21.

[20] Christiano, Lawrence, Martin Eichenbaum, and Sergio Rebelo, 2011, "When Is the Government Spending Multiplier Large?," Journal of Political Economy, 119(1), pp. 78-121.

[21] Correia, Isabel, Emmanuel Farhi, Juan-Pablo Nicolini, and Pedro Teles, 2013, "Unconventional Fiscal Policy at the Zero Bound," the American Economic Review,103(4), pp. 1172-1211.

[22] Coval, Joshua D., Jakub W. Jurek and Erik Stafford, 2009, "The Economics of Structured Finance," Journal of Economic Perspectives, Vol. 23, No. 1, Winter.

[23] Cúrdia, Vasco, Andrea Ferrero, Ging Cee Ng, and Andrea Tambalotti 2015, "Has U.S. monetary policy tracked the efficient interest rate?," Journal of Monetary Economics, 70(C), pp. 72-83.

[24] Daly, Kevin, 2016, "A Secular Increase in the Equity Risk Premium," International Finance.

[25] De Long, Bradford J. Lawrence H. Summers, 1986, "Is Increased Price Flexibility Stabilizing?," American Economic Review, 76(5), pp. 1031-44.

[26] Del Negro, Marco, Marc Giannoni and Christina Patterson, 2015, "The Forward Guidance Puzzle," mimeo Federal Reserve Bank of New York.

[27] Duarte, Fernando M. and Carlo Rosa, 2015. "The equity risk premium: a review of models," Economic Policy Review, Federal Reserve Bank of New York, issue 2, pages 39-57.

[28] Eggertsson, Gauti B., and Paul Krugman, 2012, "Debt, Deleveraging, and the Liquidity Trap: A Fisher-Minsky-Koo Approach," Quarterly Journal of Economics, 127(3), pp. 1469-1513. 
[29] Eggertsson, Gauti B., and Michael Woodford, 2003, "The Zero Bound on Interest Rates and Optimal Monetary Policy," Brookings Papers on Economic Activity, pp. 139-211.

[30] Eggertsson, Gauti B., and Neil Mehrota 2014, "A Model of Secular Stagnation,” mimeo Brown University.

[31] Farhi, Emmanuel, Pierre-Olivier Gourinchas, and Helene Rey, "Reforming the International Monetary System," CEPR ereport, Setpember 2011.

[32] Farhi, Emmanuel, and Ivan Werning, 2012, "Fiscal Multipliers: Liquidity Traps and Currency Unions," NBER working paper 18381.

[33] Gennaioli, Nicola, Andrei Shleifer, and Robert Vishny, 2011. "Neglected Risks, Financial Innovation, and Financial Fragility," forthcoming in the Journal of Financial Economics.

[34] Goldman Sachs 2012. "Are there Fewer Safe Assets than Before?," Goldman Sachs Global Economics Weekly.

[35] Gomme, Paul, B. Ravikumar, and Peter Rupert, 2015. "Secular Stagnation and Returns to Capital," Economic Synopses, Federal Reserve Bank of Saint Louis.

[36] Gorton, Gary B., 2010, "Slapped by the Invisible Hand: The Panic of 2007," Oxford University Press.

[37] Gorton, Gary B. and Guillermo Ordoñez, 2013, "The Supply and Demand for Safe Assets," NBER working paper 18732.

[38] Gourinchas, Pierre-Olivier and Hélène Rey. 2007. "From World Banker to World Venture Capitalist: US External Adjustment and The Exorbitant Privilege," in Richard Clarida, editor, G7 Current Account Imbalances: Sustainability and Adjustment, The University of Chicago Press, pp. 11-55.

[39] Greenwood, Robin, and Dimitri Vayanos, 2010, "Price Pressure in the Government Bond Market," American Economic Review, 100(2), pp. 585-90, May.

[40] Greenwood, Robin, Sam Hanson, and Jeremy Stein, 2012, "A Comparative-Advantage Approach to Government Debt Maturity", mimeo, Harvard.

[41] Guerrieri, Veronica, and Guido Lorenzoni, 2011, "Credit Crises, Precautionary Savings, and the Liquidity Trap," NBER working paper 17583.

[42] Gurkaynak, Refet S., Brian Sack, and Jonathan H. Wright, 2007, "The U.S. Treasury yield curve: 1961 to the present," Journal of Monetary Economics, Elsevier, 54(8), pp. 2291-2304, November.

[43] Hall, Robert E., 2011a, "The Long Slump," American Economic Review, 101, pp. 431-469. 
[44] Hall, Robert E., 2011b, "Clashing Theories of Unemployment," mimeo, Hoover Institution and Stanford University.

[45] Hall, Robert E., 2014, "Quantifying the Lasting Harm to the U.S. Economy of the Financial Crisis," NBER Macroeconomics Annual, 29(1), pp 71-128.

[46] Hansen, Alvin, 1939l, "Economic Progress and Declining Population Growth," American Economic Review, 29(1), pp 1-15.

[47] He, Zhiguo, Arvind Krishnamurthy, and Konstantin Milbradt, 2015, "A Model of the Reserve Asset," mimeo Chicago Booth.

[48] Holmström, Bengt and Jean Tirole, 1997, "Financial Intermediation, Loanable Funds and the Real Sector," Quarterly Journal of Economics,112(3), pp663-691.

[49] Holmström, Bengt and Jean Tirole, 1998, "Private and Public Supply of Liquidity," Journal of Political Economy, 106(1), pp. 1-40.

[50] Keynes, John M, 1936, "The General Theory of Employment, Interest, and Money," Macmilan.

[51] Kocherlakota, Narayana, 2013, "Impact of a Labor Price Fall when Labor Markets are Incomplete," mimeo, Federal Reserve Bank of Minneapolis.

[52] Korinek, Anton and Alp Simsek, 2013, "Liquidity Traps and Excessive Leverage", mimeo, MIT.

[53] Krishnamurthy, Arvind and Annette Vissing-Jorgensen, 2011, "The Effects of Quantitative Easing on Interest Rates: Channels and Implications for Policy," Brookings Papers on Economic Activity.

[54] Krishnamurthy, Arvind and Annette Vissing-Jorgensen, 2012, "The Aggregate Demand for Treasury Debt," Journal of Political Economy, 120:2, pp. 233-267

[55] Krugman, Paul R., 1998, "It's Baaack: Japan's Slump and the Return of the Liquidity Trap," Brookings Papers on Economic Activity, 29(2), pp. 137-206.

[56] Malinvaud, Edmond. 1977, "Theory of Unemployment Reconsidered," Oxford: Blackwell Publishers.

[57] McKay, Alisdair, Emi Nakamura and Jón Steinsson, 2015, "The Power of Forward Guidance Revisited," NBER working paper 20882.

[58] Obstfeld, Maury, 2011, "International Liquidity: The Fiscal Dimension," Monetary and Economic Studies, pp. 33-48, November.

[59] Stein, Jeremy C., 2012, "Monetary Policy as Financial-Stability Regulation," Quarterly Journal of Economics, 127(1), pp. 57-95. 
[60] Summers, Lawrence H., 2013, Speech at the IMF Annual Economic Conference.

[61] Werning, Ivan, 2012, "Managing a Liquidity Trap: Monetary and Fiscal Policy," MIT mimeo.

[62] Woodford, Michael, 1990, "Public Debt as Private Liquidity," American Economic Review, Papers and Proceedings 80, pp. 382-88, May.

[63] Woodford, Michael, 2003, "Interest and Prices," Princeton University Press.

\section{A Appendix}

\section{A.1 Detailed Derivations}

\section{A.1.1 Derivations for Section 2.1}

In this section, we assume that prices are flexible. We focus on stochastic steady states before the Poisson event. There are two cases, depending on whether we are in the constrained regime or in the unconstrained regime. Recall that both in the constrained regime and in the unconstrained regime, we have the following implications of goods market clearing:

$$
\begin{gathered}
V=W=\frac{X}{\theta}, \\
V^{+}=W^{+}=\mu^{+} \frac{X}{\theta} \text { and } V^{-}=W^{-}=\mu^{-} \frac{X}{\theta}, \\
V^{S}=V^{S+}=V^{S-}=\rho \mu^{-} \frac{X}{\theta} . \\
V^{R}=\left(1-\rho \mu^{-}\right) \frac{X}{\theta}, \quad V^{R+}=\left(\mu^{+}-\rho \mu^{-}\right) \frac{X}{\theta}, \quad \text { and } \quad V^{R-}=\left(\mu^{-}-\rho \mu^{-}\right) \frac{X}{\theta} .
\end{gathered}
$$

Unconstrained regime. Suppose first that we are in the unconstrained regime with $r=r^{K}$ and $W^{K} \leq V^{S}$. The equilibrium equations are

$$
\begin{gathered}
r V^{S}=\delta^{S} X, \\
r V^{R}=\left(\delta-\delta^{S}\right) X+\lambda^{+}\left(V^{R+}-V^{R}\right)+\lambda^{-}\left(V^{R-}-V^{R}\right), \\
0=-\theta W^{K}+\alpha(1-\delta) X+r W^{K}, \\
0=-\theta W^{N}+(1-\alpha)(1-\delta) X+r W^{N}-\lambda^{+}\left(V^{R+}-V^{R}\right)-\lambda^{-}\left(V^{R-}-V^{R}\right), \\
W^{K}+W^{N}=V^{S}+V^{R} .
\end{gathered}
$$

We can sum the two asset pricing equations and the two wealth evolution equations to get the 
following aggregate asset pricing equation and aggregate wealth evolution equation

$$
\begin{gathered}
r V=\delta X+\lambda^{+}\left(V^{+}-V\right)+\lambda^{-}\left(V^{-}-V\right), \\
0=-\theta W+(1-\delta) X+r W-\lambda^{+}\left(V^{+}-V\right)-\lambda^{-}\left(V^{-}-V\right), \\
W=V .
\end{gathered}
$$

Combining equations (12), (13), and (14) immediately implies that as already anticipated

$$
W=V=\frac{X}{\theta} .
$$

Plugging this back in the aggregate asset pricing equation (12) yields

$$
r \frac{X}{\theta}=\delta X+\lambda^{+}\left(\frac{\mu^{+} X}{\theta}-\frac{X}{\theta}\right)+\lambda^{-}\left(\frac{\mu^{-} X}{\theta}-\frac{X}{\theta}\right),
$$

which can be rewritten as

$$
r=\delta \theta+\lambda^{+}\left(\mu^{+}-1\right)+\lambda^{-}\left(\mu^{-}-1\right) .
$$

We are indeed in the constrained regime if

$$
W^{K} \leq V^{S}
$$

Using equation (7), we can rewrite this condition as

$$
\frac{\alpha(1-\delta) X}{\theta-r} \leq \frac{\rho \mu^{-} X}{\theta},
$$

or equivalently, using expression (15) for the equilibrium interest rate $r$, as

$$
\frac{\alpha-\rho \mu^{-}}{\rho \mu^{-}} \theta(1-\delta)+\lambda^{+}\left(\mu^{+}-1\right)+\lambda^{-}\left(\mu^{-}-1\right) \leq 0 .
$$

Constrained regime. Suppose now that we are in the constrained regime with $r>r^{K}$ and $W^{K}=V^{S}$. We then have

$$
\begin{gathered}
r^{K} V^{S}=\delta^{S} X \\
r V^{R}=\left(\delta-\delta^{S}\right) X+\lambda^{+}\left(V^{R+}-V^{R}\right)+\lambda^{-}\left(V^{R-}-V^{R}\right) \\
0=-\theta W^{K}+\alpha(1-\delta) X+r^{K} W^{K}, \\
0=-\theta W^{N}+(1-\alpha)(1-\delta) X+r W^{N}-\lambda^{+}\left(V^{R+}-V^{R}\right)-\lambda^{-}\left(V^{R-}-V^{R}\right), \\
W^{K}=V^{S}, \\
W^{N}=V^{R} .
\end{gathered}
$$


In this regime we have

$$
\begin{gathered}
W^{K}=V^{S}=\frac{\rho \mu^{-} X}{\theta}, \\
W^{N}=V^{R}=\frac{\left(1-\rho \mu^{-}\right) X}{\theta} .
\end{gathered}
$$

Plugging the expression for Knightian wealth (22) back in the evolution equation (18) for Knightian wealth, we get

$$
0=-\theta \frac{\rho \mu^{-} X}{\theta}+\alpha(1-\delta) X+r^{K} \frac{\rho \mu^{-} X}{\theta}
$$

which can be rewritten as

$$
r^{K}=\delta \theta-\frac{\alpha-\rho \mu^{-}}{\rho \mu^{-}}(1-\delta) \theta
$$

We then plug back the expression for the value of safe assets (22) and the expression for safe real interest rates (24) into the asset pricing equation (16) for safe assets to get

$$
\left[\delta \theta-\frac{\alpha-\rho \mu^{-}}{\rho \mu^{-}}(1-\delta) \theta\right] \frac{\rho \mu^{-} X}{\theta}=\delta^{S} X
$$

which can be rewritten as

$$
\delta^{S}=\delta \rho \mu^{-}-\left(\alpha-\rho \mu^{-}\right)(1-\delta)
$$

We use the expression for the value of Neutral wealth (23) and the expression (25) for $\delta^{S}$ to get

$$
r \frac{\left(1-\rho \mu^{-}\right) X}{\theta}=\left(\delta-\delta^{S}\right) X+\frac{\lambda^{+}\left(\mu^{+}-1\right) X}{\theta}+\frac{\lambda^{-}\left(\mu^{-}-1\right) X}{\theta}
$$

which can be rewritten as

$$
r=\delta \theta+\frac{\alpha-\rho \mu^{-}}{1-\rho \mu^{-}}(1-\delta) \theta+\frac{\lambda^{+}\left(\mu^{+}-1\right)+\lambda^{-}\left(\mu^{-}-1\right)}{1-\rho \mu^{-}} .
$$

We are in the constrained regime if the risk premium is positive

$$
r-r^{K}>0
$$

which, using equations (24) and (26) for the safe and risky expected rates of return $r^{K}$ and $r$, leads to the sufficient condition for the constrained regime:

$$
\frac{\alpha-\rho \mu^{-}}{\rho \mu^{-}}(1-\delta) \theta+\lambda^{+}\left(\mu^{+}-1\right)+\lambda^{-}\left(\mu^{-}-1\right)>0 .
$$

\section{A.1.2 Derivations for Section 2.2}

In this section, we assume that prices are rigid and that we are in the constrained regime. We focus on stochastic steady states before the Poisson event. 
With rigid prices, actual output can be below potential output $\xi X<X$ before the Poisson event if $r^{K, n}<0$ and $r^{K}=0$ but never after the Poisson event where $r^{K+}=r^{+}=r^{K-}=r^{-}=\delta \theta$.

We now have the following implications of goods market clearing:

$$
\begin{gathered}
V=W=\frac{\xi X}{\theta}, \\
V^{+}=W^{+}=\mu^{+} \frac{\xi X}{\theta} \text { and } V^{-}=W^{-}=\mu^{-} \frac{\xi X}{\theta}, \\
V^{S}=V^{S+}=V^{S-}=\rho \mu^{-} \frac{X}{\theta} . \\
V^{R}=\left(1-\rho \frac{\mu^{-}}{\xi}\right) \frac{\xi X}{\theta}, \quad V^{R+}=\left(\mu^{+}-\rho \mu^{-}\right) \frac{X}{\theta}, \quad \text { and } \quad V^{R-}=\left(\mu^{-}-\rho \mu^{-}\right) \frac{X}{\theta} .
\end{gathered}
$$

The equilibrium equations are

$$
\begin{gathered}
r^{K} V^{S}=\delta^{S} \xi X, \\
r V^{R}=\left(\delta-\delta^{S}\right) \xi X+\lambda^{+}\left(V^{R+}-V^{R}\right)+\lambda^{-}\left(V^{R-}-V^{R}\right), \\
0=-\theta W^{K}+\alpha(1-\delta) \xi X+r^{K} W^{K}, \\
0=-\theta W^{N}+(1-\alpha)(1-\delta) \xi X+r W^{N}-\lambda^{+}\left(V^{R+}-V^{R}\right)-\lambda^{-}\left(V^{R-}-V^{R}\right), \\
W^{K}=V^{S}, \\
W^{N}=V^{R}, \\
r^{K} \geq 0, \quad 0 \leq \xi \leq 1, \quad \text { and } r^{K}(1-\xi)=0 .
\end{gathered}
$$

The last equation (37) is a ZLB complementary slackness condition. Recall from Sections 2.1 and A.1.1 that

$$
r^{K, n}=\delta \theta-\frac{\alpha-\rho \mu^{-}}{\rho \mu^{-}}(1-\delta) \theta
$$

As long as $r^{K, n} \geq 0$, full capacity utilization $\xi=1$ derived in Sections 2.1 and A.1.1 can be achieved by simply setting $i=r^{K, n}$ so that $r^{K}=r^{K, n} \geq 0$. But when $r^{K, n}<0$ as we assume from now on, the constraint $r^{K}=0$ binds, and actual output is below potential with $\xi<1$ (note that $\xi$ is an equilibrium variable). To solve for the equilibrium, we note that the equilibrium equations are then isomorphic to those in Section A.1.1 but with the following renormalization: $\mu^{+}$is replaced by $\frac{\mu^{+}}{\xi}$, $\mu^{-}$by $\frac{\mu^{-}}{\xi}$, and $X$ by $\xi X$. Equilibrium capacity utilization must be such that $r^{K}=0$, which using expression (24) for $r^{K}$ together with the aforementioned renormalization, can be written as

$$
0=\delta \theta-\frac{\alpha-\rho \frac{\mu^{-}}{\xi}}{\rho \frac{\mu^{-}}{\xi}}(1-\delta) \theta,
$$

or

$$
\xi=\frac{\theta}{\theta-r^{K, n}}<1
$$


Using expression (26) for $r$ together with the renormalization, we get

$$
r=\delta \theta+\frac{\alpha-\rho \frac{\mu^{-}}{\xi}}{1-\rho \frac{\mu^{-}}{\xi}}(1-\delta) \theta+\frac{\lambda^{+}\left(\frac{\mu^{+}}{\xi}-1\right)+\lambda^{-}\left(\frac{\mu^{-}}{\xi}-1\right)}{1-\rho \frac{\mu^{-}}{\xi}} .
$$

To derive the Keynesian cross representation of the equilibrium, we simply combine the asset pricing equations (31) to replace $\delta^{S}$ in (32). We then use $V^{R}=W^{N}$ to replace $V^{R}$ by $W^{N}$ in the resulting equation and get

$$
r W^{N}-\lambda^{+}\left(\frac{\mu^{+}}{\xi}-1\right) \frac{\xi X}{\theta}-\lambda^{-}\left(\frac{\mu^{-}}{\xi}-1\right) \frac{\xi X}{\theta}=\delta X-r^{K} V^{S}
$$

We can then plug back this expression in the evolution equation (34) for Neutral wealth to get

$$
0=-\theta W^{N}+(1-\alpha)(1-\delta) \xi X+\delta \xi X-r^{K} V^{S}
$$

which we can rewrite as

$$
W^{N}=(1-\alpha)(1-\delta) \xi \frac{X}{\theta}+\delta \xi \frac{X}{\theta}-\frac{r^{K}}{\theta} V^{S}
$$

Using the fact that the total value of Knightian wealth is $W^{K}=V^{S}$, we get that aggregate demand for goods is given by

$$
\theta\left(W^{N}+W^{K}\right)=A D(\xi X)
$$

where

$$
A D(\xi X)=(1-\alpha)(1-\delta) \xi X+\delta \xi X+\left(\theta-r^{K}\right) V^{S}
$$

with $r^{K} \geq 0$. Aggregate supply is simply the 45 degree line

$$
A S(\xi X)=\xi X
$$

When $r^{K, n} \geq 0$, we have $A D(X)=A S(X)$ when $r^{K}=r^{K, n}$. But when $r^{K, n}<0$, we have $r^{K}=0$ and $\xi$ is the solution of the fixed point equation $A D(\xi X)=A S(\xi X)$.

\section{A.1.3 Derivations for Section 2.2.3}

In this section, we assume that the economy is in the unconstrained regime and that prices are rigid. The stochastic steady state equilibrium equations before the Poisson event for aggregate asset values $V$, aggregate wealth $W$, the interest rate $r$ and capacity utilization are given by:

$$
\begin{gathered}
r V=\delta \xi X+\lambda^{+}\left(\frac{\mu^{+} X}{\theta}-V\right)+\lambda^{-}\left(\frac{\mu^{-} X}{\theta}-V\right), \\
0=-\theta W+(1-\delta) \xi X+r W-\lambda^{+}\left(\frac{\mu^{+} X}{\theta}-V\right)-\lambda^{-}\left(\frac{\mu^{-} X}{\theta}-V\right),
\end{gathered}
$$




$$
\begin{gathered}
V=W \\
r \geq 0, \quad 0 \leq \xi \leq 1, \quad \text { and } \quad r(1-\xi)=0 .
\end{gathered}
$$

Let

$$
r^{n}=\delta \theta+\lambda^{+}\left(\mu^{+}-1\right)+\lambda^{-}\left(\mu^{-}-1\right) .
$$

If $r^{n}>0$, we can set $r=r^{n}$ and get $\xi=1$. We then have

$$
V=W=\frac{X}{\theta}
$$

If $r^{n}<0$, we have $r=0$ and $\xi<1$. We then have

$$
V=W=\frac{\xi X}{\theta}
$$

and

$$
0=\delta \theta+\lambda^{+}\left(\frac{\mu^{+}}{\xi}-1\right)+\lambda^{-}\left(\frac{\mu^{-}}{\xi}-1\right) .
$$

The alternative expressions for $V$ and $W$ used in the text

$$
\begin{gathered}
V=\frac{\delta \xi X+\lambda^{+} \frac{\mu^{+} X}{\theta}+\lambda^{-\frac{\mu^{-} X}{\theta}}}{r+\lambda^{+}+\lambda^{-}}, \\
W=\frac{(1-\delta) \xi X-\lambda^{+} \frac{\mu^{+} X}{\theta}-\lambda^{-\frac{\mu^{-} X}{\theta}}}{\theta-r-\lambda^{+}-\lambda^{-}},
\end{gathered}
$$

are simple rearrangements of equations (38) and (39) respectively.

\section{A.1.4 Derivations for Section 3}

Public debt. We start with the model with public debt. We follow the same steps as in Section A.1.2. The equilibrium equations are exactly the same as in Section A.1.2 with one difference: $\rho$ must be replaced by $\rho\left(\tau^{-}\right)+\tau^{-}$.

QE. Suppose that additional public debt is issued from $D$ to $\hat{D}>D$. This requires an increase from $\tau^{-}$to $\hat{\tau}^{-}=\frac{\hat{D}}{D} \tau^{-}>\tau^{-}$. But assume that instead of rebating the proceeds of the debt issuance, they are used to purchase risky assets. This only change the equilibrium value of $\hat{\tau}$ but does not affect any of the stochastic steady state equilibrium equations derived in Section A.1.2.

\section{A.1.5 Derivations for Section 4}

We give a detailed derivation of the new element of Section 4: the determination of output after the good Poisson event with forward guidance. Indeed, given $\xi_{\sigma^{+}}^{+}$, the equilibrium before the Poisson event is exactly the same as that characterized in Sections 2.2 and A.1.2 with $\mu^{+}$replaced by $\xi_{\sigma^{+}}^{+} \mu^{+}$. 
After the good Poisson event, we are in the unconstrained regime, and we can represent the equilibrium with an aggregate asset pricing equation, an aggregate wealth evolution equation, and an aggregate market clearing condition. Because the interest rate $i_{t}^{+}=r_{t}^{+}$is not constant, the solution features a transition. We have

$$
\begin{gathered}
i_{t}^{+} V_{t}^{+}=\delta \xi_{t}^{+} \mu^{+} X+\dot{V}_{t}^{+} \\
\dot{W}_{t}^{+}=-\theta W_{t}^{+}+(1-\delta) \xi_{t}^{+} \mu^{+} X+i_{t}^{+} W_{t}^{+} \\
W_{t}^{+}=V_{t}^{+}
\end{gathered}
$$

Combining these equations yields the goods market clearing condition

$$
W_{t}^{+}=V_{t}^{+}=\frac{\xi_{t}^{+} \mu^{+} X}{\theta}
$$

that can then be replaced into the aggregate asset pricing equation to yield

$$
i_{t}^{+} \frac{\xi_{t}^{+} \mu^{+} X}{\theta}=\delta \xi_{t}^{+} \mu^{+} X+\frac{\dot{\xi}_{t}^{+} \mu^{+} X}{\theta}
$$

that can be rewritten as the differential equation

$$
\frac{\dot{\xi}_{t}^{+}}{\xi_{t}}=i_{t}^{+}-\delta \theta,
$$

that must be solved with the terminal condition

$$
\xi_{\sigma^{+}+T}^{+}=1
$$

The solution for $\sigma^{+} \leq t \leq \sigma^{+}+T$ is

$$
\xi_{t}^{+}=e^{\int_{t}^{\sigma^{+}+T}\left(\delta \theta-i_{s}\right) d s} \geq 1
$$

\section{A.1.6 Derivations for Section 5.1}

The stochastic steady state equilibrium equations with inflation before the Poisson event are exactly the same as in Section A.1.2 but with the following differences: There are three new equilibrium equations and one of the equilibrium conditions must be modified.

The three new equilibrium equations are the Fisher equation, the truncated Taylor rule, and the Phillips curve:

$$
\begin{gathered}
r^{K}=i-\pi, \\
i=\max \left\{0, r^{K, n}+\pi^{*}+\phi\left(\pi-\pi^{*}\right)\right\} \\
{\left[\pi+\left(\kappa_{0}+\kappa_{1}(1-\xi)\right)\right](1-\xi)=0 .}
\end{gathered}
$$


In addition, the ZLB complementary slackness condition (37) becomes

$$
i \geq 0, \quad 0 \leq \xi \leq 1, \quad \text { and } i(1-\xi)=0
$$

Given the equilibrium value of $r^{K}$, the real equilibrium allocation is exactly the same as in Section A.1.2. But there is now an endogenous link between $\xi$ and $r^{K}$ through the Fisher equation (46), the truncated Taylor rule (47), and the Phillips curve (48).

When $-\kappa_{0}+r^{K, n}<0$, in the bad safety trap equilibrium inflation $\pi$ and capacity utilization are jointly determined by the requirement that $r^{K}=-\pi$ and by the Phillips curve:

$$
\begin{gathered}
-\pi=\delta \theta-(1-\delta) \theta \frac{\alpha-\frac{\rho \mu^{-}}{\xi}}{\frac{\rho \mu^{-}}{\xi}}, \\
\pi=-\left(\kappa_{0}+\kappa_{1}(1-\xi)\right) .
\end{gathered}
$$

We can rewrite these equations as

$$
\begin{gathered}
\pi=-\theta+(1-\delta) \theta \alpha \frac{\xi}{\rho \mu^{-}} \\
\pi=-\left(\kappa_{0}+\kappa_{1}\right)+\kappa_{1} \xi
\end{gathered}
$$

Assumption 2 guarantees that there exists a unique solution to this system of equations with $\xi<0$ and $\pi<-\kappa_{0} \leq \pi^{*}$. Indeed, these are two linear equations for $\pi$ as a function of $\xi$, and Assumption 2 guarantees that equation (50) (aggregate demand) is steeper than equation (51) (aggregate supply) and crosses it once from below for a value of $\xi \in(0,1)$ and corresponding value of $\pi<-\kappa_{0} \leq \pi^{*}$.

There can also be good equilibria with $\pi>-\kappa_{0}$ and $\xi=1$. In these equilibria, inflation is either

determined by $\pi=\frac{1}{\phi-1}\left[\phi \pi^{*}+r^{K, n}\right]$ if $r^{K, n}+\pi^{*}+\phi\left(\pi-\pi^{*}\right)>0\left(\right.$ in which case $i=r^{K, n}+\pi^{*}+\phi\left(\pi-\pi^{*}\right)$ ) or by $\pi=-r^{K, n}$ if $r^{K, n}+\pi^{*}+\phi\left(\pi-\pi^{*}\right) \leq 0$ (in which case $i=0$ ). The condition for existence of these good both good equilibria is the same and is given by $0 \leq r^{K, n}+\pi^{*}$.

\section{A.2 Money, the ZLB, and the Cashless Limit}

\section{A.2.1 Flexible Prices}

To justify a ZLB $i_{t} \geq 0$, we introduce money into the model. We then define and focus on the cashless limit (see e.g. Woodford 2003).

We represent the demand for real money balances for transactional services using a cash-inadvance constraint that stipulates that individuals with wealth $w_{t}$ and money holdings $m_{t}$ can only consume $\min \left(w_{t}, \frac{m_{t}}{\varepsilon}\right)$.

We focus on equilibria where the price level $P_{t}$ has continuous paths (later when we introduce 
nominal rigidities, this necessarily will be the case), and we denote by $\pi_{t}$ the rate of inflation. This implies that money is a safe asset with real rate of return $-\pi_{t}$, whereas non-monetary safe assets have a real rate of return of $i_{t}-\pi_{t}$. When $i_{t}>0$, money is held only for transaction services. When $i_{t}=0$ money is also held as a pure safe store of value. This model has no equilibrium with $i_{t}<0$, because then money would dominate other safe assets. Hence there is a ZLB $i_{t} \geq 0$.

The demand for real money balances for transactional services is $\varepsilon W_{t}^{K}$ and $\varepsilon W_{t}^{N}$ for Knightians and Neutrals respectively. We assume that the real money supply is $\varepsilon M^{\varepsilon}$ with $M^{\varepsilon}=\frac{X}{\theta}$ before the Poisson event and that it adjusts to accommodate one for one the change in potential output after the Poisson event $\left(M^{\varepsilon-}=\mu^{-\frac{X}{\theta}}\right.$ and $M^{\varepsilon+}=\mu^{+} \frac{X}{\theta}$ for bad and good events, respectively).

We also assume that potential adjustments in the nominal stock of money supply are distributed lump sum in proportion to equilibrium real money holdings. This implies that in equilibrium, nominal money holdings and lump sum nominal money grants add up to deliver a total real return of zero on real money holdings.

After the (bad) Poisson event, the value of the safe tranches of trees $\rho\left(\mu^{-} \frac{X}{\theta}-\varepsilon M^{\varepsilon-}\right)=$ $\rho \mu^{-}(1-\varepsilon) \frac{X}{\theta}$ is a fraction $\rho$ of the total value of assets excluding money $\mu^{-} \frac{X}{\theta}-\varepsilon M^{\varepsilon-}=\mu^{-}(1-\varepsilon) \frac{X}{\theta}$. This is also the value of the safe assets (excluding money) before the Poisson event:

$$
V^{S}=\rho \mu^{-}(1-\varepsilon) \frac{X}{\theta}
$$

Denoting by $M_{t}^{K}$ and $M_{t}^{M}$ the real money holdings of Knightians and Neutrals respectively, the equilibrium equations are now:

$$
\begin{gathered}
r_{t}^{K} V^{S}=\delta^{S} X \\
r_{t} V^{R}=\left(\delta-\delta^{S}\right) X+\lambda^{+}\left(V^{R+}-V^{R}\right)+\lambda^{-}\left(V^{R-}-V^{R}\right) \\
\dot{W}_{t}^{K}=-\theta W_{t}^{K}+\alpha(1-\delta) X+r_{t}^{K}\left(W_{t}^{K}-M_{t}^{K}\right)-\pi_{t} M_{t}^{K} \\
\dot{W}_{t}^{N}=-\theta W_{t}^{N}+(1-\alpha)(1-\delta) X+r_{t}^{K}\left(V^{S}-W_{t}^{K}+M_{t}^{K}\right)-\pi_{t} M_{t}^{N}+r_{t} V_{t}^{R}-\lambda^{+}\left(V^{R+}-V^{R}\right)-\lambda^{-}\left(V^{R-}-V^{R}\right) \\
M_{t}^{K}+M_{t}^{N}=M^{\varepsilon} \\
W_{t}^{K}+W_{t}^{N}=V^{S}+V^{R}+M^{\varepsilon} \\
r_{t} \geq r_{t}^{K}, \quad W_{t}^{K}-M_{t}^{K} \leq V^{S}, \quad \text { and } \quad\left(r_{t}-r_{t}^{K}\right)\left(V^{S}-W_{t}^{K}+M_{t}^{K}\right)=0 \\
M_{t}^{K} \geq \varepsilon W_{t}^{K} \text { and } M_{t}^{N} \geq \varepsilon W_{t}^{N}, \quad \text { with equality if } i_{t}>0
\end{gathered}
$$

and the requirement that

$$
r_{t}^{K}=i_{t}-\pi_{t} \text { with } i_{t} \geq 0
$$

The first two equations are the asset pricing equations for non-monetary safe and risky assets, which are identical to the one in the main text. The third and fourth equations are the wealth accumulations of Knighitans and Neutrals. They differ from the ones in the main text because some of the wealth of their wealth is held in the form of money with a real rate of return $-\pi_{t}$. The 
fifth and sixth conditions are the market clearing conditions for money and total assets. The seventh equation must hold because Neutrals rank non-monetary assets according to expected returns, so that either $r_{t}=r_{t}^{K}$ and Neutrals are indifferent between safe and risky assets or $r_{t}>r_{t}^{K}$ and the only non-monetary assets held by Neutrals are risky assets. The eight condition is the cash-inadvance constraint for Knightians and Neutrals. The ninth condition is the Fisher equation which links nominal interest rates and safe real interest rates.

The cashless limit $\varepsilon \rightarrow 0$ yields the same model as the model with flexible prices analyzed in the main text.

\section{A.2.2 Rigid Prices}

With rigid prices, the equilibrium equations are

$$
\begin{gathered}
r_{t}^{K} V^{S}=\delta^{S} \xi_{t} X, \\
r_{t} V_{t}^{R}=\left(\delta-\delta^{S}\right) \xi_{t} X+\lambda^{+}\left(V^{R+}-V_{t}^{R}\right)+\lambda^{-}\left(V^{R-}-V_{t}^{R}\right)+\dot{V}_{t}^{R}, \\
\dot{W}_{t}^{K}=-\theta W_{t}^{K}+\alpha(1-\delta) X+r_{t}^{K}\left(W_{t}^{K}-M_{t}^{K}\right), \\
\dot{W}_{t}^{N}=-\theta W_{t}^{N}+(1-\alpha)(1-\delta) X+r_{t}^{K}\left(V^{S}-W_{t}^{K}+M_{t}^{K}\right)+r_{t} V_{t}^{R}-\lambda^{+}\left(V^{R+}-V^{R}\right)-\lambda^{-}\left(V^{R-}-V^{R}\right)+\dot{V}_{t}^{R}, \\
M_{t}^{K}+M_{t}^{N}=M^{\varepsilon}, \\
W_{t}^{K}+W_{t}^{N}=V^{S}+V_{t}^{R}+M^{\varepsilon}, \\
r_{t}^{K} \geq \varepsilon W_{t}^{K} \text { and } M_{t}^{K} \geq \varepsilon W_{t}^{N}, \quad \text { with equality if } i_{t}>0,
\end{gathered}
$$

and the requirement that

$$
r_{t}^{K}=i_{t} \text { with } i_{t} \geq 0
$$

There are three main differences with the case where prices are flexible. The first difference is that $X$ is replaced by $\xi_{t} X$, where $\xi_{t}$ is capacity utilization. The second difference is that even conditional on no Poisson event, the value of risky assets can change over time, leading to an extra source of capital gains $\dot{V}_{t}^{R}$. The third difference is that inflation is zero $\pi_{t}=0$.

The cashless limit $\varepsilon \rightarrow 0$ yields the same model as the model with rigid prices analyzed in the main text with a ZLB constraint. In the next section we analyze additional issues that arise away from the cashless limit.

\section{A.2.3 Helicopter Money and Fiscal Capacity}

We consider the model with taxes and government debt of Section 3 but unlike in the main text, we consider what happens away from the cashless limit. We assume that prices are rigid and that 
we are in the constrained regime. We focus on stochastic steady states before the realization of the Poisson event and drop $t$-subscripts. We incorporate the modification of the model introduced in Section 4 which allows for capacity over-utilization as well as capacity under-utilization.

The question is what happens when the government issues extra money before the Poisson event when the economy is in a safety trap. There are two options which differ in what the government does once the economy is no longer at the ZLB after the Poisson event: (a) retire the extra money and keep; (b) not retire the extra money.

Option (a): retire the extra money after the Poisson event. This option is identical to what would happen if instead of extra money, the government had issued extra safe short-term debt before the Poisson event and paid it back after the Poisson event. For simplicity, we assume throughout that we are in the non-Ricardian region where government debt does not crowd out private safe assets.

Let us start backwards. In order to buy back the money stock after the bad Poisson event, the government undertakes an open market operation immediately after the realization of the event, swapping the extra supply of money $M^{\varepsilon}-M^{\varepsilon-}$ for debt $D$ where

$$
D=M^{\varepsilon}-M^{\varepsilon-}
$$

and the interest payment associated to this debt is financed by a tax $\tau^{-}$on the dividends of trees, where

$$
\tau^{-} \mu^{-} \frac{X}{\theta}=D
$$

Consider what happens when the government issues additional money $\hat{M}^{\varepsilon}>M^{\varepsilon}=\frac{X}{\theta}$ in a safety trap, but maintains an adequate supply of money $M^{\varepsilon-}=\frac{\mu^{-} X}{\theta}$ after the bad Poisson event and $M^{\varepsilon+}=\frac{\mu^{-} X}{\theta}$ after the good Poisson event.

Before the Poisson event when the economy is in a safety trap, the value of private non-monetary safe assets is unchanged at $\rho \mu^{-}(1-\varepsilon) \frac{X}{\theta}$. But money increases from $\varepsilon M^{\varepsilon}$ to $\varepsilon \hat{M}^{\varepsilon}$, so that the total value of safe assets increases by a proportional factor of

$$
\frac{\rho \mu^{-}(1-\varepsilon) \frac{X}{\theta}+\varepsilon \hat{M}^{\varepsilon}}{\rho \mu^{-}(1-\varepsilon) \frac{X}{\theta}+\varepsilon M^{\varepsilon}}=\frac{\rho \mu^{-}+\frac{\varepsilon}{1-\varepsilon} \frac{\hat{M}^{\varepsilon}}{M^{\varepsilon}}}{\rho \mu^{-}+\frac{\varepsilon}{1-\varepsilon}} .
$$

This stimulates output to

$$
\hat{\xi}=\frac{\rho \mu^{-}+\frac{\varepsilon}{1-\varepsilon} \frac{\hat{M}^{\varepsilon}}{M^{\varepsilon}}}{\rho \mu^{-}+\frac{\varepsilon}{1-\varepsilon}} \xi>\xi .
$$

This is exactly the same effect as that which would be achieved by issuing additional short-term debt in the amount $\varepsilon\left(\hat{M}^{\varepsilon}-M^{\varepsilon}\right)$, which is intuitive given that money and short-term debt are perfect substitutes at the ZLB. And exactly like this debt issuance policy, it requires that the government 
be able to increase taxes $\hat{\tau}^{-}>\tau^{-}$after the bad Poisson event and after the good Poisson event

$$
\begin{aligned}
& \left(\hat{\tau}^{-}-\tau^{-}\right) \mu^{-} \frac{X}{\theta}=\varepsilon\left(\hat{M}^{\varepsilon}-M^{\varepsilon}\right), \\
& \left(\hat{\tau}^{+}-\tau^{+}\right) \mu^{+} \frac{X}{\theta}=\varepsilon\left(\hat{M}^{\varepsilon}-M^{\varepsilon}\right) .
\end{aligned}
$$

Option (b): do not retire the extra money after the Poisson event. Consider next what happens when the government issues additional money $\hat{M}^{\varepsilon}>M^{\varepsilon}=\frac{X}{\theta}$ before the Poisson event when the economy is in a safety trap, but does not retire the extra money after the bad Poisson event occurs, while maintaining an interest rate of $\delta \theta$. We show that this option further stimulates the economy in a safety trap before the Poisson event, but at the cost of over-stimulating the economy after the Poisson event when the economy is no longer at the ZLB.

In this case, after the bad Poisson event, output is above potential at $\xi_{\sigma^{-}}^{-} \mu^{-} X$ where

$$
\xi_{\sigma^{-}}^{-}=\frac{\hat{M}^{\varepsilon}}{M^{\varepsilon^{-}}}>1
$$

The mechanism is simple: starting with a capacity utilization of one or equivalently output at potential, the extra money increases wealth, which increases consumption, which stimulates output, increases the value of the dividend of the Lucas' trees, increases the value of Lucas' trees, which further increases wealth, etc. This feedback loop settles at a new fixed point with higher output above potential and higher capacity utilization above one.

Given that it stimulates output after the Poisson event, option (b) increases the cash flows hat Neutral can promise to pledge after the Poisson event, and in particular after the bad Poisson event. This in turn increases the supply of private non-monetary safe assets before the Poisson event to $\frac{\rho \mu^{-} \xi_{\sigma^{-}}^{-} X(1-\varepsilon)}{\theta}=\frac{\hat{M}^{\varepsilon}}{M^{\varepsilon-}} \frac{\rho \mu^{-} X(1-\varepsilon)}{\theta}$. Money increases from $\varepsilon M^{\varepsilon}$ to $\varepsilon \hat{M}^{\varepsilon}$ as in option (a). The total value of safe assets increases by a proportional factor of

$$
\frac{\rho \mu^{-}(1-\varepsilon) \frac{X}{\theta} \frac{\hat{M}^{\varepsilon}}{M^{\varepsilon-}}+\varepsilon \hat{M}^{\varepsilon}}{\rho \mu^{-}(1-\varepsilon) \frac{X}{\theta}+\varepsilon M^{\varepsilon}}=\frac{\rho \mu^{-} \frac{\hat{M}^{\varepsilon}}{M^{\varepsilon-}}+\frac{\varepsilon}{1-\varepsilon} \frac{\hat{M}^{\varepsilon}}{M^{\varepsilon}}}{\rho \mu^{-}+\frac{\varepsilon}{1-\varepsilon}}>\frac{\rho \mu^{-}+\frac{\varepsilon}{1-\varepsilon} \frac{\hat{M}^{\varepsilon}}{M^{\varepsilon}}}{\rho \mu^{-}+\frac{\varepsilon}{1-\varepsilon}} .
$$

The result is a mitigation of the recession before the Poisson event when the economy is in a safety trap, increasing the value of $\xi$ to $\hat{\xi}$ where

$$
\hat{\xi}=\frac{\rho \mu^{-} \frac{\hat{M}^{\varepsilon}}{M^{\varepsilon-}}++\frac{\varepsilon}{1-\varepsilon} \frac{\hat{M}^{\varepsilon}}{M^{\varepsilon}}}{\rho \mu^{-}+\frac{\varepsilon}{1-\varepsilon}} \xi>\frac{\rho \mu^{-}+\frac{\varepsilon}{1-\varepsilon} \frac{\hat{M}^{\varepsilon}}{M^{\varepsilon}}}{\rho \mu^{-}+\frac{\varepsilon}{1-\varepsilon}} \xi>\xi .
$$

Because of the further increase in the value of private non-monetary safe assets brought about by the over-stimulation of the economy after the bad Poisson event, the mitigation of the recession is stronger in option (b) than by option (a).

Thus issuing money while the economy is in a safety trap and not taking it away when the 
economy exits the safety trap further mitigates the recession associated with the safety trap. However, this extra effectiveness is not a free lunch, as it comes with the important cost of excessively stimulating the economy when it exits the safety trap.

\section{A.3 Supporting Asset Values in Bad Times}

The previous section hints that a safety trap can be addressed by committing to provide support during bad rather than good times, as would be the case of a commitment to lower interest $i_{t}^{-}$rates after the bad Poisson event. ${ }^{35}$ By setting the nominal interest rate $i_{t}^{-}$below the natural interest rate $\delta \theta$ after the bad Poisson event, monetary authorities stimulate the economy and inflate the value of safe assets to

$$
\hat{V}^{S}=\rho \mu^{-} \frac{\xi_{\sigma^{-}}^{-}}{\theta} X
$$

where

$$
\xi_{\sigma^{-}}^{-}=e^{\int_{\sigma^{-}}^{\sigma^{-}+T}\left(\delta \theta-i_{s}^{-}\right) d s}>1
$$

This mitigates the recession in the safety trap by raising $\xi$ to $\xi \xi_{\sigma^{-}}^{-}>\xi$ (the analysis is almost identical to that of a monetary stimulus after the good Poisson event explained above, and the model before the Poisson event is isomorphic to that analyzed in Section 2.2 but with $\mu^{-}$replaced by $\left.\mu^{-} \xi_{\sigma^{+}}^{-}\right) .{ }^{36,37}$

However, it is natural to question whether monetary authorities would have the ability to lower interest rates in that state. If indeed the bad state happens to coincide with yet another safety or liquidity trap, monetary authorities could find themselves unable to deliver a lower interest rate. ${ }^{38}$

\footnotetext{
${ }^{35}$ Another example is the OMT (outright monetary transactions) program established by the ECB in late 2012, which had an immediate impact on the Eurozone risk perception.

${ }^{36}$ There are transitional dynamics before the Poisson event when forward guidance is announced, which we do not report in the interest of space. After the (future) policy announcement, the economy first goes through a phase where it is in the unconstrained regime for a while because because Knightian wealth only increases gradually over time while the value of safe assets jumps up immediately. But conditional on no Poisson event occuring, the economy eventually re-enters the constrained regime as Knightian wealth increases. All variables converge to their new stochastic steady state values gradually over time.

${ }^{37}$ Note we could just as well have used the model with public debt. The central banker's put works by increasing both the public and private sectors' ability to provide safe assets.

${ }^{38}$ Perhaps a more realistic policy option would be a commitment by the authorities to buy up safe assets at an inflated price after the Poisson events - a form of government (central bank?) put. A commitment to buy up safe private assets at an inflated value $\omega^{-} \rho \mu^{-} \frac{X}{\theta}>\rho \mu^{-} \frac{X}{\theta}$ would mitigate the recession and increase the value of $\xi$ to $\hat{\xi}$ where$$
\hat{\xi}=\omega^{-} \xi>\xi .
$$

It could be carried out by monetary authorities but it does require spare fiscal capacity (in the form of taxes or seigniorage). This kind of public insurance policy can potentially play a crucial role in a safety trap. See, e.g., Caballero and Kurlat (2010) for a proposal to increase the resilience of the financial system in a shortage of safe assets environment. Also, see Brunnermeir et al (2012) for a related proposal in the context of the current Euro crisis. 


\section{A.4 Welfare}

In this section, we analyze the welfare properties of the different policies that we have considered. We treat the case of public debt issuances, increases in the inflation target, and FG. The analysis for $\mathrm{QE}$ is more complex because it features nontrivial transitional dynamics. We focus on safety traps when the economy is in the constrained regime against the ZLB at $r^{K}=0$. We also focus on the limit $\lambda^{+} \rightarrow 0$ and $\lambda^{-} \rightarrow 0$.

Public debt issuance. After a public debt issuance $\hat{D}>D$, there is no transitional dynamics, so that the economy jumps immediately to a new stochastic steady state before the Poisson event, and also to a steady state after the Poisson event. Before the Poisson event it, increases output to $\hat{\xi} X=\frac{\hat{D}}{D} \xi X>\xi X$, increases Neutral and Knightian wealth to $\hat{W}^{N}=\frac{\hat{D}}{D} W^{N}>W^{N}$ and $\hat{W}^{K}=$ $\frac{\hat{D}}{D} W^{K}>W^{K}$, leaves $r$ and $r^{K}$ unchanged. After the Poisson event it leaves output and interest rates unchanged. These imply that: Neutrals and Knightians that are already born at the time of the public debt issuance are strictly better off (their wealth jumps up at impact and the rates of return on their wealth is unchanged going forward); Neutrals and Knightians that are born after the public debt issuance but before the Poisson event are strictly better off (their income when newborn is higher and the rates of return on their wealth is unchanged); Neutrals and Knightians that are born after the public debt issuance and the Poisson event are as well off (their income when newborn is identical and the rates of return on their wealth is unchanged). ${ }^{39}$

Increase in the inflation target. After an increase in the inflation target that creates the possibility of a good equilibrium, assuming that the economy moves to that equilibrium, there is no transitional dynamics, so that the economy jumps immediately to a new stochastic steady state before the Poisson event, and also to a steady state after the Poisson event. Before the Poisson event it, increases output to $X>\xi X$, increases Neutral and Knightian wealth to $\hat{W}^{N}=\frac{1}{\xi} W^{N}>W^{N}$ and $\hat{W}^{K}=\frac{1}{\xi} W^{K}>W^{K}$, increases $r$ and decreases $r^{K}$. After the Poisson event, it leaves output and interest rates unchanged. These imply that: Neutrals that are already born at the time of the increase in the inflation target are strictly better off (their wealth jumps at impact and the rates of return on their wealth is unchanged going forward); Neutrals that are born after the increase in the inflation target but before the Poisson event are strictly better off (their income when newborn is higher and the rates of return on their wealth is unchanged); Neutrals and Knightians that are born after the increase in the inflation target and the Poisson event are as well off (their income when newborn is identical and the rates of return on their wealth is unchanged); however Knightians that are already born at the time of the increase of the inflation target are strictly worse off (their initial wealth is unchanged but the rate of return on their wealth is lower); and Knightians that are born

\footnotetext{
${ }^{39}$ With $\lambda^{+}>0$ or $\lambda^{-}>0, r$ now decreases to $\hat{r}<r$ after the public debt issuance, so that we can no longer conclude that the public debt issuance generates a Pareto improvement through the reasoning above. It clearly makes Knightians better off, it will benefit some Neutrals, but it might make some Neutrals worse off. The welfare properties of public debt issuances then depend on the relative weighting of gains and losses. For example, we can consider a weighted Utilitarian welfare function that puts a weight $\nu^{N}\left(1-\beta^{N}\right) \beta^{N t}$ on the welfare of Neutrals born at date $t$ and $\nu^{K}\left(1-\beta^{K}\right) \beta^{K t}$ on the welfare of Knightians born at date $t$. For $\nu^{N}$ low enough, $\nu^{K}$ high enough, $\beta^{N}$ high enough, or $\lambda^{+}$and $\lambda^{-}$low enough, we can be sure that the public debt issuance increases total welfare even though it does not necessarily lead to a Pareto improvement.
} 
after the increase in the inflation target but before the Poisson event are not clearly better off (their income when newborn is higher but the rates of return on their wealth is lower).

The welfare properties of an increase in the inflation target depends on the relative weighting of gains and losses. For example, we can consider a weighted Utilitarian welfare function that puts a weight $\nu^{N}\left(1-\beta^{N}\right) \beta^{N t}$ on the welfare of Neutrals born at date $t$ and $\nu^{K}\left(1-\beta^{K}\right) \beta^{K t}$ on the welfare of Knightians born at date $t$. For $\nu^{N}$ high enough, $\nu^{K}$ low enough, or $\beta^{K}$ low enough, we can be sure that the increase in the inflation target increases total welfare even though it does not necessarily lead to a Pareto improvement. ${ }^{40}$

Another possibility is to introduce lump sum taxes that allow arbitrary redistribution within Knightians and within Neutrals but not across these two groups. Because they only redistribute within groups, these taxes do not change the characterization of the equilibrium. With these lump sum taxes, we can be sure that we have a Pareto improvement from an increase in the inflation target if $\hat{W}_{t}^{N} \geq W_{t}^{N}$ and $\hat{W}_{t}^{K} \geq W_{t}^{K}$ for all $t$ with a strict inequality for some positive measure of $t$, which is obviously the case. ${ }^{41}$

FG. To analyze FG, we must put ourselves in the case $\lambda^{+}>0$ and $\lambda^{-}>0$. FG is then Pareto dominated by no FG because: it does not change the allocation of Neutrals before the Poisson event and Knightians born before the Poisson event: it only increases the consumption of Neutrals and Knightians (born after the good Poisson event) after the good Poisson event at a net utility cost to them.

\section{A.5 Bubbles and Fiscal Capacity}

The very low interest rates that characterize a safety trap raises the issue of whether speculative bubbles may emerge, and whether these can play a useful role through their wealth effect. We show that bubbles can indeed arise in safety traps, but that only the emergence of safe bubbles (as opposed to risky bubbles) can stimulate economic activity. This is because only safe bubbles alleviate the shortage of safe assets. We associate the latter to public debt, and in fact the existence of a bubbly-region is equivalent to an expansion of the fiscal capacity of the government. We focus on the constrained regime and on safety traps throughout in Sections A.5.1, A.5.2, A.5.3. We briefly consider the unconstrained regime in liquidity traps in Section A.5.4.

\footnotetext{
${ }^{40}$ With $\lambda^{+}>0$ or $\lambda^{-}>0, r$ now decreases to $\hat{r}<r$ after the increase in the inflation target, so that Neutrals that are already born at the time of the increase in the inflation target or that are born after the increase in the inflation target but before the Poisson event are not necessarily better off. With the Utilitarian welfare function considered in the text, we can be sure that for $\beta^{K}$ low enough and $\beta^{N}$ high enough, or for $\lambda^{+}$and $\lambda^{-}$low enough and either $\nu^{N}$ high enough, $\nu^{K}$ low enough, or $\beta^{N}$ low enough, the increase in the inflation target increases total welfare even though it does not necessarily lead to a Pareto improvement.

${ }^{41}$ This argument holds even if $\lambda^{+}>0$ or $\lambda^{-}>0$.
} 


\section{A.5.1 Growth}

We extend the model to allow for bubbles. It is well understood in the rational bubbles literature that the growth rate of the economy is a key determinant of the possibility and size of bubbles.

We generalize our model by allowing for an arbitrary growth rate $g>0$. At every point in time, there is a mass $X_{t}$ of trees. A mass $\dot{X}_{t}=g X_{t}$ of new trees are created, which are claims to a dividend of $\delta$ units of goods at every future date until a Poisson event occurs, at which point the dividend jumps permanently to $\delta \mu^{+}$if the good Poisson event takes place and to $\delta \mu^{-}$if the bad Poisson event takes place. For reasons that will appear clear below, we assume that new trees are initially endowed to Neutral newborns. ${ }^{42}$ Endowments to newborns also grow at the rate $g$.

With some abuse of notation, we suppress time indices throughout. Hence we write $X, V^{S}$, $V^{R}, V, W^{K}, W^{N}, W$ for $X_{t}, V_{t}^{S}, V_{t}^{R}, V_{t}, W_{t}^{K}, W_{t}^{N}, W_{t}$. All these variables grow at rate $g$ in equilibrium. We also write $r^{K}, r, \delta^{S}$ for $r_{t}^{K}, r_{t}, \delta_{t}^{S}$. All these variables are constant in equilibrium.

We focus on the constrained regime. With flexible prices or with rigid prices as long as we are not in a safety trap $r^{K}>0$, the steady state equilibrium equations are

$$
\begin{gathered}
r^{K} V^{S}=\delta^{S} X, \\
r V^{R}=\left(\delta-\delta^{S}\right) X+\lambda^{+}\left(V^{R+}-V^{R}\right)+\lambda^{-}\left(V^{R-}-V^{R}\right), \\
g W^{K}=-\theta W^{K}+\alpha(1-\delta) X+r^{K} W^{K}, \\
g W^{N}=-\theta W^{N}+(1-\alpha)(1-\delta) X+r W^{N}-\lambda^{+}\left(V^{R+}-V^{R}\right)-\lambda^{-}\left(V^{R-}-V^{R}\right)+g\left(V^{S}+V^{R}\right), \\
W^{K}+W^{N}=V^{S}+V^{R}, \\
W^{K}=V^{S}=\frac{\rho \mu^{-} X}{\theta} .
\end{gathered}
$$

We then have

$$
\begin{gathered}
r^{K}=g+\delta \theta-\theta(1-\delta) \frac{\alpha-\rho \mu^{-}}{\rho \mu^{-}} \\
r=g+\delta \theta+(1-\delta) \theta \frac{\alpha-\rho \mu^{-}}{1-\rho \mu^{-}}+\frac{\lambda^{+}\left(\mu^{+}-1\right)+\lambda^{-}\left(\mu^{-}-1\right)}{1-\rho \mu^{-}}-\frac{g}{1-\rho \mu^{-}}
\end{gathered}
$$

Now suppose that prices are rigid and that we are in a safety trap where

$$
r^{K, n}=g+\delta \theta-\theta(1-\delta) \frac{\alpha-\rho \mu^{-}}{\rho \mu^{-}}<0
$$

\footnotetext{
${ }^{42}$ If new trees are endowed in equal proportions to Knightians and Newborns, then bubbles do stimulate the economy in a safety trap because they reduce the value of the new trees endowed to Knigithian newborns and hence reduce the growth rate of Knightian wealth. Endowing the new trees exclusively to Neutrals shuts down this somewhat artificial effect of bubbles on safe asset demand.
} 
then as in Section 2, we have a recession determined by

$$
r^{K}=g+\delta \theta-(1-\delta) \theta \frac{\alpha-\frac{\rho \mu^{-}}{\xi}}{\frac{\rho \mu^{-}}{\xi}}=0 .
$$

This formula shows that in the constrained regime with a scarcity of safe assets, the lower is the structural growth rate $g$ of the economy, the lower is the natural safe interest rate, and if the latter is negative, the deeper is the recession (the lower is utilization capacity $\xi$ ). In this sense supply side secular stagnation can lead to or reinforce demand side secular stagnation - a powerful and perverse complementarity.

\section{A.5.2 Bubbles}

To ensure that bubbles are stationary, we allow for new bubbles to be created. Just like new trees, new bubbles are endowed to Neutral newborns. The total value of the bubble $B_{t}$ grows at rate $\dot{B}_{t}=g B_{t}$ until the bad Poisson event occurs, at which point the bubble drops to $B_{t}^{-}<$ $B_{t}$ and then keeps growing at rate $g$, or until the good Poisson event occurs, at which point the bubble jumps to $B_{t}^{+} \geq B_{t}$. The value of the bubble $B_{t}^{+}$after the good Poisson event is irrelevant for our analysis. The bubble can be separated into a safe bubble $B_{t}^{S}=B_{t}^{-}$with rate of return $r_{t}^{K}$ and a risky bubble $B_{t}^{R}=B_{t}-B_{t}^{-}$with rate of return $r_{t}$. We assume that new safe bubbles per unit of time are then given by $\left(g-r_{t}^{K}\right) B_{t}^{S}$, and new risky bubbles per unit of time by $\left(g-r_{t}\right) B_{t}^{R}+\lambda^{+}\left(B_{t}^{+}-B_{t}^{R}-B_{t}^{S}\right)+\lambda^{-}\left(B_{t}^{-}-B_{t}^{R}-B_{t}^{S}\right)$. New bubbles and existing bubbles must be positive in equilibrium. Again, we focus on balanced growth paths and suppress the dependence on time and write $B, B^{-}, B^{+}, B^{S}$ and $B^{R}$ for $B_{t}, B_{t}^{-}, B_{t}^{+}, B_{t}^{S}$ and $B_{t}^{R}$.

After the bad Poisson event, goods market clearing requires that

$$
\theta\left(B^{-}+\frac{\delta \mu^{-} X}{r^{-}}\right)=\mu^{-} X
$$

This implies that the interest rate $r^{-}$is given by

$$
r^{-}=\frac{\delta \mu^{-} X}{\frac{\mu^{-} X}{\theta}-B^{-}}=\frac{\delta \theta}{1-\frac{\theta B^{-}}{\mu^{-} X^{-}}} .
$$

The value of safe assets before the bad Poisson event is therefore

$$
V^{S}=B^{-}+\frac{\delta \rho \mu^{-} X}{r^{-}}
$$

which can be rewritten as a function

$$
V^{S}=\frac{\mu^{-} X}{\theta} v^{S, B}\left(\frac{B^{-}}{X}\right)
$$


with

$$
v^{S, B}\left(\frac{B^{-}}{X}\right)=\rho+\frac{\theta}{\mu^{-}} \frac{B^{-}}{X}(1-\rho) .
$$

This expression makes clear that safe bubbles increase the value of safe assets because of the implicit assumption that there is no agency problem involved in the tranching of bubbles into a safe and a risky part. For future reference we also define the interest rate $r^{+}$after the good Poisson event

$$
r^{+}=\frac{\delta \mu^{+} X}{\frac{\mu^{+} X}{\theta}-B^{+}} .
$$

As above, we focus on the constrained regime where $W^{K}=V^{S}$ and $r>g+\delta \theta>r^{K}$. With flexible prices or with rigid prices as long we are not in a safety trap $r^{K}>0$, the steady state equilibrium equations are

$$
\begin{gathered}
r^{K}\left(V^{S}-B^{S}\right)=\delta^{S} X, \\
r\left(V^{R}-B^{R}\right)=\left(\delta-\delta^{S}\right) X, \\
g W^{K}=-\theta W^{K}+\alpha(1-\delta) X+r^{K} W^{K}, \\
g W^{N}=-\theta W^{N}+(1-\alpha)(1-\delta) X+\left[\left(g-r^{K}\right) B^{S}+(g-r) B^{R}\right]+r W^{N}, \\
W^{K}+W^{N}=V^{S}+V^{R}, \\
W^{K}=V^{S}=\frac{\mu^{-} X}{\theta} v^{S, B}\left(\frac{B^{-}}{X}\right) .
\end{gathered}
$$

In addition, we must have $\max \left\{r^{-}, r^{+}\right\} \leq g$ and $r^{K} \leq g$,

$$
B^{S}=B^{-},
$$

and

$$
\lambda^{+}\left(B^{+}-B^{-}\right) \geq\left(r-g+\lambda^{+}+\lambda^{-}\right) B^{R}
$$

We find the following expressions for the safe and risky rates:

$$
\begin{gathered}
r^{K}=g+\delta \theta-\theta(1-\delta) \frac{\alpha-\mu^{-} v^{S, B}\left(\frac{B^{S}}{X}\right)}{\mu^{-} v^{S, B}\left(\frac{B^{S}}{X}\right)}, \\
r=\frac{\delta \theta-r^{K}\left(\mu^{-} v^{S, B}\left(\frac{B^{S}}{X}\right)-\theta \frac{B^{S}}{X}\right)}{1-\mu^{-} v^{S, B}\left(\frac{B^{S}}{X}\right)-\theta \frac{B^{R}}{X}},
\end{gathered}
$$

The condition for the constrained regime is that $r>r^{K}$.

Now suppose that prices are rigid and that we are in a safety trap with

$$
r^{K, n}=g+\delta \theta-\theta(1-\delta) \frac{\alpha-\mu^{-} v^{S, B}\left(\frac{B^{S}}{X}\right)}{\mu^{-} v^{S, B}\left(\frac{B^{S}}{X}\right)}<0 .
$$


Then we have a recession with $\xi<1$ determined exactly as in the bubbleless equilibrium analyzed in Section A.5.1 above

$$
r^{K}=g+\delta \theta-\theta(1-\delta) \frac{\alpha-\frac{v^{S, B}\left(\frac{B^{S}}{X}\right) \mu^{-}}{\xi}}{\frac{v^{S, B}\left(\frac{B^{S}}{X}\right) \mu^{-}}{\xi}}=0 .
$$

Clearly, output $\xi X$ is increasing in the size of the safe bubble $\frac{B^{S}}{X}=\frac{B^{-}}{X}$. A larger safe bubble $\frac{\hat{B}^{S}}{X}=\frac{\hat{B}^{-}}{X}>\frac{B^{-}}{X}=\frac{B^{S}}{X}$ stimulates output to $\hat{\xi} X$ with

$$
\hat{\xi}=\frac{\hat{V}^{S}}{V^{S}}>\xi
$$

where $\hat{V}^{S}=v^{S, B}\left(\frac{\hat{B}^{S}}{X}\right)$ and $V^{S}=v^{S, B}\left(\frac{B^{S}}{X}\right)$. However output is invariant to the size of the risky bubble $\frac{B^{R}}{X}$, and for the same reason is also invariant to $\phi^{R}$. This is because the safe bubbles increase the supply of safe assets $V^{S}$ while the risky bubbles only increase the risky expected rate of return $r$ (they fail to increase the supply of risky assets $V^{R}$ since they perfectly crowd out other risky assets through an increase in the risky expected rate of return $r$ ). In other words, in terms of the AS-AD equilibrium representation, only safe bubbles increase aggregate demand, not risky bubbles.

The fact that risky bubbles have no effect on output in a safety trap formalizes some interesting observations in Summers (2013) that in secular stagnation environments, even large financial bubbles only seem to create moderate economic expansions.

\section{A.5.3 Fiscal Capacity: Debt as a Safe Bubble}

A natural interpretation of safe bubbles is that they are a form of government debt. To develop this idea, assume that the risky bubble is equal to zero, and interpret the safe bubble $B^{-}$as government debt $B^{-}=D$. When $r<g$, and by implication $\delta \theta<g$, the government can sustain a stable debt to output ratio without ever having to levy any taxes $\left(\tau=\tau^{+}=\tau^{-}=0\right)$. The government can then increase the supply of safe assets by levering on the bubble in $V^{S}=\frac{\mu^{-} X}{\theta} v^{S, B}\left(\frac{B^{-}}{X}\right)$, with a crowding out (of private safe assets) by public debt of:

$$
\frac{\mu^{-}}{\theta}\left[1-\frac{d v^{S, B}\left(\frac{B^{-}}{X}\right)}{d\left(\frac{B^{-}}{X}\right)}\right]=\rho<1 .
$$

Finally, note that as the government issues more public debt, $r^{-}$and $r^{+}$increase, which limits how much public debt can be issued without ever having to tax, namely $\frac{B^{-}}{X} \leq \frac{\mu^{-}}{\theta}\left(1-\frac{\delta \theta}{g}\right)$. In a safety trap, this gives the government some fiscal space to increase debt and stimulate the economy. 


\section{A.5.4 Bubbles and Fiscal Capacity in Liquidity Traps}

In this section, we consider the possibility and consequences of bubbles in the unconstrained regime in a liquidity trap, allowing for growth, and introducing safe and risky bubbles $B_{t}=B_{t}^{R}+B_{t}^{S}$.

Suppose that prices are rigid and that we are in a liquidity trap with $r^{n}=r^{K, n}<0, r=r^{K}=$ $i=0$, and $\xi<1 .{ }^{43}$ We then have the following steady state equilibrium equations

$$
\begin{gathered}
r\left(V-B^{R}-B^{S}\right)=\delta \xi X+\lambda^{-}\left[\frac{\mu^{-} X}{\theta}-B^{-}-\left(V-B^{R}-B^{S}\right)\right]+\lambda^{+}\left[\frac{\mu^{+} X}{\theta}-B^{+}-\left(V-B^{R}-B^{S}\right)\right] \\
\theta V=\xi X, \\
r=0 .
\end{gathered}
$$

In addition we must have $\max \left\{r^{-}, r^{+}\right\} \leq g, r \leq g$,

$$
B^{S}=B^{-}
$$

and

$$
\lambda^{+}\left(B^{+}-B^{-}\right) \geq\left(r-g+\lambda^{+}+\lambda^{-}\right) B^{R}
$$

This also yields

$$
0=\delta \xi X+\lambda^{-}\left[\frac{\mu^{-} X}{\theta}-B^{-}-\left(\frac{\xi X}{\theta}-B^{R}-B^{S}\right)\right]+\lambda^{+}\left[\frac{\mu^{+} X}{\theta}-B^{+}-\left(\frac{\xi X}{\theta}-B^{R}-B^{S}\right)\right]
$$

or

$$
\xi=\frac{\frac{\lambda^{-}}{\lambda^{-}+\lambda^{+}}\left[\mu^{-}+\theta \frac{B-B^{-}}{X}\right]+\frac{\lambda^{+}}{\lambda^{-}+\lambda^{+}}\left[\mu^{+}+\theta \frac{B-B^{+}}{X}\right]}{1-\frac{\delta \theta}{\lambda^{-}+\lambda^{+}}},
$$

and finally

$$
\xi=\frac{\frac{\lambda^{-}}{\lambda^{-}+\lambda^{+}} \mu^{-}+\frac{\lambda^{+}}{\lambda^{-}+\lambda^{+}} \mu^{+}+\frac{\theta}{X}\left[\frac{\lambda^{+} B^{S}}{\lambda^{-}+\lambda^{+}}+\frac{g B^{R}+\left(\lambda^{+}+\lambda^{-}-g\right) B^{R}-\lambda^{+} B^{+}}{\lambda^{-}+\lambda^{+}}\right]}{1-\frac{\delta \theta}{\lambda^{-}+\lambda^{+}}},
$$

Assume that $\lambda^{+}+\lambda^{-}>g$ and that risky bubbles have their maximal equilibrium values so that $\left(\lambda^{+}+\lambda^{-}-g\right) B^{R}=\lambda^{+} B^{+}$. We then have

$$
\xi=\frac{\frac{\lambda^{-}}{\lambda^{-}+\lambda^{+}} \mu^{-}+\frac{\lambda^{+}}{\lambda^{-}+\lambda^{+}} \mu^{+}+\frac{\theta}{X}\left[\frac{\lambda^{+} B^{S}}{\lambda^{-}+\lambda^{+}}+\frac{g B^{R}}{\lambda^{-}+\lambda^{+}}\right]}{1-\frac{\delta \theta}{\lambda^{-}+\lambda^{+}}}
$$

Hence we see that both risky and safe bubbles stimulates output in a standard liquidity trap. This is because in this unconstrained case, both risky and safe bubbles increase the total value of assets.

\footnotetext{
${ }^{43}$ Under these assumptions, bubbles are possible as long as $\delta \theta<g$.
} 


\section{A.6 Securitization Externality}

In this section, we endogenize the securitization capacity of the economy. We assume that by investing resources $j_{t} X d t$, a Neutral agent can increase $\rho\left(j_{t}\right)$ and, with it, increase the supply of safe assets (i.e., the share of the tree's revenue in the bad state of the world that is pledgable today).

We show in this extension that outside of a safety trap, the competitive equilibrium is constrained Pareto efficient, but that in a safety trap, it is constrained inefficient (there is underprovision of safe assets).

We trace back this inefficiency to a securitization externality. In a safety trap, private agents do not internalize the full social benefit of creating safe assets. More specifically, they do not take into account the stimulative effects of these assets, which creates a role for government intervention in the securitization market. This argument is distinct from the comparative advantage of the government in safe asset creation that we analyzed in Section 3, but it can also be used to support it if we associate the government extra-taxation power to the private sector's technology to increase safe assets (at a cost).

\section{A.6.1 Securitization Externality in a Safety Trap}

We focus throughout on the constrained regime and on safety traps, and we specialize the model to the limit $\lambda^{+} \rightarrow 0$ and $\lambda^{-} \rightarrow 0$ for simplicity.

With flexible prices (or with rigid prices as we are not in a safety $\operatorname{trap} r_{t}^{K}>0$ ), the equilibrium equations are

$$
\begin{gathered}
r_{t}^{K} V_{t}^{S}=\delta_{t}^{S} X+\dot{V}_{t}^{S}, \\
r_{t} V_{t}^{R}=\left(\delta-\delta_{t}^{S}-j_{t}\right) X+\dot{V}_{t}^{R}, \\
\dot{W}_{t}^{K}=-\theta W_{t}^{K}+\alpha(1-\delta) X+r_{t}^{K} W_{t}^{K}, \\
\dot{W}_{t}^{N}=-\theta W_{t}^{N}+(1-\alpha)(1-\delta) X+r_{t} W_{t}^{N}, \\
V_{t}^{S}=\frac{\rho\left(j_{t}\right) \mu^{-} X}{\theta}, \\
\left(r_{t}-r_{t}^{K}\right) \frac{\rho^{\prime}\left(j_{t}\right) \mu^{-}}{\theta}=1 .
\end{gathered}
$$

There are two differences with the baseline model of Section 2. First, the asset pricing equation for risky assets reflects the fact that dividends are reduced by securitization investment $j_{t} X$. Second, there is a new equation (the last one) which is simply the first order condition for securitization. This condition is intuitive: a Neutral managing a tree equates the marginal cost of increasing securitization investment by $X d j_{t}$ between $t$ and $t+d t$ to the marginal benefit of issuing $\frac{\rho^{\prime}\left(j_{t}\right) \mu^{-}}{\theta} X d j_{t}$ additional safe assets on which he earns a spread $\left(r_{t}-r_{t}^{K}\right)$ between $t$ and $t+d t$.

Apart from that, the analysis of the equilibrium is almost identical to that of the baseline model. In particular, and focusing on steady states, there is an unconstrained regime with $r=r^{K}$ and a 
constrained regime with $r>r^{K}$. If prices are rigid, we can enter a safety trap where $r^{K, n}<0$, $r^{K}=0$, and output $\xi X$ is below potential with $\xi<1$. We denote by $j$ the associated level of investment. The details are omitted in the interest of space.

We now investigate the efficiency properties of the competitive equilibrium. To do so, it is convenient to introduce lump sum taxes that allow arbitrary redistribution within Knightians and within Neutrals but not across these two groups. Because they only redistribute within groups, these taxes do not change the characterization of the equilibrium.

Consider the steady state of the competitive equilibrium with Neutral wealth $W^{N}$, Knightian wealth $W^{K}$, interest rates $r$ and $r^{K}$, and securitization $j$. We focus on the constrained regime throughout. We analyze first the case where prices are flexible. We then analyze the case with rigid prices. In the first case, output is always at capacity. The corresponding planning problem is easier to analyze. Moreover, as long as the natural safe real interest rate is positive, this flexible prices planning problem is a constrained version of the rigid prices planning problem, but the corresponding constraints are satisfied at the optimum of the latter, so that their solutions coincide. This is no longer the case when the natural safe real interest rate is negative.

We are interested in whether it is possible to generate a Pareto improvement by controlling securitization $j_{t}$ (either through taxes or quantity restrictions) and setting it at a different level than would occur in a competitive equilibrium without government interventions in securitization. With the lump sum taxes mentioned above, this happens if and only if we can find processes $\hat{W}_{t}^{K}$, $\hat{W}_{t}^{N}, \hat{W}_{t}, \hat{V}_{t}^{S}, \hat{V}_{t}^{R}, \hat{V}_{t}, \hat{r}_{t}, \hat{r}_{t}^{K}, \hat{\delta}_{t}^{S}$ and $\hat{\jmath}_{t}$ that verify all the equilibrium equations except the first order condition for $\hat{\jmath}_{t}$, and such that $\hat{W}_{t}^{N} \geq W_{t}^{N}$ and $\hat{W}_{t}^{K} \geq W_{t}^{K}$ for all $t$ and a strict inequality for some positive measure of $t$.

Therefore, the steady state of the competitive equilibrium is constrained Pareto efficient if and only if we can find Pareto weights $\lambda_{t}^{N}>0$ and $\lambda_{t}^{K}>0$ such that the solution of the following planning problem is such that $\hat{W}_{t}^{N}=W^{N}, \hat{W}^{K}=W^{K}$, and $\hat{\jmath}_{t}=j$ :

$$
\max _{\hat{W}_{t}^{K}, \hat{W}_{t}^{N}, \hat{\jmath}_{t}} \int_{0}^{\infty} \lambda_{t}^{N} \theta \hat{W}_{t}^{N}+\lambda_{t}^{K} \theta \hat{W}_{t}^{K} d t
$$

subject to $\hat{W}_{t}^{N}=\frac{X}{\theta}-\frac{\left[\hat{\jmath}_{t}+\rho\left(\hat{\jmath}_{t}\right) \mu^{-}\right] X}{\theta}, \hat{W}_{t}^{K}=\frac{\rho\left(\hat{\jmath}_{t}\right) \mu^{-} X}{\theta}$ and $\hat{W}_{0}^{K}=W^{K}$.

The solution to this problem is

$$
\left(\lambda_{t}^{K}-\lambda_{t}^{N}\right) \frac{\rho^{\prime}\left(\hat{\jmath}_{t}\right) \mu^{-}}{\theta}=\frac{\lambda_{t}^{N}}{\theta}
$$

Taking $\lambda_{t}^{K}=\lambda_{t}^{N}\left(1+\frac{r-r^{K}}{\theta}\right)$ and $\lambda_{t}^{N}>0$ arbitrary such that $\int \lambda_{t}^{N} d t<\infty$, we can rewrite the solution as $\left(r_{t}-r_{t}^{K}\right) \frac{\rho^{\prime}\left(\hat{\jmath}_{t}\right) \mu^{-}}{\theta}=1$ or equivalently $\hat{\jmath}_{t}=j$. This shows that with flexible prices, the competitive equilibrium is constrained Pareto efficient.

Now suppose that prices are entirely rigid. The steady state of the competitive equilibrium (which may or may not feature a safety trap) is constrained Pareto efficient if and only if we can 
find Pareto weights $\lambda_{t}^{N}>0$ and $\lambda_{t}^{K}>0$ such that the solution of the following planning problem is such that $\hat{W}_{t}^{N}=W^{N}, \hat{W}^{K}=W^{K}, \hat{\jmath}_{t}=j$ and $\hat{\xi}_{t}=\xi$ :

$$
\max _{\hat{W}_{t}^{K}, \hat{W}_{t}^{N}, \hat{\jmath}_{t}, \hat{r}_{t}^{K}, \hat{\xi}_{t}} \int_{0}^{\infty} \lambda_{t}^{N} \theta \hat{W}_{t}^{N}+\lambda_{t}^{K} \theta \hat{W}_{t}^{K} d t
$$

subject to $\hat{W}_{t}^{N}=\frac{\hat{\xi}_{t} X}{\theta}-\frac{\left[\hat{\jmath}_{t}+\rho\left(\hat{\jmath}_{t}\right) \mu^{-}\right] X}{\theta}, \hat{W}_{t}^{K}=\frac{\rho\left(\hat{\jmath}_{t}\right) \mu^{-} X}{\theta}, \hat{W}_{0}^{K}=W^{K}, \frac{d \hat{\jmath}_{t}}{d t}=\frac{\theta}{\rho^{\prime}\left(\hat{\jmath}_{t}\right) \mu^{-}}\left[\alpha(1-\delta)-\frac{\rho\left(\hat{\jmath}_{t}\right) \mu^{-}}{\hat{\xi}_{t}}\right] \hat{\xi}_{t}+$ $\hat{r}_{t}^{K} \frac{\rho\left(\hat{\jmath}_{t}\right)}{\rho^{\prime}\left(\hat{\jmath}_{t}\right)}, \hat{r}_{t}^{K} \geq 0$ and $\hat{\xi}_{t} \leq 1^{44}$

This is an optimal control problem with a state variable $\hat{\jmath}_{t}$. However as long as $\hat{r}_{t}^{K}>0$, the corresponding costate variable $\hat{\nu}_{t}$ is equal to zero so that $\hat{\xi}_{t}=1$ and the solution coincides with that of the flexible prices planning problem. Below we state the main results and omit some derivations. We refer the reader to the Appendix A.6.2 for the details.

If the steady state of the competitive equilibrium does not feature a safety $\operatorname{trap}\left(r^{K}>0\right.$ and $\xi=1)$, then taking $\lambda_{t}^{K}=\lambda_{t}^{N}\left(1+\frac{r-r^{K}}{\theta}\right)$ and $\lambda_{t}^{N}>0$ arbitrary such that $\int \lambda_{t}^{N} d t<\infty$, the solution of the planning problem coincides with the the competitive equilibrium, showing that the competitive equilibrium is constrained Pareto efficient.

But if the steady state of the competitive equilibrium does feature a safety trap $\left(r^{K}=0\right.$ and $\xi<1$ ), then it is not possible to find weights $\lambda_{t}^{N}>0$ and $\lambda_{t}^{K}>0$, such that the solution of the planning problem coincides with the competitive equilibrium. This shows that the competitive equilibrium is not constrained Pareto efficient.

We can take $\lambda_{t}^{K}=\lambda_{t}^{N}\left(1+\frac{r-r^{K}}{\theta}\right)$ with $\lambda_{t}^{N}=\frac{e^{-\phi t}}{X}$ with $\phi>0$. As is usual in such problems, we renormalize the costate variable by multiplying it by $e^{\phi t}$. Then, as long as the allocation (including the costate renormalized costate) converge to a non-degenerate steady state when $t$ goes to $\infty$, we have that $\left(r-r^{K}\right) \frac{\rho^{\prime}\left(\hat{\jmath}_{\infty}\right) \mu^{-}}{\theta}=1+\theta(\sigma+\theta) \hat{\nu}_{\infty}<1$. This implies that $\hat{\jmath}_{\infty}>j$, and by implication $\hat{\xi}_{\infty}=\frac{\rho\left(\hat{\jmath}_{\infty}\right) \mu^{-}}{\alpha(1-\delta)}>\xi$.

Moreover, one can show that $\hat{r}_{\infty}<r_{\infty}=r$ and $\hat{r}_{\infty}^{K}=r_{\infty}^{K}=r^{K}=0$ so that $\hat{r}_{\infty}-\hat{r}_{\infty}^{K}<r_{\infty}-r_{\infty}^{K}=$ $r-r^{K}$. It follows that:

$$
\left(\hat{r}_{\infty}-\hat{r}_{\infty}^{K}\right) \frac{\rho^{\prime}\left(\hat{\jmath}_{\infty}\right) \mu^{-}}{\theta}<1
$$

These results show that there is a positive externality from securitization. This is because securitization stimulates economic activity, which is not internalized by private agents, creating a role for government intervention in the securitization market.

The government could use taxes or quantity restrictions to encourage securitization. This should not be interpreted too narrowly. Indeed, in practice, one possible interpretation of $j_{t}$ is as a proxy for the net worth of financial intermediaries. Forcing financial intermediaries to increase $j_{t}$ could then be interpreted as forcing them to raise more fresh capital than they would do otherwise. This

\footnotetext{
${ }^{44}$ To undestand where the equation for $\frac{d \hat{\jmath}_{t}}{d t}$ is coming from, combine the asset pricing equation for safe assets with the wealth accumulation equation for Knightians to get $\frac{\rho\left(\hat{\jmath}_{t}\right) \mu^{-}}{\hat{\xi}_{t}}=\alpha(1-\delta)+\hat{\delta}_{t}^{S}$. Solve out this equation for $\hat{\delta}_{t}^{S}$ and replace in the asset pricing equation for safe assets $\hat{r}_{t}^{K} \frac{\rho\left(\hat{\jmath}_{t}\right) \mu^{-}}{\theta}=\delta_{t}^{S} \hat{\xi}_{t}+\frac{\rho^{\prime}\left(\hat{\jmath}_{t}\right) \mu^{-}}{\theta} \frac{d \hat{\jmath}_{t}}{d t}$. The equation in the text follows.
} 
would improve welfare by stimulating the economy. Another interpretation is that $\rho$ is increased by monitoring, either private or public. Assume, for example, that public and private monitoring are perfect substitutes with associated costs $j_{t}^{G} \geq 0$ and $j_{t}^{P} \geq 0$ and that $\rho\left(j_{t}\right)$ is increasing in total monitoring $j_{t}=j_{t}^{G}+j_{t}^{P}$. With the additional assumption that public monitoring is financed by taxes on dividends, this model can be mapped exactly to the model in this section. Then a possible implementation of constrained Pareto efficient allocations in safety traps is an increase in public monitoring $j_{t}^{G}=\hat{\jmath}_{t}$ and $j_{t}^{P}=0$ (assuming that monitoring cannot be negative). ${ }^{45}$

\section{A.6.2 Derivations for Section A.6.1}

We analyze the planning problem corresponding to the case of rigid prices. The first order conditions are

$$
\begin{gathered}
-\frac{d \hat{\nu}_{t}}{d t}=\left(\lambda_{t}^{K}-\lambda_{t}^{N}\right) \frac{\rho^{\prime}\left(\hat{\jmath}_{t}\right) \mu^{-} X}{\theta}-\lambda_{t}^{N} \frac{X}{\theta}+\nu_{t} \frac{d}{d \hat{\jmath}_{t}}\left\{\frac{\theta}{\rho^{\prime}\left(\hat{\jmath}_{t}\right) \mu^{-}}\left[\alpha(1-\delta)-\frac{\rho\left(\hat{\jmath}_{t}\right) \mu^{-}}{\hat{\xi}_{t}}\right] \hat{\xi}_{t}\right\} \\
0=\lambda_{t}^{N} \frac{X}{\theta}+\hat{\nu}_{t}\left\{\frac{\theta}{\rho^{\prime}\left(\hat{\jmath}_{t}\right) \mu^{-}}\left[\alpha(1-\delta)-\frac{\rho\left(\hat{\jmath}_{t}\right) \mu^{-}}{\hat{\xi}_{t}}\right]\right\}-\hat{\eta}_{t}, \\
\hat{\nu}_{t} \frac{\rho\left(\hat{\jmath}_{t}\right)}{\rho^{\prime}\left(\hat{\jmath}_{t}\right)}+\hat{\gamma}_{t}=0, \\
\lim _{t \rightarrow \infty} \hat{\nu}_{t}=0, \\
\hat{\eta}_{t}\left(1-\hat{\xi}_{t}\right)=0, \\
\hat{\gamma}_{t} \hat{r}_{t}^{K}=0 .
\end{gathered}
$$

Can we find $\lambda_{t}^{K}>0$ and $\lambda_{t}^{N}>0$ such that the solution coincides with the steady state of the competitive equilibrium? If the steady state of the competitive equilibrium does not feature a safety trap $\left(r^{K}>0\right.$ and $\left.\xi=1\right)$, then taking $\lambda_{t}^{K}=\lambda_{t}^{N}\left[1+\frac{r-r^{K}}{\theta}\right]$ and $\lambda_{t}^{N}>0$ arbitrary such that $\int \lambda_{t}^{N} d t<\infty$, the solution of the planning problem coincides with the the competitive equilibrium, showing that the competitive equilibrium is constrained Pareto efficient.

But if the steady state of the competitive equilibrium does feature a safety trap $\left(r^{K}=0\right.$ and $\xi<1$ ), then for any weights $\lambda_{t}^{N}>0$ and $\lambda_{t}^{K}>0$, the solution of the planning problem is different from the competitive equilibrium, showing that the competitive equilibrium is not constrained Pareto efficient. This would require $\hat{\eta}_{t}=0$ and $\lambda_{t}^{N}=0$, a contradiction. This shows that the competitive equilibrium is not constrained Pareto efficient.

Now continue to assume $r^{K}=0$ and $\xi<1$, and take $\lambda_{t}^{K}=\lambda_{t}^{N}\left[1+\frac{r-r^{K}}{\theta}\right]$ and $\lambda_{t}^{N}>0$, i.e. the Pareto weights that rationalize the competitive equilibrium outside of a safety trap. And take $\lambda_{t}^{N}=\frac{e^{-\phi t}}{X}$ so that the integrals converge. Renormalizing the Hamiltonian (and the multipliers), we

\footnotetext{
${ }^{45}$ This latter interpretation can be seen as another rationalization for the sort of government interventions in securitization markets (public debt and QE) considered in Section 3, with public monitoring $j_{t}^{G}$ playing a role similar to the role of taxes $\tau_{t}$ in Section 3. The difference is that public monitoring is costly in terms of resources while taxes are not because they are not distortive.
} 
get

$$
\begin{gathered}
\phi \hat{\nu}_{t}-\frac{d \hat{\nu}_{t}}{d t}=\frac{r-r^{K}}{\theta} \frac{\rho^{\prime}\left(\hat{\jmath}_{t}\right) \mu^{-}}{\theta}-\frac{1}{\theta}+\hat{\nu}_{t} \frac{d}{d \hat{\jmath}_{t}}\left\{\frac{\theta}{\rho^{\prime}\left(\hat{\jmath}_{t}\right) \mu^{-}}\left[\alpha(1-\delta)-\frac{\rho\left(\hat{\jmath}_{t}\right) \mu^{-}}{\hat{\xi}_{t}}\right] \hat{\xi}_{t}\right\} \\
0=\frac{1}{\theta}+\hat{\nu}_{t}\left\{\frac{\theta}{\rho^{\prime}\left(\hat{\jmath}_{t}\right) \mu^{-}}\left[\alpha(1-\delta)-\frac{\rho\left(\hat{\jmath}_{t}\right) \mu^{-}}{\hat{\xi}_{t}}\right]\right\}-\hat{\eta}_{t}, \\
\hat{\nu}_{t} \frac{\rho\left(\hat{\jmath}_{t}\right)}{\rho^{\prime}\left(\hat{\jmath}_{t}\right)}+\hat{\gamma}_{t}=0, \\
\lim _{t \rightarrow \infty} \hat{\nu}_{t} e^{-\phi t}=0, \\
\hat{\eta}_{t}\left(1-\hat{\xi}_{t}\right)=0, \\
\hat{\gamma}_{t} \hat{r}_{t}^{K}=0 .
\end{gathered}
$$

Assume that the solution converges to a non-degenerate steady state (including multipliers), then we necessarily have

$$
\begin{gathered}
\frac{\theta}{\rho^{\prime}\left(\hat{\jmath}_{\infty}\right) \mu^{-}}\left[\alpha(1-\delta)-\frac{\rho\left(\hat{\jmath}_{\infty}\right) \mu^{-}}{\hat{\xi}_{\infty}}\right] \hat{\xi}_{\infty}=0, \\
\left(r-r^{K}\right) \frac{\rho^{\prime}\left(\hat{\jmath}_{\infty}\right) \mu^{-}}{\theta}=1+\theta(\sigma+\theta) \hat{\nu}_{\infty} \leq 1,
\end{gathered}
$$

where the last inequality is strict if $\nu_{\infty}<0$ (which we can show holds by contradiction, as it would imply $j_{\infty}=j, \eta_{\infty}=\frac{1}{\theta}>0$ and $\xi_{\infty}=\xi=1$, which is impossible). This shows that in the long run, as long as we converge to a non-degenerate steady state (including multipliers), we have

$$
\hat{\jmath}_{\infty}>j
$$

Using

$$
\hat{r}_{\infty}=\delta \theta+(1-\delta) \theta \frac{\alpha-\hat{\jmath}_{\infty}-\frac{\rho\left(\hat{\jmath}_{\infty}\right) \mu^{-}}{\hat{\xi}_{\infty}}}{1-\hat{\jmath}_{\infty}-\frac{\rho\left(\hat{\jmath}_{\infty}\right) \mu^{-}}{\hat{\xi}_{\infty}}}<r
$$

and

$$
r_{\infty}^{K}=0
$$

we can also show that

$$
\left(\hat{r}_{\infty}-\hat{r}_{\infty}^{K}\right) \frac{\rho^{\prime}\left(\hat{\jmath}_{\infty}\right) \mu^{-}}{\theta}<\left(r-r^{K}\right) \frac{\rho^{\prime}\left(\hat{\jmath}_{\infty}\right) \mu^{-}}{\theta}<1 .
$$

